

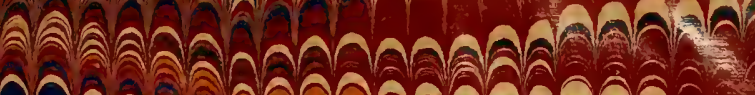

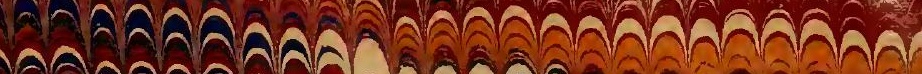
Mลลลลลลลลลล์

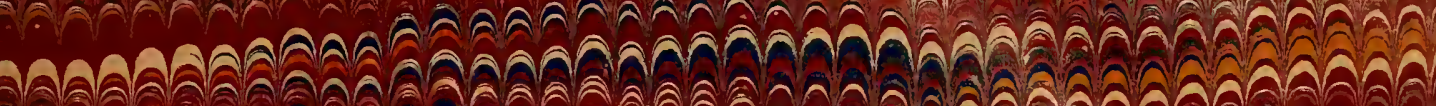

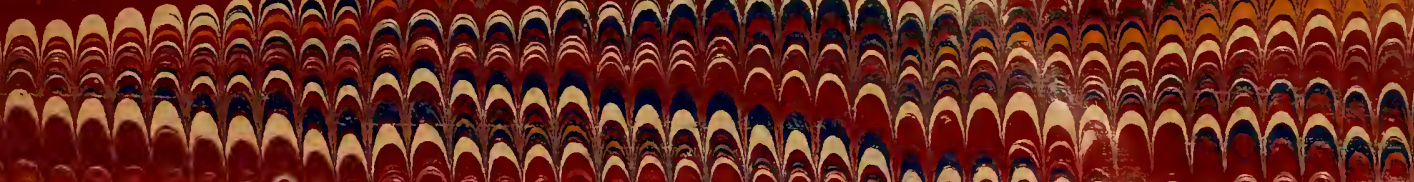

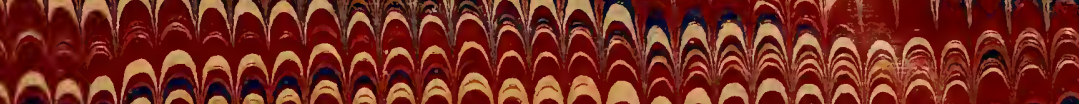

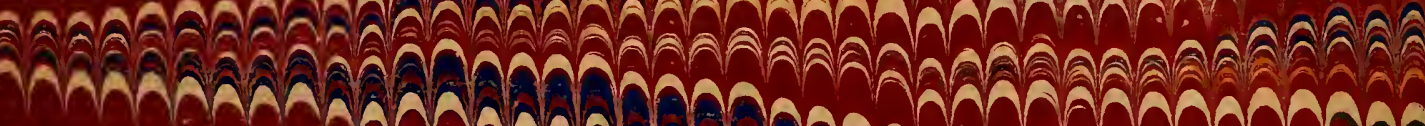

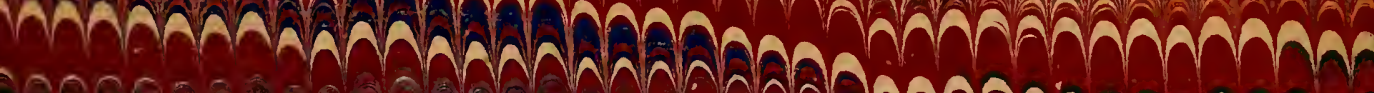
ה

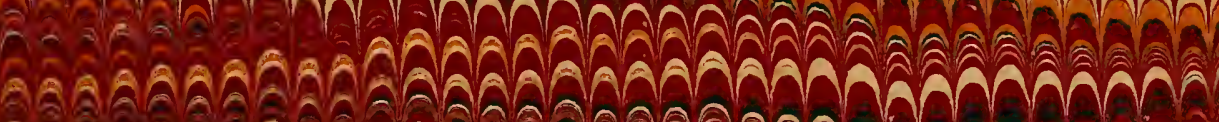

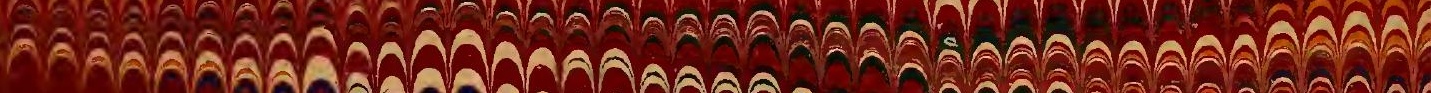

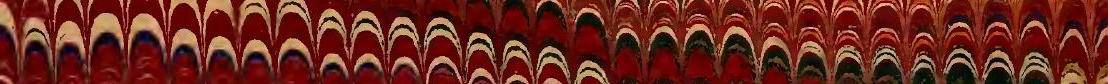

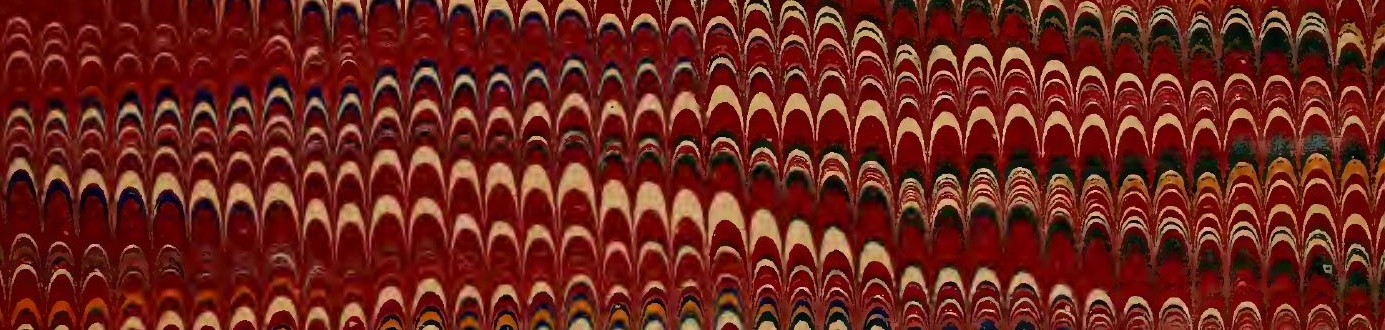

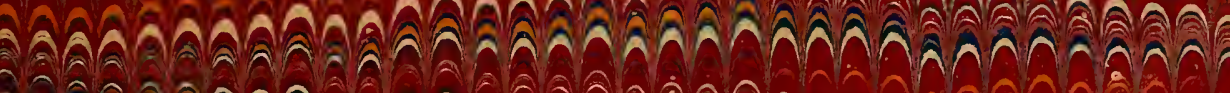

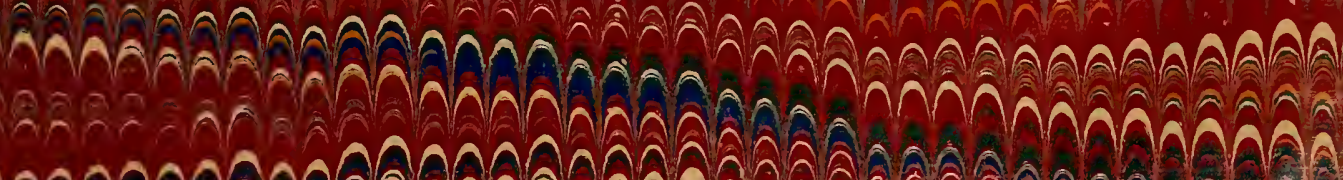

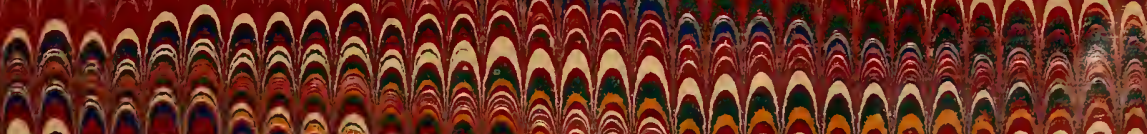

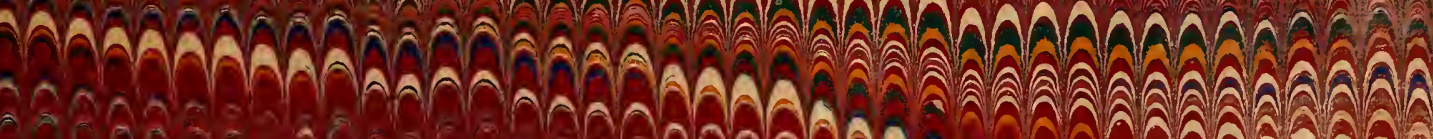
-

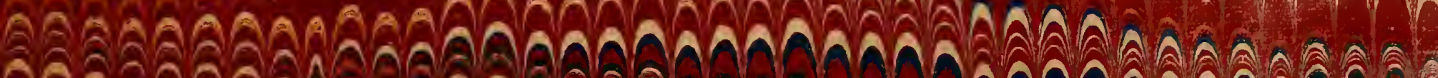

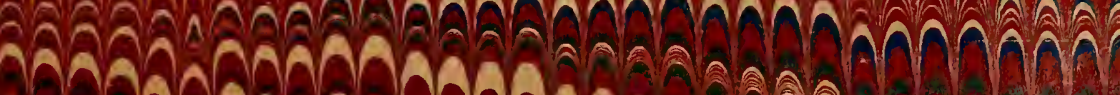









\section{PALAONTOGRAPHICAL SOCIETY.}

INSTITUTEN HDCCOXLVII.

VOLUME FOR 1S7U.

L O N D O N :

MDCCCLXXI.

Smithsonian Instifution -

APR 201935

M. 

QE

881

894

1871

MAMH

\section{O N G R A P H}

OF THE

\section{FOSSIL MAMMALIA}

OF THE

\section{MESOZOIC FORMATIONS.}

B)

PROFESSOR OWEN, F.R.S., D.C.L.,

FOREIGN ASSOCIATE OF THE IXSTITUTE OY FRANCE, ETC. ETC.

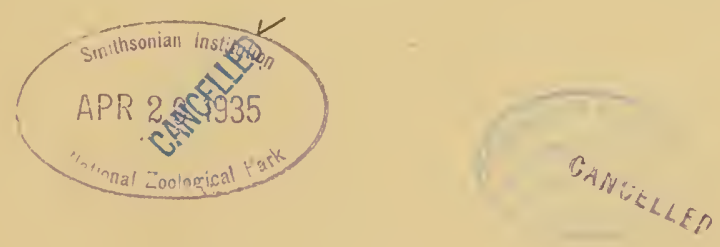

LONDON :

PRINTED FOR THE PALEONTOGRAPHICAL SOCIETY.

1571. 
inis 


\section{CONTENTS.}

\section{MONOGRAPH OF BRITISH MESOZOIC MAMMALS.}

$\S$ I. Introduction

a. Mammals from Trias (Rhetic Bens)

$\$$ II. Genus Microlestes

1. Species Microlestes antiquus

2. " " Moorei

3. " " rhreticus

B. Mamals from Lower Oolite

$P A G B$
1
3
3
3
6
8
10
12
12
15
16
16
18
18
21
21
21
28
29
29
31
33
33
35
37
37
39
40
40
41
41
44
73

\$ III. Genus Amphitherium

1. Species Amphitherium Prevostii

2. " " Broderipii

§ IV. Genus Phascolotherium

1. Species Phascolotherium Bucklandi

§ V. Genus Stereognathus

1. Species Stereognathus ooliticus .

c. Mamals from Purbeck Beds . . . . . . . . . 21

\$ VI. Genus Spalacotuerium . . . . . . . . 21

1. Species Spalacotherium tricuspidens . . . . . 21

2. $"$ minus . . . . . . 28

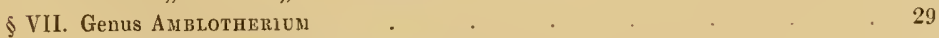

1. Species Amblotherium soricinum . . . . . . . . 29

2. " " mustelula. . . . . . 31

§ VIII. Genus Peralestes . . . . . . . . . 33

1. Species Peralestes longirostris . _ _ . . . . 33

2. " " " . . . . . 35

\$ IX. Genus Achyrodon . . . . . . . . . . . . . . 37

1. Species Achyrodon nanus . . . . . . . . . . 37

2. " $\quad$ pusillus . . . . . . . . . . $\quad 39$

$\S \mathrm{X}$. Genus Peraspalax . . . . . . . . . 40

1. Species Peraspalax talpoïdes . . . . . . 40

\$ XI. Genus Peramus . . . . . . . . . . . 41

1. Species Peramus tenuirostris . . . . . . . 41

2. " $\quad$ minor (?) . . . . . . 44 
c. Mammils from PURBeck Beds (continued) -

1. Species Stylodon pusillus

$2 . \quad$,

(var. ?) robustus

3. ,

(var. ?)

4. " Incerte sedis (Leptocladus dubius ?)

\$ XIII. Genus Bolodon

1. Species Bolodon crassidens

$2 . \quad$,

,

Incerte sedis

5 XIV. Genus Triconodon

1. Species Triconodon mordax

2. " " (sp.indet.)

3. " " firox

$4 ., "$ occisor

5. ", major.

\$ IV. Geuns Truacantuonon

1. Species Triacanthodon serrula

\$ XV1. Genus Plaghaclax .

1. Species Plagiaulax minor

2

?.

Becklesii

3. ,

,

Falconeri

4.

\$. IVII. Taxonomic deductions

medius (?)

\$ XVIII. Physiological deductions

$\$$ XIX. Objections to the carnivority of Plagiaulax examined.

$\$ \mathbf{X X}$. Conclusion

T'able of Genera of Mesozoic Mammals 


\section{MON O R A P H}

OF

\section{BRITISH MESOZOIC MAMMALS.}

\section{§ 1. IN'lRODUCTION.}

Since $1839^{1}$ there has not been further question of the occurrence of fossils of the Mammalian Class in Mesozoic deposits.

The number of confirmatory facts and the rapidity with which they lave accumulated are significant and encouraging.

To two members of the University of Oxford Palæontology owes the acquisition of the first evidences from an Oolitic deposit of animals so high in the scale as the Mammalia. In 1812 Prof. Bucki,and, D.D., F.R.S., and Wildiam John Brodertp, then an undergraduate, were in friendly relations as professor and pupil. Mr. Broderip had early been initiated by his father, who had formed a fine collection of Natural History, in the elements of that science, and to him, therefore, the lectures of BuckLand had a peculiar charm; whilst the professor found in his pupil one to whose judgment he frequently deferred in the determination of Invertebrate Fossils. Mr. Broderip's fine and choice collection of shells was, in after times, purchased by the British Museum. The history of the acquisition of the original Mesozoic Mammalian Fossils was recorded by Mr. Broderip in 1825, as follows:- "Some years have elapsed since an ancient stone-mason, living at Heddington, who used to collect for me, made his appearance in my rooms at Oxford with two specimens of the lower jaws of mammiferous animals, imbedded in Stonesfield slate, fresh from the quarry. One of the jaws was purchased by

1 Grant (Prof. R. E.), "General View of the Characters and Distribution of Extinct Animals," iti 'Thomson's British Annual' for 1839.

OGruby (Wm., F.G.S.), 'Proceedings of the Geological Society,' vol. iii, p. 21, December, 183s. 
my friend Prof. Bnckland, who exclaimed against my retaining both, and the other I lent to him sone time ago. Dr. Buckland's specimen, which wants incisor aud eanine teeth, has been examined by MI. Cuvier, and is figured by M. Prévost as an illustration to his 'Observations sur les schistes calcaires oolitiques de Stonesfield en Angleterre."1"

The other and more perfect specimen is described by Broderip in the "Zoological Journal,' Sro, vol. iii (1 S:8), p. 108, pl. xi, from which the above quotation is taken.

Both professor and pupil believed in the mammalian nature of the fossil jaws thus nequired. But the exceptional eharacter of remains of that high grade of organization in strata so ancient as Buekland had satisfied limself was the tilestone of Stonesfield, induced them to hold back the amonneement of the discovery until they had the sanetion of the great Palacontologist of the period.

This they had the gratification to receive on the occasion of the visit which Baron Cuvier paid to the University of Oxford in the year 1818, when he pronounced Dr. Buckland's specimen to be mammalian, resembling the jaw of a Didelphys.

So cneouraged and confirmed in his belief, Dr. Buckland announced the fact in his "Memoir on the Megalosaurus," published in 1823, and referred the jaw, on the authority of Cuvier, to the genus Didelphys, althongh there is little doubt that Cuvier used the term in a wider sense than it signifies in modern systems of Mammalogy.

In 1825 M. Prérost, in a paper' on the geology of Stonesfield, in the 'Annales des Seiences,' vol. iv, p. 396, refers to the specimen in the following words:- "Cette pièce unique était eonservée diuns la collection de l'unversité d'Oxford, lorsque M. Cuvier la vit en 1818. Une inspection rapide fit dire à ce savant anatomiste qu'clle avait des rapports avec la mîchoire de quelque Didelple." Baron Cuvier himself, in the concluding volnme of his great work on 'Tossil Remains,' published in 18:5, appended the following note:"M. Prévost, who is at present travelling in England, has just sent me a drawing of one of these jaws; it confirms me in the idea which my first inspection gave me of it. It is that of a small Carnassial, the jaws of which bear mueh resemblance to those of the Opossums; but it has ten teeth in a row, a number which no known Carnassial displays. At all events, if this animal be really from the schist of Stonesfield, it is a most remarkable exception to an otherwise very general rule, that the strata of that high antiquity do not contain the remains of Mammals.",

The above statements did excite close inquiry, first in regard to the geological relations of the bed of the fossil, and next as to the zoological eharacters of the fossil itself.

The arguments by which M. Prérost endeavonred to invalidate the conelusions of Buckland as to the relative position of the oolitic tilestone were satisfactorily rebutted by Dr. Fitton. ${ }^{4}$ The antiquity of this bed (No. S, fig. 2, p. 11), conld not be reduced to

1 'Anuales des Sciences Nat.', Avril, 1825.

2 'Transactions of the Geological Socjety of London, 4 to, vol, i (2nd series), p. 399.

3 'Recherches sur les Ossemens Fossiles,' 4to, vol. v, pt. ii, p. 349.

4 'Zoologicul Jourual,' vol. iii, p. 402, 1828 . 
correspond with the then presumed exclusively Mammalian epoch, and the attempts to do away with the supposed anomalons exception were afterwards confined to arguments in favour of the jaw in question having belonged to a cold-blooded oviparous animal, either fish or reptile.

The grounds of such conchusion will be found in the papers by Prof. Agassiz, in 'Leonhard und Bronn's Neue Jahrbuch für Mineralogie und Geologie,' 8vo. 1835, vol. iii, p. 185; by De Blainvilue, in his "Doutes sur le prétcudu Didelphe de Stonesfield," in 'Comptes Rendus de l'Académie des Sciences,' Paris, August 20th and October 6th, 1835; in Prof. R. E. Grant's "General View of the Characters and Distribution of Extinct Animals," in 'Thomson's British Annual' for 1839; and in Mr. Ogilby's communication to the London Geological Society in December, 1838.

The facts and arguments for the mammalian character of the fossil in question are given in a paper by Prof. Valenciennes, in the 'Comptes Rendus de l'Académie des Sciences,' Septembre, 1S38, p. 572, and in my Memoir containing a description and figures of Dr. Buckland's, Mr. Broderip's, and subsequently discovered specimens from Stonesfield, published in the 'Transactions of the Geological Society of London; 2nd series, vol. vi, pp. $47-65$, pls. 5 and 6 .

Subsequent discoveries have not only confirmed Cuvier's conclusion, but have extended our knowledge of small Mammals in Secondary strata both older and newer than the Lower Oolitic one in which they were first discovered.

The subjoined table of the eartli's strata containing evidences of life shows the relations to time of the first-known appearances of the warm-blooded viviparous Vertebrates (p. 4).

'Tn the description of these fossils, for the most part British, I now proceed.

\section{A. Rhetic Mammats.}

\section{§ II. Genus-Microlestes, Plieninger, 1847. ${ }^{1}$}

Species 1-Microlestes antiquos, Plieninger. Plate I, figs. 14, 15, 15 A.

In 1847 Prof. Phieninger, of Stuttgart, discovered, in sifting the sand of a 'bonebed' in the 'Keuper' of Diegerloch and Steinenbronn, two minute teeth, each showing a well-defined enamelled tuberculate crown, supported by two distinct roots or fangs. ${ }^{1}$

The professor, referring to my paper on the Stonesfield jaws, in which the supposed occurrence of that mammalian dental characteristic in the teeth of sharks and of the

I "Jahreshefte des Vereins für Vaterländische Naturkunde in Würtemberg," 8vo, Bd, ii (1847), p. 164, Laf. i, figs. 3, 4; and "Nova Acta Cæs. Acad. Nat. Cur.," Sc., vol. xxii (1850), p. 902, pl. 71, figs. 14, 15. 


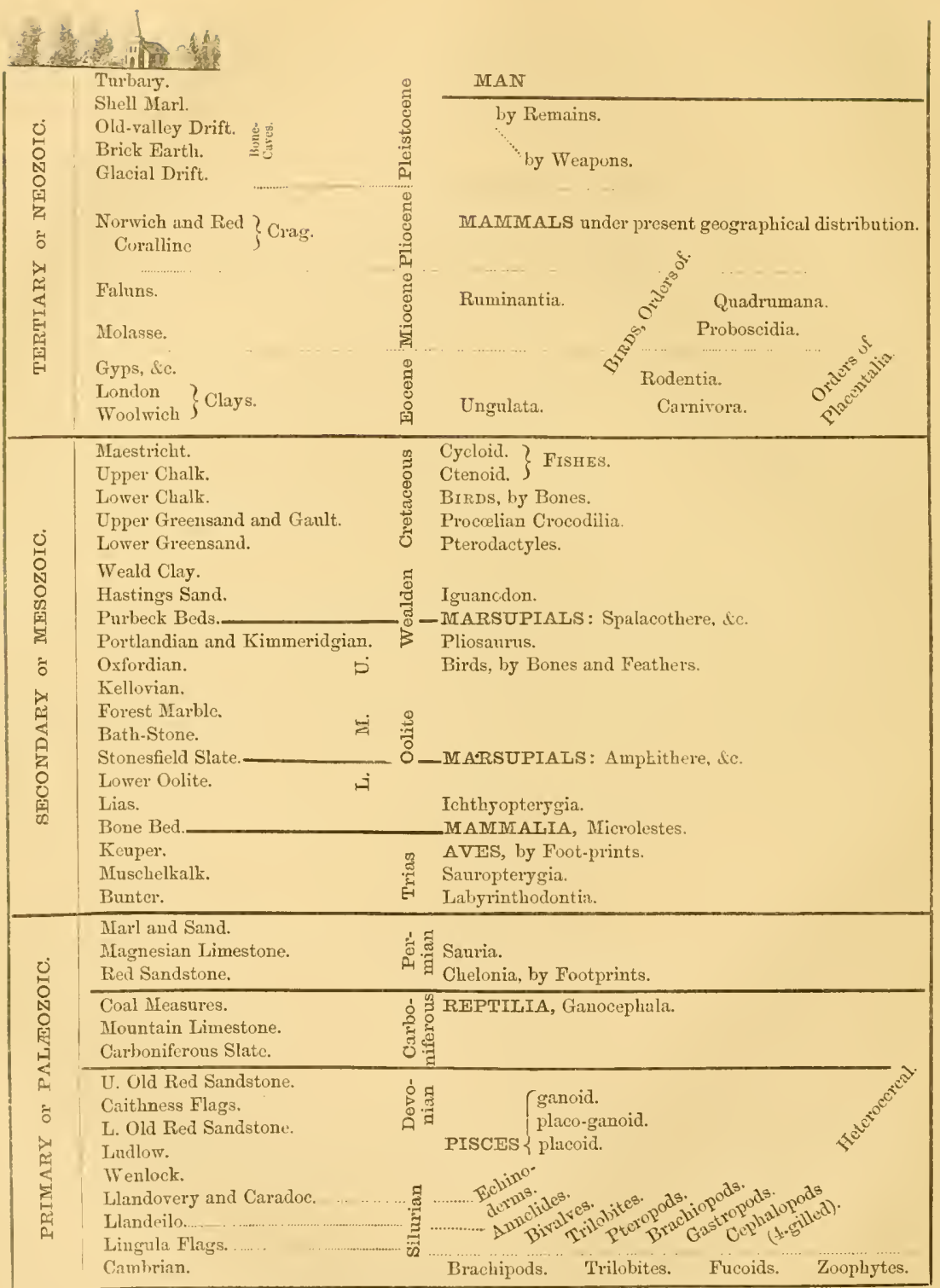


Basilosaurus of Harlan is shown not to affect the rule of two roots, being exclusively mammalian, ${ }^{1}$ concluded that he had evidence of a Mammal from that Mcsozoic group of strata now termed 'Rhætic,' which is older than the Oolitic or Jurnssic group, and he proposed for the small species represented by the two teeth the name Microlestes antiques, ${ }^{2}$ rightly referring it, notwithstanding the diminutive size indicated by the fossils, to have been a predaceous or zoophagons Mammal.

The long diameter of the crown of the larger of the two teeth (op. cit., taf. I, fig. 4) is one eighth of an inch; it is divided into two low subobtuse lobes or cones, each of which shows tuberculate subclivisions; the lobes are united at the exposed side by a basal ridge or 'cingulnm.' Each ront contracts to a subobtnse closed end. This tooth is preserved imbedded in the matrix.

The second tooth (ib., fig. $3, a-d$ ) is of smaller dimensions; the fore-and-aft diameter does not exceed one line $\left(=\frac{1}{12}\right.$ th inch $)$; the transverse diameter is little more than a third of a line, the tooth being of compresserl form, from side to side. The onter side of the crown (Pl. I, fig. 15, of this Monograph) presents one chief cone at the anterior half, succeeded by a low tubercle, and then a smaller one; the imer side of the crown (ib., fig. 14) slows three or more smaller tubercles, decreasing in size as they approach the hind end of the tonth, but the foremost is lower than the one on the outer side of the crown. They are joinerl anteriorly by a small basal talon. Thus, the grinding surface of this tooth (Pl. I, fig. 15 A) shows an irregular longitndinal mid depression between an outer and an inner tuberculate ridge or rising of the crown. It is a type of molar which prevails in a still existing member of the multidentate division of the Marsupial order (Myrmecobius fasciatus, WV th., Pl. I, fig. 19, from upper jaw, magn. 4 diam. ; fig. 20, from lower jaw, magn. 4 diam.), and which we shall find repeated in the ultimate molar of the lower jaw of a small predaceons paucidentate Marsupial from an Upper Mesozoic deposit (comp. Pl. I, figs. 14 and 15, with Pl. IV, fig. 9 B, Plagiaulax minor, and ib., fig. 12 в, Plagiaulax Becklesii).

The tooth (Pl. I, figs. 14, 15, 15 A) from Degerloch is, most probably, a mandibular nolar, and, like those in Mryrmecobius, is supported by an anterior longer and narrower root and a posterior shorter and rather broader root, both tapering, with progressive widening of their interval, to their implanted end.

The crown is short or low in proportion to its fore-and-aft breadth, constitnting about one third the length of the entire tooth, which is about two lincs. The teeth of the microlestian type still manifested by the Australian Insectivore (Pl. I, fig. 24) are quite as minute, with as short crowns, as in Microlestes antiquus; they are carried by an animal with a

1 "Nachdem auch das unter dem Namen 'Basilosaurus' bekannte, mit 2-wurzlichen Zähnen versehene Fossil, mit welchem man die Stonesfielder Kiefer zu Reptilien-resten stempeln wollte, unter die Cetaceen versetzt war."-Loc. cit.

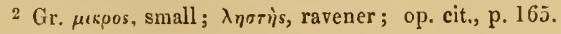


skull two and a quarter inches long, and having a total length of body of eight inches, with a tail of six inches. ${ }^{1}$

The keenness of observation and patient research with which were scrutinised, lens in hand, bushels of a formation rife with organic and mostly fragmentary remains, ${ }^{2}$ cannot be sufficiently praised; and PLieninger was worthily rewarded with this capital discovery of the oldest known Mammal.

Species 2.-Microlestes Moonei, Oven. Plate I, figs. 1-13.

To like perseverance and qualities of discovery applied by Charles Mloore, Esq., F.G.S., to the fossils of breccia of Rhatic bone-bed and Limestone, filling a fissure in the Mountain Limestone at Holwell, Frome, in Somersetshire, is due the discovery of teeth corresponding in size and general character with those of the Microlestes antiques of Plieninger. ${ }^{3}$

These teeth, with other fossils, were submitted to my inspection in 185S, referred to the genns Microlestes, and the following notes were taken of their characters.

Pl. I, figs. 1-4, represent (the natural size in outline, and magnified four times in tint) an upper molar tooth, of which the grinding surface (fig. 1) consists of a central smooth depressed area enclosed by a low thick tubercular wall. The immer side of the tooth is indicated by the more prominent part of the wall, which is divided into three tubereles; the onter side by the lower wall with indications of snbdivision into smaller and more numerous tubercles, the largest forming the hind part of the wall and a great part of that end of the tooth. The working surface of the crown is oblong, narrowest transversely, with the inner and linder end most produced.

'The length (vertical diameter or depth) of the crown is very short compared with its breadtl (fore-and-aft diameter) and thickness (transverse diameter). It is divided by a well-defined constriction or 'neck' from the roots, which are four in number. Of these the post-internal root is the best preserved, the other three being broken off near their base.

A second upper molar is represented in Pl. I, fig. 5, from the outer side. In this tooth the enamelled crown has been worn almost to the cement-covered base. One of the larger tubercles at, probably, the fore part of the crown remains. At this part there are the beginuings of two fangs, or of the division of a broad anterior root; the base of a third smaller root supports the opposite end of the crown. The indenta-

1 Waterhovse, "Description of a new Genus of Mammiferous Animals from Australia, \&c.," "Trans. Zool. Soc.,' vol. ii, p. 149 pls. 27 and 28.

2 "Eine ungeheure Jasse von Zähnen, Sehuppen, Coprolithen und unkenntlichen Skelettheilen ron Fischen und Sauriern."-Op. cit., p. 16.5.

${ }^{3}$ For a description of the Rhætic Beds of Somersetshire and an excellent account of the geology of the district in which these Microlestian remains were found, see Mr. Mloorc's paper "On the Abnormal Condition of Sccondary Deposits," Sc., in the "Quarterly Journal of the Geological Society of London,' December, $186 \%$. 
tion of the coronal basis continuing to the fang from between two of the coronal tubercles may be noted, in elucidation of the like character described and figured (in Letter) by Prof. Phillips, F.R.S., in the tooth of Hicrolestes rhaticus, which is decisive against the alleged resemblance and affinity signified by the generic name IIypsiprymnopsis imposed upon that tooth by Mr. Boyd DAwkins, F.R.S. ('Quart. Journ. Geol. Soc.,' vol, xx, p. 411.)

Pl. I, fig. 6, represents the crown of a lower molar, showing a well-defined neck and the beginnings or bases of two equal fangs. The circumference of the crown describes an irregular ellipse, the compression being from without inward.

The Microlestian generic character of a smooth subdepressed central area, enclosed by a thick tubercular wall, is well shown in this tooth. The outer part of the wall developes three tubercles, the divisions between which extend from their onter side upon that surface of the base of the crown toward the fangs. The inner part of the wall $(a)$ developes four small tubercles, the anterior one, forming the antero-internal angle of the crown, being the largest and most prominent.

Were this tubercle to be broken off and the outer part of the tooth worn down as far as the line $b$, the portion left of the working surface of the crown would offer an instructive subject of comparison with the portion of the crown of the Microlestes (Hypsiprymnopsis) rhaticus represented in Pl. I, fig. 16, from a drawing of the original kindly made for the anthor by Prof. Philuips, T.R.S.

The subject of figs. 7 and $7 \mathrm{~A}, \mathrm{Pl}$. I, is the crown, with the base of the two fangs, of a lower molar; the working surface is more worn than in fig. 6 . Consequently the three onter tubercles of the coronal wall are represented by a plicate outline such as would be presented by the premolar of Hypsiprymmus murinus, (ib., fig. 17) if it were worn down to near the base of its enamel-foldings; only the contrasted extreme shortness of the crown in Microlestes brings the intervals of the tubercles nearer to the origius of the roots of the tooth. The smaller tubercles of the imner side of the wall are almost obliterated in this tooth, and the smooth central area is proportionally enlarged. A fourth lower molar in an old Myrmecobius closely repeats this character.

Pl. I, figs. S, $8 \mathrm{~A}$, show the crown and beginning of the roots of a lower molar with the trituberculate outer wall, and the summit of the anterior angular larger tubercle of the inner wall. Fig. $8 \mathrm{~A}$ gives a view of the crown from the fore end or side, showing the degree of compression from without inwards; it also shows the hindmost of the three outer tubercles, and the summits and intervals of the smaller tubercles of the inner wall extending to the hind end of the crown.

Pl. I, fig. 9, represents the crown of a lower two-fanged molar with the working surface but little worn, showing the three outer tubercles and the five smaller inner ones, with the characteristic anterior large and prominent corner tubercle (broken off in fig. $16 \mathrm{~A}$ ).

Pl. I, fig. 10, represents the crown of a small molar viewed obliquely from the inner side, showing the anterior larger tubercle followed by three smaller ones; the three larger tubercles of the outer wall are also brought into vicw. 
Pl. 1, fig. 11, represents a sualler, probably anterior, tooth, with one fang supporting a crown or portion of crown, showing its extreme shortness, increased seemingly by attrition, which has reduced the intervals of the coronal tubercles to low notches of the enancl, with intervening exposed dentine.

Pl. I, fig. 12, shows a minnte tooth with a crown of more simple character than the larger molars; it, nevertheless, repeats the characteristic shortness or lowness of the crown, but shows a nore simple tubercular accentuation of the grinding surface, and an indication of two fangs of unequal size; this indication may, however, be due to a basal fricture of a large single fang, as in fig. 11.

Species 3.-Microles'tes miéricus, Plate I, figs. 16, 16 A.

Hypsiprymopsis Riletices, Boyd Dawkins, 1864.'

In 1864 Mr. Boyd Dawkins, F.R.S., F.G.S., discovered a small two-fanged, laterally worn molar in Rhætic nurlstone at Watchet, Somersetshire, and, assuming a common or persistent level of the detached patches or 'pockets' of bone-bed in that county, claims for the marlstone a higher antiquity than the matrix of "the Microlestian teetls of Frome and Diegerloch.,'?

This tooth is figured of the natural size and magnified four diameters, in Pl. I, figs. $16,16 \mathrm{~A}$.

The crown, as in Microlestes, is very short in proportion to its fore-and-aft width, being 1 line (1-12th in.) in height at the bifurcation of the two fangs, and 2 lines ( 1 - (ith in.) from the front to the hind border. The total length of the tooth, includiug the entire fang, very slightly exceeds the fore-and-aft diameter of the crown. The breadth or transverse diameter of the tooth, cammot be accurately determined, for the side imbedded is "entirely concealed,"3 and the side exposed to view has been subject to attrition, presenting " a smooth polished surface, which extends without interruption from the crown into the fangs," and exposing " a dark band, from $b$ to $b$, crossing what would be called the base of the crown." $\quad$ This part of the base shows "four grooves passing downwards from the crown towards the fangs." Whether these grooves (fig. 16,c) are due to the wearing force or indicate original structure is uncertain; if the latter, thcy are repeated in the lower molars of Microlestes and in one of the molars of Plagiaulax, but not in the trenchant premolars of either this genus or of IIypsiprymmus.

'The higher side of the tooth ( $a$ b, fig. $16 \mathrm{~A}$ ) is the one imbedded in the matrix; so much of it as is exposed shows the upper and imner, not the onter, side; it is the thick cuamelled border of a low crown bounding the inner side of a pounding surface which

1 "On the Rhretic Beds and White Lias of Western and Central Somersetshire," \&c., 'Quarterly Journal of the London Geological Society,' vol, xx, 1864. p, 396, \&c.

2 Op. cil., p. 410.

${ }^{3}$ Letter to the Author from Prof. Phillips, F.R.S., dated Oxford, 29 th August, 1870. 
was depressed, flat and smooth in the centre. This coronal border (fig. 16, a) was disposed in four, probably five, tubercles; on the latter alternative the fifth is broken away, most likely as being the largest and most prominent. 'The attrition of the masticatory tubercles of the preserved border of the crown of this little molar has exposed the dentine. "The crown of the tooth," writes Prof. Phillips, "is obliquely worn, and on the worn surface are little cusps, as in my figure, also worn, but a little projecting at the edges, as at fig. $16 \mathrm{~A}$, as if they were formed of enamel and dentine within the general border of enamel." 1

Now, this is precisely the appearance which the similarly worn multituberculate border of certain molars of Microlestes present. The lofty compressed trenchant premolars of Hypsiprymmus (fig. 17) lose all trace of the grooves and ridges at the basal part of the crown in proximity with the fangs. The bulging basal part of the premolar is covered by a smooth polished coat of enamel in both Plagianlax (Pl. IV, figs. 9, 10), Hypsiprymus (Pl. I, fig. 17), and Bettongia, (ib., fig. 18).

In Hypsiprymnus it is very true that the 'length' or vertical diameter of the crown of the tooth is great compared with the breadtl or transverse diameter; but in this 'main characteristic' the Rhætic tooth, like those of Microlestes and the true molars of Plagiaulax, differs widely from the premolar of Hypsiprymus. The oldest Rat-Kangaroo shows no such wearing down of the crown as must have happened to the rhætic tooth (fig. 16), if it ever possessed one as lofty as that of the hypsiprymnal premolar (figs. 17, 18). "The implantation by two fangs [is] seen alike in both" the Rhætic tooth and the premolar of Hypsiprymmus" add, also, in Microlestes (lower molars). Only there is a vagueness of meaning in Mr. Boyd Dawkins' phrase "seen alike;" for though, doubtless, the Rhætic molar and the hypsiprymmal premolar, with divers other teeth, are each implanted " by two fangs," those fangs are not "alike" in the teeth compared; and where the field of comparison is so restricted-where so few characters can be securely got out of the worn and broken fossil denticle in the slab of hard marlstone-it is satisfactory to have anything so plain and conspicuous to reason from as the two fangs so unlike in form and proportions as are those in Hypsiprymnus (fig. 17) and in the so-called Hypsiprymnopsis (fig. $16 \mathrm{~A}$ ). The proportions of the fangs in the Rhætic tooth, supposing them to be the only two it possessed, are much more alike in it and in the lower molar of Microlestes (Pl. I, figs. 7 A, 14, 15).

The hind fang in Hypsiprymums is more than twice the breadth, antero-posteriorly, of the front fang; it is subcompressed like the crown it helps to support, and in Hypsiprymnus minor (PI.I, fig. 17) its proportion of the crown is such as to include all the four vertical ridges and grooves that impress the upper half of the crown.

Mr. Boyd Dawkins figures the anterior (broken) root of the Rhrtic denticle as stouter, i.e. antero-posteriorly broader, than the posterior root, and describes the 
"stout" fang which supports "all the plicx" of the "four-plicated premolars" of Hypsiprymnus murinus, \&c., as the anterior one. ${ }^{1}$ Prof. Phillips's figure gives a more equal share of the crown to the two supporting fangs. 'The stonter fang of the premolar of IIypsiprymmus (Pl. I, fig. 17), always posterior in position, is impressed by a longitudinal groove. In the mandible of Hypsiprymmus minor the front fang is much smaller than the hind one, and the interval relatively much less than in the Rhætic tooth.

In sum, the Watchet denticle has two fangs and a crown, and a "well defined cervix" between them; and so has the premolar of Hypsiprymnus : their composition in regard to enamel and dentine is the same. Further than this no point of resemblance can be truly preclicated as between the Rhrtic tooth and the premolar of any living form of saltatory herbivorous Marsupial.

The microlestian denticles are comparable with the molars of Myrmecobius and Plagianlax, and with these alone in the Marsnpial order. The molars of Myrmecobius form a larger proportion of the entire dental series than do those of Plagiaulax. If these genera were represented by detached fossil teeth, it is, numerically, probable that Plagiaulax would be represented by some of its sixteen ${ }^{2}$ obliquely ridged carnassials, and Myrmecobius by some of its tuberculate molars.

Now, the numbers of such minute tubercular molars as have brought to light the former existence of a small-toothed predaceous, probably insectivorous, Marsupial, in times so far back as the Triassic, lead me to surmise that the extinct species more resembled the multiclentate Myrmecobius and Amplitherinm than the paucidentate Plagiaular.

The small tooth figured in Pl. I, fig. 13, nat. size in ontline, closely resembles a mammalian eanine, and bears the same proportion to the molars of Microlestes as does the canine to the molars in Myrmecobius.

\section{B. Oolitic Mammals.}

The geological relations of the bed from which the fossils next to be described have been obtained will be understood by reference to the diagram, fig. 2, of the section at Stonesfield from litton's Memoir. ${ }^{3}$

On the side opposite the right hand is marked the deptli of the shaft to the horizontal gallery where the "slate" is worked which contains the mammalim fossils; on the opposite side the strata are numbered in succession as follows:

1 Op. cit., p. 410.

2 On the assumption that there were as many premolars in the upper as in the lower jaw of Plagiculas minor.

3 'Zoological Journal,' loc. cit. 
Fie. 2.

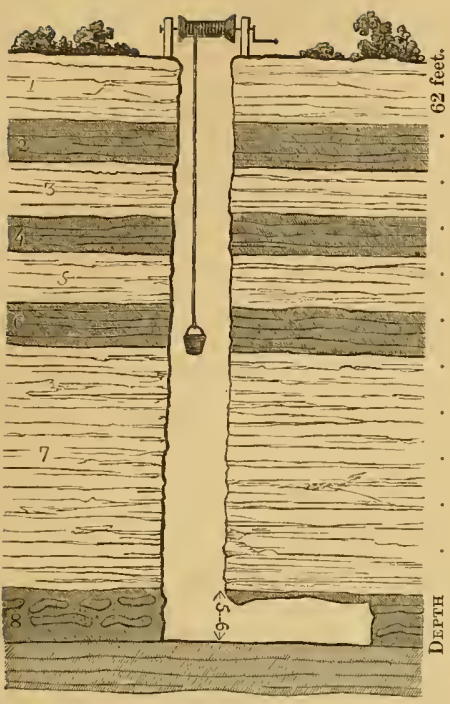

1. Rubbly limestone (Cornbrash).

2. Clay with Terebratulites.

3. Limestone rock.

4. Blue clay.

5. Oolitic rock.

6. Blne clay.

7. 'Rag,' or Oolitic limestone.

8. Sandy bed, containing the 'Stonesfield slate.'

To this succeed other Lower Oolites, leading to the Lias. Prof. Sedgwick ${ }^{1}$ was the first to point out the removal of the upper members' of the Oolitic or Jurassic series from the locality, near Oxford, where the above shaft is sunk.

It may be acceptable to some readers to have a brief statement of the generalisations from the exhaustive survey of mandibular and dental characters of Vertebrata required for an effectual grappling with the question discussed, in 1835, before the Academy of Sciences in Paris and the Geological Society of London.

The mandible in Mammalia consists of two symmetrical halves or 'rami,' which in some coalesce at the symphysis. Each ramus is a single or continuous bone, and offers a convex or flattened surface for the joint with the cranium; not a concavity, as in lower Vertebrates. In most placentals the lower and hind part of the ramus projects backward and is called the 'angle.' In some Carnivora (Hyana crocuta, e.g.) the angle is excavated on its upper and inner surface with a semblance of inflection, but the sharp inner margin is not produced beyond the vertical plane of the coronoid. In the Hare the lower border of the angle expands, so as to project a little beyond both the outer and inner surfaces of the 'asceuding ramus:' viewed from the inner side, it appears to be slightly inflected. But the inward bending of the part answering to the 'angle of the jaw ' in higher Mammals is peculiar to the Marsupialia, and in some species (Pliascolomys, e.g.) to a remarkable extent.

1 'Trans, of the Geol. Soc.,' 2nd series, vol. iv (1835), p. 26, note. 
The implantation of certain teeth by two or more roots in correspondingly complex sockets, to which the roots do not coalesce, is a mammalian peculiarity, though not common to the entire class.

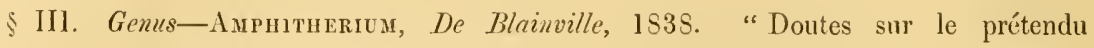
Didelphe fossile de Stonesfield ; " Comptes rendus de l'Acad. des Sciences,' August 20th, 1838 .

AupHigonus, Agassiz, 1835. Neues Jahrbuch fïr Mineral. und Geolog. von Leonhard und Bronn, Bd. iii, p. 185. (This name was proposed to express the, then, ambiguous nature of the fossil.)

Timlacotherium, Falenciennes, 1838. Comptes rendus de l'Acad. des Sciences, Septembre, 1838, p. 572.

Species 1.-Auphimerium Prevostu, Owen. Phate I, figs. 21, 21 A, 22, 22A $23,233_{\text {A. }}$ Brit. Foss. Mammals, 8ro, 1846, p. 29.

Thylacotherium Prevostil, $\boldsymbol{V} a$. Comptes rendus de l'Acad. des Sciences, September, 1838.

Pl. I, fig. 21 , gives the natural size in ontline, and fig. $21 \mathrm{~A}$, part of the same four times that size, in tint, of the original specimen examined by Cuvien in 1815, and noticed by him in 1824." 'The fossil partly exhibits, partly represents by impression in the matrix, the left half of the lower jaw, with the fore extremity broken off. A thin layer of the original bone adheres to that part of the impression which was formed by the joint or 'condylc' $(b)$; the impression above gives the size and shape of the coronoid process $(c)$; a portion of the angle $(a)$, remains, which is continued backward nearly as far as the condyle. The part of the jaw containing the three hindmost grinders is almost entire; the outer wall of the rest of the bone is left imbedded in the Oolitic slate, but this part retains seven of the molar series, with their roots, undisturbed in their sockets.

From what has been premised of the mammalian characters of the lower jaw and teeth, those which led Cuvier to conclude that the present fossil belonged to that class will be readily appreciated. The convexity of the condyle and the implantation of the teeth, each by two fangs, are decisive on this point.

'l'en molars are shown in the present fossil, and the two long implanted fangs are exposed in seven of these teeth, lorkged in deep sockets.

A subseqnently acquired half-jaw of the same species (Pl. I, fig. $23,23 \mathrm{\Lambda}$ ), with the whole dentition of that mandibular ramus, shows that the first four tecth of the original fossil, comnting backward (fig. 21, A), correspond with the third, fourth, fifth, and sixth premolars,

' "Carnassier de Stonesfield, voisin des Sarigues," Cuvier, 'Ossem. fossiles,' tom. v, pt. ii, 4to, 1824, p. 349 . Id., 8vo ed., 1836 , tom. $x$, p. 484. 
and the remaining six to the true molars. The crowns of the fourth, fifth, and sixth premolars are entire, and consist of a single compressed conical cusp, with a minute tubercle at the hind part of its base, and a more minute one in front; the base of the crown is slightly tumid, and from it are continued, without the intervention of a cervix, the two slender and slightly diverging roots. The fractured crown of the first true molar shows more distinct anterior and posterior basal cusps ; those of the second and third show an increased thickness. The fourth gives a view of the anterior cusp, of the large middle cone, and of part of the posterior cusp; the thicker and more complex crowns, as compared with those of the premolars, are unequivocally shown in the last three molars. The roots of the teeth are seen in the specimen, fig. 2l, to descend half way or more toward the lower borcler of the ramus; their substance is contrasted by its denser texture and deeper colour with the surrounding bone, from which the tooth-roots are separated by a thin layer of a distinct substance, infiltrated apparently from the matrix into the sockets. In most Reptiles the base of the fully developed tooth is confluent with the bony substance of the jaw; in the few in which the implanted base remains distinct it is simple; in both cases, with a series of seven contiguous teeth exposed as in the jaw in question, the germ of a successional tooth wonld be found beneath some of the teeth.

The broad, elevated, slightly recurved coronoid process resembles that in Didelphys, Dasyurus, Perameles, Erinaceus, and the like small predatory manmals ; the position of the condyle, on a level with the teeth, is also a character of a feeder on animal substances.

The position and form of the entry of the canal $(d)$ transmitting the nerve and vessel of the teeth accord with the mammalian type of the jaw. The (mylohyoid) groove is present in the jaw of Myrmecobius (fig. 24, g); its depth and length are greater in the fossil. Comparative anatomy supports the inference that the Stonesfield fossil examined by Cuvier belonged to a small ferine ${ }^{1}$ mammal with a jaw much resembling that of an Opossum, but differing in the great number of the molar teeth, in this respect exceeding the Myrmecobius, Pl. I, fig. 24), in which they are nine in number.

Four names have been proposed for the Mammalian genns represented by this jaw ; of these Amplitherium is the one adopted in my 'History of British Fossil Manmals,' and which I here retain.

The second fossil of this species (Pl. I, figs. 22, 22 A)-also a ramus or half of the mandible-discovered in the Stonesfield slate, supplied additional evidence of the osseous structure. It is preserved in the Geological Museum at Oxford, and is described and figured in my Memoir of $1838 .^{2}$ With the exception of parts of the coronoid, condyloid and articnlar processes, the exposed inner surface of the ramus is entire; the symplysis $(s)$

1 I nse the word 'ferine' as equivalent to the French 'carnassier,' the term by which Cuvier signified collectively the Cheiroptera, Insectivora, Carnivora, and Marsupialia.

2 'Geol. Trans.,' ser. 2, vol, vi (1839), p. 49, pl, v, fig. 2. 
is very characteristic of the mammalian nature of the hone; it is long, marrow, and continued forward in the same line with the gently convex inferior margin of the jaw, preeisely as in Didelplyys, as well as in some other Ferines of both the marsupial and placental series; its lower margin presents a small notels corresponding with that in the symphysis of the jaw in Nyrmecobius. A greater proportion of the convex articular condyle $(b)$ is preserved in this than in the preceding specimen; suffieient of the coronoid remains to show that it had the same size and shape as that process in the type specimen. A groove $(g)$ is continued from below the dental canal $(d)$, gradually contracting to a point at the middle of the ramus. There is a broader and shorter groove in the corresponding part of the jaw in the Mryrmecobius, and a narrower groove in that of the Sarcoplitus ursinus. The posterior molar shows a small middle internal and part of a larger external cnsp; the premolars ( 4 and 5 ) are entire, and show the principal and posterior basal cusp, as in fig. 21. The sockets of the missing teeth give not less than sixteen teeth in each ramus of the jaw, viz. three incisors and one eanine, each with a simple socket; six premolars and six true molars, each witli a donble socket.

Thus, Amplitherium was seen to differ from Didelplyys even more than was inferred from the evidenee possessed by Cuvier. The only known existing Mammal with a dentition approaching to the above is the Marsupial Myrmecobius (fig. 24), pecnliar to Australia. It has $i 3-3, c 1-1, p 4-4, m 5-5=13$ teeth, in each ramus. The incisors are conical, separated at their base, the first the largest; the premolars have compressed eonieal crowns with a hinder talon; the molars are relatively smaller than in Amplitherium, and of the type of those of Microlestes.

The additional evidenee, from the second jaw, strengthens the inferenee from the first, viz. that the Amplitherium was a true warm-blooded Mammiferous speeies, ungniculate and insectivorons, with a probability of its being marsupial.

The third jaw in the order of diseovery of Amphitherian fossils (Pl. I, fig. $23,23 \mathrm{~A}$ ) is the most complete one, containing the whole series of molar teeth, the last six being quinqueenspidate; the first six micuspidate, with basal ensps either on one or both sides; it also displays the socket of one small camine $(c)$ and three longish slender ineisors (i) in situt, altogether amounting to sixteen teeth on each side of the mandible, as was indicated by the sockets of the second speeimen above described.

This speeimen is the right mandibular ramus presenting the onter side to view. The conver condyle, the broad and high coronoid process, the backwardly projecting angle, the lower margin of which bends slightly inward, the varied kinds and double-rooted implantation of the teeth-all mequivoeally displayed in this unique fossil-establish beyond question the conelusions deduced from the foregoing specimens of the existence of a small inseetivorons Mammal during the Lower Oolitie epoch.

Dr. BuскцAxd kindly transmitted to me this specimen, soon after it came into his possession, and acceded to my request to make some further explorations with a view to 
determine the shape of the angular process. The resnlt showed that the lower margin of this process $(a)$ was inflected, so as to render the nuter surface convex, yet not in so great and traceable a degree as in Didelphys, Phascogale, and Dasyurus. The outer surface of the ramus presents no trace of the fissures or sutures which, in Lizards and other cold-blooded Vertebrates, separate the angular, dentary, and other, in them, distinct elements of the lower jaw. ${ }^{1}$ The broad and simple coronoid process $(c)$ of the fossil slsows the wide concavity and the anterior marginal ridge, such as were deduced from the impressed matrix in the second specimen of Amplitherium; the entire and prominent condyle $(b)$ rises somewhat higher above the level of the molar teeth than was indicated by its incomplete remains in the former specimens, and the onter surface of the fore part of the present jaw shows four or five small outlets of the dental canal, as in Myrmecobius.

Species 2.-Amphitherium Broderipir, Owen. Plate I, figs. 25, 25a, 25в.

IIistory of British Fossil Mammals and Birds, 8vo, 1846, p. 58, fig. 19.

The fourth specimen of Amplitherium, discovered in the Oolitic slate at Stonesfield, was obtained there by the Rev. II. Srkes, M.A., and was presented by lim to the Museum of the Philosophical Institution at York, where it is now preserved. It contributes as much additional information in respect to the shape of the crowns of the teeth as the third specimen had done in respect to that of the jaw-bone. It consists of the left ramus of the jaw, and offers its inner surface to the observer. It presents at its anterior part the sockets of three incisors and one canine, of small and nearly equal size; then follow the empty sockets of three small premolars, each with two fangs; to these succeed three larger premolars, in place, each having two fangs protruded to a certain extent from their sockets. Each of these teeth shows a small anterior as well as posterior tubercle at the base of the large middle cusp, and there is a slight ridge, or 'cingulum,' along the inner side of the base of the hindmost of these premolars. The first true molar is wanting, the next four have their crowns entire, the last is a little mutilated. The crowns of these molars present a different form from that which might be inferred from the fractured molars of the foregoing specimens, they are more compressed, and have not two cusps on the same transverse line. Each presents a large middle cusp, with a smaller but welldeveloped and pointed one, at the fore and back part of its base; the 'cingulum,' a part peculiar to mammalian teeth, plainly traverses the inner side of the crowl, where it developes three small cusps, one at the base of the large external cusp, and the other two forming the anterior and posterior extremities of the crown of the tooth. This form of tooth is unknown in existing Mammalia, but is as well adapted for crushing the cases of

1 'Owen, Anatomy of Vertebrates,' 8ro, vol. i, figures-88 Arupaima, 91 Chelone, 92 Emys, 93 Crocodilus, 97 Python, 272 Cyclodus, \&c. 
colcopterons Insects as are any of the insectivorous multicuspid molars of the Bats and Shrews. The existence of the wing-covers of Insects in the Oolitic slate of Stonesfield has heen long known; many of them approach most nearly to those of a Buprestis, a genus now best represented in warm climates.

In the present jaw the condyloid and coronoid processes are wanting, but have left their impressions on the matrix; there is the same wide and shallow groove near the lower margin of the hind part of the ramus, and the same notch at the symphysis, as in Amplittherium Prevostii and in Myrmecobius.

The chief value of the present specimen arises out of the very perfect state of the crowns of the molar teeth (fig. 25, B). If the structure they exhibit be really the same with that of the teeth of the Amplitherium Prevostii, yet they differ in number, there being but five instead of six premolars. The York jaw also differs in size to a greater degree than has been observed in mature individuals of the same species of Insectivorous Mammal in a state of nature.

I referred this jaw, therefore, to a distinct species, dedicated to my lamented friend the accomplished naturalist and scholar, William John Broderip, F.R.S. It probably, indeed, indicates a distinct genus, for which, if confirıned, the name Amphilestes uight be appropriated.

\section{§ IV. Gemus-Pihascolotherium, Owen, 1839.1}

Species 1.-Phascolotheriun Buckiand, Owen. ${ }^{2}$ Plate I, figs. 26, 26a.

Didelphys Buchland, Broderip, 1828. Zoological Journal, vol. iii, p. 408, pl. xl.

This genus and species are founded on the right half or ramus of a lower jaw imbedded in a slab of Stonesfield slate, and presenting the inner side to view. The natural size is shown, in outline, in Pl. I, fig. 26 ; and a carefnlly finished view of the specimen, twice the natural size, is given in fig. $26 \Lambda$.

The teeth, in sitû, include three incisors, a canine, and seven molars; it is open to conjecture that a fourth incisor may have projected near the symphysis.

The incisors in place have long slender crowns, divided by interspaces rather exceeding the breadth of the tooth. A similar interval divides the hind incisor from the canine $(c)$. 'This tooth $(e)$ is longer, larger, and rises almost vertically with a slight backward curve of the crown. The incisors incline more forward as they recede in position from the canine.

An interval of twice the breadth of the canine divides that tooth from the first of the molary series. 'The first molar (1) is divided by a space of about half the breadth of the crown from the second (2), which, with the rest of the seven molars, are nearly or quite in contact with cach other.

$$
1 \text { 'Geological Transactions,' 2nd series, vol. vi, p. 58, pl. vi. } \quad 2 \text { lbid. }
$$


Of the three incisors present in the fossil, only the inner and hinder parts of the somewhat mutilated crown are seen, not the entire breadth of the crown, so that these teeth appear to be narrower and farther apart than they really were. Nevertheless, they could not have been so closely in contact as in Sarcoplitus or Thylacinus, nor have occupied so short a relative extent of the alveolar tract, nor a situation turned inward at such an angle from the line of the rest of the teeth. In all these characters the incisors of Phascolotherium more resemble those of Myrmecobius. The canine, also, in its proportion to the incisors and molars much more resembles that tooth in the above existing insectivorous Marsupial (fig. 24,c) than the canine in the carnivorous genera of recent Marsupials.

In the proportions of the molars, Phascolotherium resembles Myrmecolius more than it does Didelphlys, Sascophitus, or Thylacinus; but the hinder grinders decrease more gradnally, and the last two in a greater degree, than in Nyrmecobins. In the form of the crown the molars of Phascolotherium resemble those of Thylacinus more than those in Myrmecobius or other existing Marsupials. There is, however, a well-marked distinction in the molar type of the present Mesozoic fossil. A principal cone rises from the middle of the crown, but there is no small cusp on the immer side of this, as in the true molars of Didelphys and Phascogale.

Herein Phascololhcrium resembles Sarcophitus and Thylacinus; but it differs in the presence of a basal ridge or 'cingulum,' shown along the inner sicle of the tooth in the specimen described, which ridge projects as a 'talon' beyond both the anterior and the posterior subordinate concs, giving the quinquecuspid character of the crown of the tooth in the second to the sixth of the series inclusive (fig. $26 \mathrm{~A}$ ). The molars increase in size from the first to the third, and clecrease from the fifth to the seventh, but in slight and gradual way.

In this series there is no distinction, by way of form, between false and true molars. The character given by the successional premolar in existing Marsupials would be arbitrarily applied to mark off the first three from the last four of the molary series of Phascolotherium. The distinction, by way of specialisation of form, between the (three) false and (four) true molars is much more strongly established in the modern Opossums and Dasyures, as it is in a minor degree in Sarcoplitus and Thylacinus.

Phascolotherium shows a closer affinity in the molar type, and in the grachal assumption of that type as the teeth gain in size, to its contemporary Amplithcria; from which, however, it differs in the reduction of the number of the molary serics to the prevailing formula in existiıg Marsupials.

Plascolotherium differs from the extinct and recent 'multidentate' Marsupials, and resembles the Sarcoplitus and Thylacinus, in the direct and broad inbending of the mandible below the mandibular condyle, and in the low position of the latter. It is entire in the present specimen $(b)$, and stands ont in bold relief from the matrix. It presents the same convexity from before backward as in Sarcoplitus and Thylacinus, but is relatively less extended transversely, and is rather more convex in that direction. 'The inflected 
part or 'angle' is contimued more directly from the inner end of the condyle, and, being broken away, its base constitutes the rielge which runs forward, hounding below the large shallow depression on the inner side of the ascending ramus. Viewing the under surface of that ramus in Sarcoplitus and Thylacinus, the flattened plane formed by the inbent angle inclines from without inward and rather downward (sce Cut, fig. 5, j. 73); in Phascolotherium the slope of the same part is rather upward and inward; so that it needs the mylobyoid groove $(y)$ and symplysis $(s)$ to convince one that it is the inner and not the onter surface of the ramus which is exposed. 'The entry to the dental canal $(d)$ is more advanced in position than in the existing Australian genera above cited. The coronoid process in direction and proportion and in the depth of the noteh between it and the condyle resembles that in Thylacinus more than that of Sarcoplitus; but the anterior borler is more convex, the fore-and-aft breadth is relatively greater, and the posterior apex a little more produced. In the gentle curve by which the lower margin of the mandible is continued to the incisive alveoli, Phascolotherium more resembles Phascogale than it does Thylacinus or Sarcophilis.

The mylohyoid groove is narrow and sharply defined; it runs from below the entry of the dental canal almost straight forward and downward, terminating at the under border below the third molar tooth; it has been mistaken for a suture, and looks very like one, but the bottom of the groove is entire. In size this fossil mandibular ramus equals that of the existing marsupial Pleascogale penicillata.

The spccimen of Phascolotherium Bucklandi above described is in the British Mnsemm.

\section{$\$ \cdot$ T.-Gomu-Stereognathus, Charlesworth. ${ }^{1} 1554$.}

Species-Sterlognatuus ooluticus, Ch. Pl. I, figs. $27-30$.

The fact of a genus and species distinct from any mammalian fossil at that time got from deposits of Mesozoic age was made known by Edward Charleswonti, Esq., F.G.S., to the Geologienl Seetion of the British Association at the meeting at Liverpool in 1 S54. But there appears to he no record of generic or specific characters.

The fossil itself was submitted to me for description, ${ }^{2}$ at Mr. Charlesworth's instance, by its possessor, the Rev. J. P. B. Deris, Ml.A., F.G.S. It consists of a portion of jaw with teeth imbedded in a slab of the Oolitic slate of Stonesfield, Oxfordshire.

The portion of bone exposed to view is about nine lines in extent, and is part of a ramus of the lower jaw, containing three molar teeth (Pl. I, figs. 27 and $27 \mathrm{~A}$ ). It is nearly straight; the side exposed is convex vertically, which inclicates it to be the outer sicle; a slight increase of vertical diameter towards the end (A) indicates it to be part of al

1 'Report Brit. Assoc.' (Liverpool), 1854, Tiep. Sect., p. 80.

2 See 'Quarterly Journal of the Geological Society of London,' vol. xiii (1857), pp. 1, \&c., pl. i. 
left ramus: the inclination of the cusps of the teeth (figs. 27, 28) towards the opposite end might, indeed, be deemed evidence of its belonging to the right ramus; but neither this degree of inclination nor the position of the accessory cusp (fig. 29, $a$ ) is decisive of the way in which that end of the fragment points. Not more of the matrix could be safely meddled with, on the small chance of further evidence to this comparatively unimportant particular being had; and the description of the fossil assumes that the shallower end is the front one, the deeper one (A) the hind end of the fragment, and that it is part of the left ramus of the mandible.

This ramus is unusually shallow, and broad or thick below, the side passing by a strong convex curve into the lower part; a very narrow longitudinal ridge, continued after its subsidence by a few fine lines, forms a tract which divides the lateral from the under surface; elsewhere the bone is smooth, without conspicuons vascular perforations. The depth or vertical diameter of the ramus is not more than two lines.

This portion of jaw contains three teeth, the middle one of which is the least mutilated; and, by carefully removing the matrix which partly covered its crown, I exposed the whole of its singularly modified grinding surface. 'The first of the three teeth (fig. 27, a) appears to have been smaller than the others, but its crown has been too much broken to show its original characters. The third tooth $(c)$ is less mutilated : it is of the same size and had the same structure as the middle one (b). Of this tooth, fig. 30 shows the grinding surface magnified about five diameters. It is of a quadrate form, three millimeters by three and a half millimeters, of very little height, and supports six subequal cusps, in three pairs, each pair being more closely connected in the anteroposterior direction of the tooth than transversely. In the Plate its position is at right angles to that in the jaw, fig. 27 .

The outer side of the crown (fig. 29), supported by a narrow fang which contracts as it sinks into the socket, shows two principal cusps or cones $\left(o, o^{\prime}\right)$ and a small (anterior) accessory basal cusp $(a)$. A small portion of the outer side of the anterior cone $(o)$ has been chipped off; that of the second cone $\left(o^{\prime}\right)$ shows a well-marked convexity. The hard and shining enamel which covers these parts of the crown contrasts with the lighter cement that coats the root. The two onter lobes or cones are subcompressed, and placed obliquely on the crown, so that the hinder one is a little overlapped externally by the front one, the fore part of the base of the hinder one being prolonged inward on the inner side of the base of the front cone. 'l'he two middle cones are subcompressed laterally, with the fore part of their base a little broader than the back part. T'he two inner cones have their inner surface (fig. 2S) convex, with their summits slightly inclined forward; a small portion of enamel has been chipped off the hinder lobe. The fore part of the base of the himder cone is prolonged obliquely towards the centre of the crown, beyond the contignous end of the base of the front cone, so as to cause an arrangement like that of the tro onter cones; the obliquity of the posterior cone of both the outer and the inner pairs being such that they slightly converge as they extend forward. 
In the hindmost tooth (fig. $27, c$ ) the two outer cones are broken off, showing that their common base is divided from the two middle cones by a deeper groove than that which separated the two onter cones from each other.

Thus, the crown of these molars might be described as supporting three parallel antero-posterior ridges; the outer (fig. $29,0,0^{\prime}$ ) and the inner (fig. 25) ridges being each divided by an oblique cleft converging forward towards the middle of the tooth; whilst the middle ridge is divided by a curved cleft having its concavity turned forward (fig. 30).

The more mutilated state of the front tooth (fig. 27, a), of which only the base of the middle ridge of the crown remains, throws no additional light on the modifications of the very remarkable type of the grinding surface of the mandibular molars of Stereognathus.

This type of tooth differs from that of all other known recent or extinct Manmals. The nearest approach to it is made by the true molars of some of the latter from the most ancient of the Tertiary strata, as, e.g. Plioloplus, from a septarian nodule of the London Clay $^{1}$ (Pl. I, fig. 31, lower molar), and Ilyracotherium. ${ }^{2}$

The proportional size and regularity of form of the cones of the grinding teeth of the Stereognallus give a different character of the crown from that of the multicuspid molars of the Insectivora, and cause it to resemble more the pentecuspid or sexcuspid molars of the extinct hoofed genera above cited. No Mesozoic Mamma] save Stereognathus ooliticus: shows better grounds for being regarded as a diminutive form of the Ungulate order of Mammalia; but, assming its position in that order, it is probable that its food, if we may judge from the existing Hogs and Peccaries, was of a mixed nature. There is certainly no other known Mesozoic Mammal which las so good a claim to be considered in any degree herbivorous.

Dr. Ennoxs has described and figured the mandibular ramus, 9-10ths of an inch in length, of a Mammal (fig. 3) from the 'Chatham Coal-field' in North Carolina. It contains three incisors, one canine and ten molars; of the latter series, the first three have simple

FIG. 3.

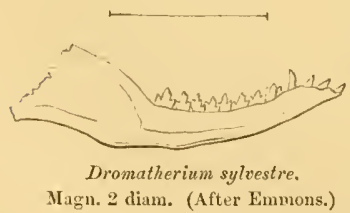
subcompressed conical crowns, the next four are multicuspid, and the last three are tricuspid (according to the figure); the incisors are separated by intervals, as in Myrmecobius and Phascolotherium.

I opine that Dromatherium was Marsupial. The extinct species indicated by this mandible Lmmons calls 'Dromatherium sylvestre.' The carbonized remains of ancient regetation in which the foregoing, with two other similar mandibular fussils, have been found, is probably, like the coal of Brora, Sutherlandshire,

1 'Quart. Journ. Geol. Soc.,' rol. xiv, p. 54, pls. ii-iv. 2 'Geol. Trans.,' 2ud ser., vol. vi, p. 203, pl. 24. 
not later than the Lower Oolite; or, like the Lettenkohle of Germany, of Triassic age. The Mammalian remains are associated in the Carolina-Virginia Coal-fields with those of thecodont Reptiles. ${ }^{1}$

\section{c. Mammals from Purbeck Beds.}

The strata of the Isle of Purbeck, on the Dorset coast, intervene between the 'Upper (Portland) Oolites' and the 'Wealden' (see Table I, p.4). 'They have been successfully studied and accurately described by Mr. Webster, ${ }^{2} \mathrm{Dr}$. Buckland, ${ }^{3}$ and Dr. Fitton, ${ }^{4}$ whose conclusions lave been verified with additional details, both palæontological and geological, by subsequent observers, especially by the able and accomplished officers of the Geological Survey of Great Britain, to one of whom, Robert Etheridge, Esq., F.G.S., Palæontologist to the Survey, I am indebted for the subjoined diagram of the deposits at Durdlestone Bay (Fig. 4), including those from which the Mammalian Fossils of the 'Purbeck' described in the present Monograph have been obtained.

\section{§ VI. Genus-Spalacotherium, Owen, $1854 .^{5}$}

Species 1-Spalacotherium tricuspidens, Ow. Pl. I, figs. 32, 32 A, 32 в, 32 c, 33, $33 \mathrm{~A}, 33 \mathrm{~B}, 33 \mathrm{c}$.

Quart. Journ. Geol. Soc,, vol. x, p. 426, 1854.

After Emmons' discovery the next evidence of a Mesozoic Mammal was obtained from a deposit of later date, one of those which are known as the 'Purbeck Series,' richly developed in the peninsula of that name, at Durdlestone Bay, near Swanage, Dorsetshire.

In the year 1854 a series of small fossils from that locality were sent to me for determination by Messrs. WrLcox and Brodie, of Swanage. 'The majority of the specimens were Saurian, and afforded characters of the lacertian genera Nuthetes, Mlacellodus, Saurillus, \&c. ; ${ }^{6}$ but some appearances of the teeth in small jaws among Mr. Brodie's specimens, suggesting evidence of a higher grade of life, attracted and excited close and continued scrutiny.

At first sight the specimens appeared, as their discoverer had supposed, to differ only in species from the similarly sized jaws of the Saurians with which they were associated, and it was only after a careful removal of the matrix concealing their most characteristic

1 'American Geology,' part vi, 1857, p. 93. A copy of Emmons' figure, and of the reference thereto, in - my 'Palæontology,' 8vo, 1860, p. 302, is given in Dana's excellent ‘ Manual of Geology', 8vo, 1864, pp. 426, 429 , and fig. 650 .

2 'Geol. Trans.,' 2nd series, vol. ii, p. $36 . \quad{ }^{3}$ Ib., vol, iv, p. $11 . \quad{ }^{4}$ Ib., ib., p. 208.

5 'Quarterly Jonrnal of the Geological Society of London,' vol. x, p. 426.

6 Ib., p. 420. 
Fig. 4.

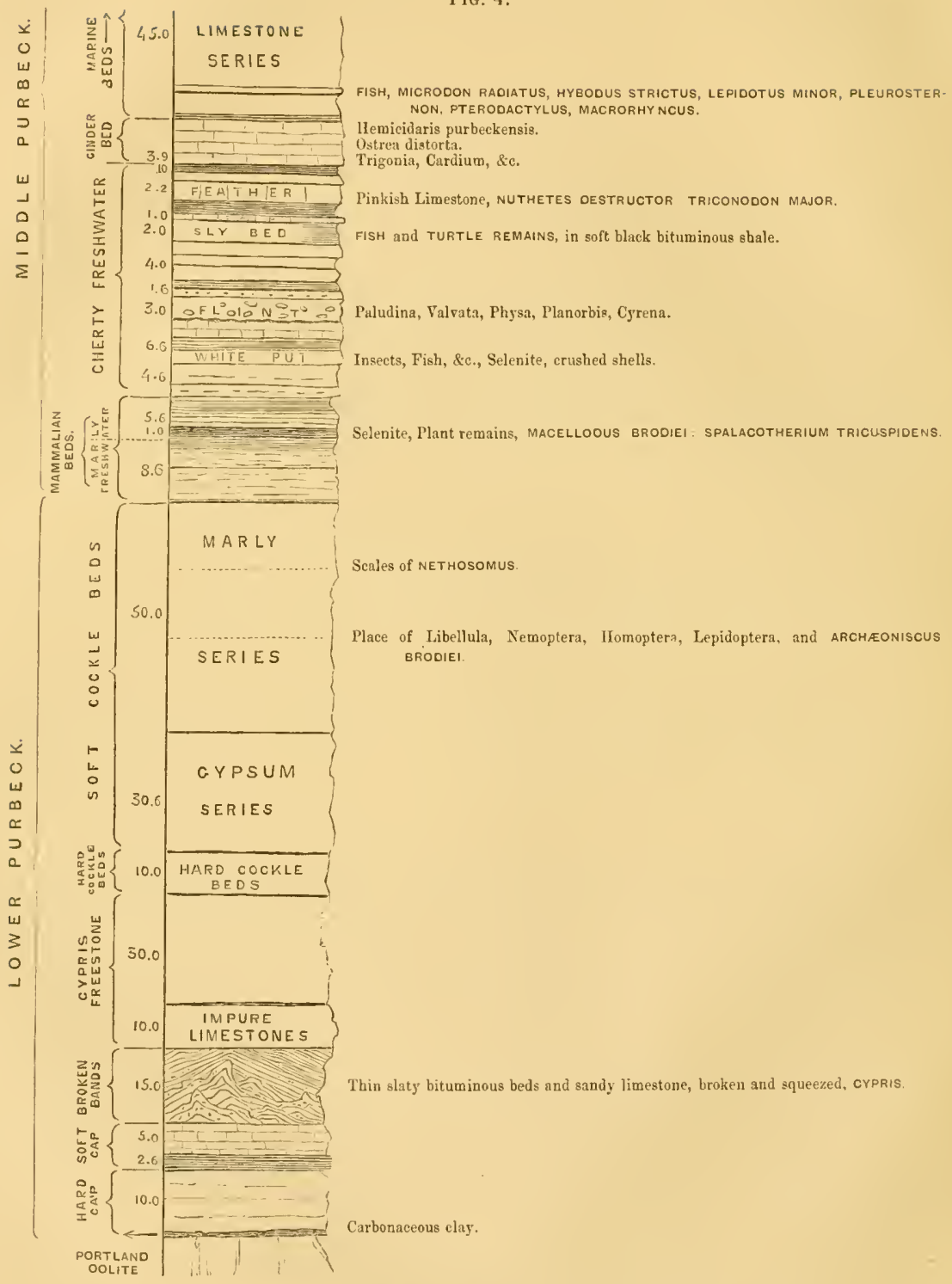

Section of Middle and Lower Purbeck Beds. 
features that I became satisfied of their relationship to the Mammalian class. I proceed to give results of re-examination of these specimens.

In a slab of Purbeck shale, showing part, and the impression of more, of a mandible, with teeth, nearly the whole of the hinder half of the ramus is exposed (Pl. I, fig. 32, natural size; in outline; $32 \Lambda$, twice natural size). This contains four teeth, not quite in contact, having a long and rather slender crown, terminated by a sharp-pointed subtriedral cone (fig. $32 \mathrm{c}, 0$ ), the inner side of the base of which is produced before and behind the main cone into a short small cusp $(e, s)$. This tricuspid crown is implanted by two roots (fig. 32 B) in a distinct bifurcate socket of the jaw-bone.

The four teeth in fig. $32 \mathrm{~A}$ gradually diminish in size to the hindmost; the jaw becomes slightly contracted vertically hehind the tecth, and then expands to include a smooth depression, recognisable as the fore part of that for the insertion of the crotaphyte muscle; the upper swollen boundary $(b)$ indicates the fore part of the base of the coronoid process; the lower boundary ridge $(a)$ is that which would have been continned to the condyle and the angle of the jaw. We have here a left mandibular ramus with the outer side of the preserved bone and teeth exposed. The onter surface is vertically convex; the imner one, as indicated by the impression, is flatter, and faintly shows the termination of a longitudinal channel.

Fig. 3: $\mathrm{B}$ is an oblique view of the anterior side of the crown of the first of the four teeth in fig. $32 \mathrm{~A}$; it shows the basal ridge of the onter side of the crown, ascending to be lost on the anterior accessory cusp; fig. $32 \mathrm{c}$ gives the form of the summit of the crown of the tooth viewed vertically.

In the number, proportion, and relative position of the cusps, this modification of the insectivorous molar resembles that in the Cape Mole (Chrysochloris); but in the proportion of the mid-cone $(o)$ and the definition of the side ones it accords more closely with the type of the Amphitherian molar (Pl. I, fig. 25 B).

The immer antero-posterior extent of the crown is considerable as compared with the proportion of that diameter with the height of the crown in the true molars of any of the modern Moles and Shrews, except the Chrysochloris. The impressions of the inner side of some teeth anterior to those in place show plainly the tricuspid character of the crown, and indicate also a greater number of such molars in the fossil than in any of the recent Mammalia, with the exception of the marsupial Myrmecobius. Of this further and more important affinity of the Spalacolherium to the Amplitherium the following specimens yield more decisive evidence.

A portion of the marly fresh-water shales from the Purbeck series at Durdlestone Bay, marked 'manmalian beds' in fig. 4, had imbedded in it part of the lower jaw of the Spalacotherium, wanting the ascending branch; the alveolar tract includes one incisor, a canine or canine-shaped premolar, and ten succeeding teeth. It is represented of the natmral size in outline Pl. I, fig. 33, and magnified in tint twice the natural size at fig. $33 \mathrm{~A}$. The incisol (i) seemed to be the smallest of these teeth, but is represented only by a portion of the 
crown, of a subquadrate or obtusely conical siape, convex externally. The canine or eanineshaped premolar $(c)$ is more than twice as long and broad as the ineisor, with a sul)compressed, sharp-pointed conical erown, a little inclined backward; it appears to have been inserted by a divided root, like the similarly shaped and proportioned first premolar in the Mole. The two suceeeding teeth (1 and 2) are one third smaller than the canine, with subcompressed, conical crowns, at the fore and back part of which the base is shightly produced; cach is implanted by two distinct fungs. The third and fonrth teeth have a similar form and complex implantation, but are somewhat larger, and the basal cusps are more developed; in the fourth tooth this development gives a distinetly tricuspid eharacter to the erown, the middle eusp, representing the crown of the preceding teeth, being the largest and highest. The six following teeth (.5 to 10) repeat the same nuequal tricuspid form, with increased but varying size, the middle teeth $(6,7,8)$ being the largest, and the last tooth (10) diminishing in size in a greater ratio than the penultimate one (9). 'These six last molar teeth are seen to be elose together when the base with the ridge or 'cingulum' is exposed. The lateral cusps incline inward, and project from a plane more internal than the longer middle cusp. The imer side of the crown presents a wide longitudinal groove at the base of the middle eusp, between the inwardly infleeted lateral eusps ; the base of the crown presents externally a well-defined narrow eingulum, beneath which the two fangs, or the two external fangs, descend into the substanee of the jaw. The last fonr teeth $(7-10)$ show an inferiority of size, as compared with those of fig. $32 \mathrm{~A}$, which may be sexual.

In the state in which this instructive portion of the Spalacothere reached me, the matrix concealed all save the large middle ensp of the molar teeth, whieh teeth seemed to be wider apart, and presented a more laeertine aspect. By the careful application of a fine needle and graving tool I succeeded in displaying the lateral cusps and grinding surface of the crown, and the other teeth, as shown in the enlarged view given in fig. $33 \mathrm{~A}$. Fig. $3: 3 \mathrm{~B}$ gives a magnified view of the antepenultimate molar (s), viewed obliquely from behind; and fig. $33 \mathrm{c}$ is an ontline of the erown viewed vertically. We have here a right mantibular ramus, with the onter side exposed.

So much of the jaw-bone as is preserved in this specimen (fig. 33) nearly eorresponds in size and shape with the portion and impression of the opposite (left) ramus (fig. 3:2), and shows the rertieal contraction or decrease of that diameter behind the molar series, prior to the expansion of the jaw into the aseending ramus. The horizontal ramus has suffered an oblique fracture since its fossilization aeross the alveolar series, with a very slight depression of the fore part containing the four anterior teeth; a second fracture crosses the eontracted part of the jaw behind the last molar in place. There is not any clear evidenee of a smaller molar tooth bchind the last in place, marked 10. Between the large laniariform tooth $(c)$ and the fore end of the ramus of the jaw there is a space for three ineisors like the portion of the small one preserved ( $i$ ), and also for a small caninc-shaped tooth, which is demonstrated in one of the specimens mext to be noticed. 
The specimen, fig. 34 , nat. size, and magnified twice nat. size at $\mathrm{A}$, is the anterior half and an impression of most of the remaining part of the left ramus of the lower jaw, its inner surface exposed, showing the canine or canine-shaped premolar, $c$, and five following teeth in place, a fragment of a sixth molar, and impressions of four sncceeding molars. The crown of the canine-shaped tooth is long, subcompressed, slightly recurved, pointed, with a small post-basal tubercle. The adjoining tooth (1) has a compressed, pointed crown, scarcely half the height of the canine and two thirds as broad at the base, with a ridge along the inner side of the base, and a more developed posterior basal tubercle : it is divided by a small interval from the canine. The second molar (2), with a slight increase in size and a similar shape, has the fore part of the basal ridge developed into a low point, and the hinder tubercle is relatively larger' and more pointed. 'The third tooth (3) is larger than either of the two preceding, but resembles them in form. The fourth (4), with the same antero-posterior extent, has a lower crown, the middle cusp being relatively shorter, but both the anterior and posterior ones are larger, and now begin to assume the character of independent cusps ; their bases almost meeting upon the inner side of the base of the middle cusp. 'The fifth molar, with a slight increase of size, shows a still further development of the accessory cusps, which are slightly inclined backward, or project from a more internal plane than the middle cusp. The impressions of the succeeding teeth show that their middle cusp was longer in proportion to its basal breadth; and thus agree, like the foregoing teeth, with the teeth similarly marked in fig. 33 . The canine-like tooth seems to have a bifid fang; the three succeeding premolars, implanted each by two fangs, in this respect as in the general form and proportion resemble those of Amphitherium.

The proportion of mandibular ramus here preserved and indicated is 1 inch 1 line, or 27 millimeters, in length, that of the Mole being 1 inch, or 25 millimeters. The crown of the laniariform tooth is relatively longer, and the fourth tooth counting therefrom is of a different form, being of much smaller size and of a more simple structure than is the corresponding tooth, which forns the first true molar of the Mole. The greater number of molar teeth indicated in the present and displayed in other specimens of the Spalacotherium demonstrate its generic distinction from any known existing insectivore, placental or marsupial, the Myrmecobius having nine and the Chrysochlore laving not more than eight lower molars. The multident marsupial Myrmecobius is the sole existing Mammal, with incisors and canines, that approaches the Spalacothere in the excessive number of the molar teeth. Fig. $34 \mathrm{~B}$ is a magnified view of the teeth marked 4 and 5 in fig. $34 \mathrm{~A}$, shorving the meeting of the accessory cusps on the inner side of the crown.

The last two specimens afford grounds for determining the teeth in place in fig. 32 : they are accordingly denotéd by corresponding numerals.

T'ine evidence of the Mammalian nature of the above-described specimens, briefly subnitted to the Geological Society in 1854, excited an interest in further explorations of their place of deposit. 'I'his was undertaken with characteristic ardour by SAMUEL H. 
Beckles, Esq., F.R.S., and the success of his explorations, carried on at much cost and personal risk, may be estimated by what follows of the present Monograph, the subjects of which were exclusively brought to light by Mr. Beckles.

I commence with those which tend to complete our knowledge of the mandible and mandibular dentition of Spalacolherium.

Pl. I, fig. 35 , represents, of the natural size, in outline, and magnified three times, in tint, at $\mathrm{A}$, the fore part of the left mandibular ramus, showing its outer side, and an impression of the linder part to near the beginning of the rising branch of the same jaw. The horizontal ramus is vertically narrow, but is thick, being convex outwardly; it is flatter on the inner side, the impression of which shows a trace of the longitudinal groove $(g)$. 'T'he ramus gradually contracts, with a gentle inferior' convex curve, to the fore end, which is not abruptly raised, or bevelled up. There are four rather close-set simple alveoli, anterior to the three premolars, with more or less mutilated crowns, in place. The fourth alveolus is that of the canine $(c)$. The second premolar (2) shows, as in fig. 34 , the main cone less raised in proportion to its breadth than in the succeeding teeth. The tip of the higher cone of the third premolar (3) is preserved, with the impression of the two inner basal cusps. The fourth and fifth of the molar series are not preserved. The sixth and seventh are shown by impressions of the two inner cusps (see fig. $34 \mathrm{~B}, e, s)$. Impres. sions of the two or three following teeth are less recognisably preserved. There is a small outlet of the dental canal beneath the first premolar, and a second beneath the alveolus of the third or last incisor $(i 3)$.

Figures 36 and 37 show the portions and impressions of a mandibular ramus with teeth of Spalacotherium tricuspidens preserved in counterpart slabs of a split block of Purbeck shale.

In fig. 36, a portion of the middle of the horizontal ranus exposes its inner surface, and includes three teeth $(3,4,5)$ more or less mutilated, with part of a fourth (6). In fig. 37 the continuous hinder part of the ramus is preserved, showing the outer surface, and iucludes the basal half of the crown of the sixth and seventh molars, with inclications of the sockets of the eighth and ninth molars. The tenth molar (10) is in part preserved, together with the hind part of the ramus, broken off, and somewhat displaced, showing the characteristic contraction preceding the expanse into the ascending brauch with the crotaphyte fossa.

'The impression anterior to the portion of jaw preserved in this block answers to the part of the ramus preserved in the counterpart block : in advance of which impression a small portion of the fore part of the ramus remains, showing the posterior ontlet beneath the socket of the first premolar.

The tecth retained in the block (fig. 36) are the third, fourth and fifth of the molary series. Anterior to them is the impression of the second, showing the same proportions of the mair-cone as in 2, fig. 34. That of the third premolar (3) in fig. 36 wants the apex. 
The fourth tooth (4) preserves the summit of the main cone; but the base of the crown is mutilated. The main cone is broken away from the fifth tooth, but the two inner cusps, characteristic of Spalacotherium, are instructively shown. The accentuation of the inner, less bulging, surface of the ramus is well shown in the present slab. The thin inner alveolar wall descending sheer from the ontlets of the sockets is at first slightly concave vertically; then swells out into a convexity toward the lower border; near which, at the hind part of the fragment, may be discerned, when the specimen is held in a strong light, the termination of the longitudinal (mylo-hyoid) groove $(g)$.

In the hind portion of jaw (fig. $37 \mathrm{~A}$ ) the equally characteristic base of the external main cone, with its basal cingulum, is seen in the teeth answering to the sixth and seventh molars. The impression of these before and behind are less intelligibly preserved in the matrix.

As far as I can safely work away the matrix from the imner side of these teeth, the base (horizontal section) thereto turned seems to be indented; the working surface terminating on that side in two low cusps, as shown in fig. $36 \mathrm{~B}$, answering to those shown in the tooth (5) of fig. 34 .

All the evidence concurs in giving a tricuspid crown to the molar teeth in the present Purbeck fossil, of the character of that of the type-specimens of Spalacotherium (figs. 32-34), with which the mandibular ramus, so far as it is preserved, corresponds.

The last specimen referable to Spalacotherium tricuspidens supplies very satisfactorily the characters of the hind end and rising part of the lower jaw.

It consists of the left mandibular ramus, wanting the symphysial end, with five more or less mutilated molars in place, the inner side being exposed. It is figured of the natural size in fig. 38, and of twice the natural size at $\mathrm{A}$. This specimen includes the condyle $(b)$ and great part of the coronoid process $(c)$.

From the inner end of the condyle $(b)$ a ridge curves forward, bounding below the depression, terminating anteriorly in the entry of the dental canal $(d)$. The hinder two thirds of the ridge has been broken away in exposing the specimen, indicative that it has extended inward or transversely to the plane of the rising ramus above, to a greater degree than is here shown. The lower border of the ramus is entire and convex, showing that the angle of the jaw was represented by the inflected ridge, plate or process.

This marsupial character is well shown in Sarcoplitus and Thylacinus (fig. 5, p. 74); but the entry to the dental canal is more advanced in the present extinct marsupial than in those existing species. The condyle is transversely extended, and holds the same relation of level to the alveolar tract as in Thylacimus. A deep emargination divides it from the hind border of the coronoid. The shape of this process resembles that in Sarcoplitus. A linear groove is continued from the inner border of the dental foramen to beneath the third molar here in place.

The most perfect molar-the first in place-shows a fine but well marked 'cingulum' 
along the inner side of the base of the crown expanding into an anterior and a posterior basal cusp; between which the crown rises in two inner and lower cones, and one onter and higher cone.

Indications of the same structure are more or less clear in the four succeeding molars, which retain nearly the same fore-and-aft basal breadtlı. There is an empty socket of a smaller molar between the last in place and the base of the coronoid, and the empty twochambered socket in front of the first molar in place may have held an anterior one of the same complexity, making seven molars. There is sufficient demonstration of the multidentate character to warrant the reference, suggested by the type of molar teeth, to the genus Spalacotherium.

The contour of the lower border of the ramus is not an even curve, but is slightly wary, the convexity changing to a slight coneavity beneath the entry of the dental canal. There is an indication of a slight vertical constriction behind the molar series, as in the previously described specimens of the present genus.

Species 2.--Spalacotherium minus, Owen. Plate I, figs. 39, 39a.

The best preserved molar tooth in the specimen (Pl. I, fig. 39, nat. size, and $39 \mathrm{~A}$ magnified three times, in tint) shows the generic type of Spalacotherizm, the ant-internal and post-internal eusps meeting at the inner side of the base of the main cone. But the specimen is not only inferior in size to the type species, but cliffers in the absence of the constriction of the horizontal ramus anterior to the expansion into the aseending branch. The horizontal ramus preserves, however, the degree of vertical extent forward as far as the socket of the canine, which tooth is shown in fig. 34. The base of the ascending ramus indicates a curve upward toward the condyle, as in fig. 35. The dentition is not sufficiently preserved to afford any ground for generic separation; and I therefore retain it as a smaller species of Spalacotherium.

This species is represented by a left mandibular ramus with the imner surface exposed, retaining four juxtaposed teeth belonging to the middle of the dental series with indications of soekets before and behind then. Two of the retained teeth are molars, the hindmost yielding the Spalacotherian type of erown as above described. The next in advance gives a main cusp and indications of an accessory one in front, and a lower and more remote one behind; but the crown of this tooth is too much mutilated for precise definition. The teeth are compressed. There are indications of sockcts of two molars betwcen the last in situt and the ascending ramus. The premolars show a reduction of fore-and-aft breadih more immediately than in Spalacotherium tricuspidens: their crown consists chiefly of a subcompressed sharp-pointed cone. In advance of the two hinder mutilated teeth in place are sockets of four others, decreasing in size, and then a large and more outwardly projecting alveolns of a canine, the crown of which has left its impression. In advance of this, the symphysis with the incisive alveoli has been broken off. 
The inner side of the ramus is marked by the linear groove continued further forward than is indicated in the specimen (Pl. I, fig. $38, g$ ) of Spalacotherium tricuspidens. The vertical extent of the horizontal ramus is preserved as far forward as the socket of the canine, both upper and lower borders being nearly straight and parallel.

\section{§ VII. Genus-AmbLơtherium, ${ }^{1}$ Owen.}

In the type of the present genus (PI. II, fig. 1, nat. size and $1 \mathrm{~A}$, magn. 3 diam.) the true molars do not exceed in number those of the lower jaw in Amplitherium (Pl. I, fig. 25), and of the upper jaw in Peralestes (Pl. II, fig. 3) ; but the incisors are four in each mandibular ramus, equalling in number those in Pliascolestes (Pl. II, fig. 4). The two lind premolars have crowns exceeding in size those of the succeeding molars.

The present species, with the full or adult complement of teeth, is markedly smaller than any of the foregoing Mesozoic mandibles save Spalacotherizm minus.

Species 1-Amblotherium soricinum, Owen. Plate II, figs. 1, $1_{\text {A }}, \mathrm{l}_{\text {в. }}$

This species is founded on a right mandibular ramus, the inner side exposed (Pl. II, fig. 1 , nat. size; $1 \mathrm{~A}$, magn. 3 diam.) showing four incisors $(i 1-1)$, the canine $(c)$, four premolars $(p 1-4)$, and six molars $(m 1-6)$, with a trace of what may have been the alveolus of a seventh molar.

The condyle (b) projects midway between the summit of the coronoid $(c)$ and the angle of the jaw $(a)$, its lower end being on the level of the alveolar outlets. A thin ridge $\left(a^{\prime}\right)$, or rather the base of one showing fracture, projects inward from the lower border of the ascending branch, bounding below the groove leading to the entry of the dental canal $(d)$. From the fore part of this entry the groove $(g)$ begins, which extends as a linear fissure, simulating a suture, from a little above the rounded lower border of the ramus to the hind part of the symphysis $(r, s) .^{2}$

The hind border of the coronoid process descends from the fine recurved point $(c)$ in a bold or deep regular concave curve to the condyle, as in Amphitheriun and Phascolotherium, but its apex does not reach so far back. The state of prescrvation of the articular process shows clearly enough its convexity, but not its precise size; it is somewhat crushed, and appears larger in the specimen than it was in the recent bone.

1 ' $a \mu \beta \lambda$ íw, to abort; $\theta \eta p i o v$, beast.

2 It is remarkable that a groove corresponding in position with that lodging the mylobyoid nerve and vessels in the human mandible, but of which no trace exists in most lower placentals and existing marsupials, should reappear, as it were, so distinctly, in these small Mesozoic mammals. It may be questioned whether it was due to the same mechanical cause and relations as in mau; whether it may not rather indicate a more definite "splenial" harmonia, remaining longer open than in later mammals; but which is, nerertheless, entirely closed in all the subjects of the present Monograph. 
Below the condyle the hind border of the ascending ramus describes a deep curve to the backwardly produced end of the inflected angle of the jaw. The lower border of this inflected part is straight, and is not continued into that of the horizontal ramus with the undulated contour shown in Spalacotherium, Phascolotherium, and Amphitherium. The depth of the ramus gradually lessens to the horizontal sloping symphysis, as in Amphitherium.

The first incisor ( $i_{1}$ ) of Amblotherium soricinum is procumbent, and continues forward, as it were, the gentle curve of the lower border of the symphysis; it has a long, slightly expanded, obtusely terminated crown, but this is the worn configuration of the fossil tooth and may not have been exactly its condition in the recent subject. The crown of the second incisor $\left(i_{2}\right)$ is less than half the length of that of the first, but is almost as broad; it rises at a distance equal to its own basal breadth from the first. The third incisor $(i 3)$ is similar to the second, and rises closer thereto. The crown in each of these incisors is hollowed on the hinder and inner surface, so that the apex is subrecurved, as in Myrmecobius (Pl. 1, fig. 24). After a longer interval comes the crown of a fourth small incisor $(i, 4)$. Near this rises vertically, with a slight backward curve, the crown of a tooth which, by its length, represents the canine $(c)$; it terminates more acutely than do the incisors, and the crown is narrower in proportion to the height than in them.

Behind the canine, with an interval like that before the canine, is the simple low conical crown of a minute premolar $(p 1)$. In closer proximity rises that of the second premolar $(p 2)$. From the apex of the cone, which is near the fore part of this tooth, the hind border slopes or curves backward, swelling inwardly, and representing a hind basil prolongation or talon. The third premolar $(p 3)$ presents a like type of crown, with marked gain of size. The fourth premolar $(p 4)$ increases in height, but not in basal breadtlı. Each premolar is implanted by two fangs.

The series of true molars begins by teeth much inferior in size to $p 4$ and $p 3$ : they. have acquired, abruptly as it were, their characteristic shape and complexity of crown (fig. 1, B, magn. 6 diam.). This consists of a long and slender main cone, with an anterior $(e)$ and a posterior $(\delta)$ well-marked cusp, the anterior being the larger, and on a higher level. The interrening tract of the inner part of the crown represents there a low cingulum, rising to, without being well defined from, the base of the principal cone $(0)$ which rises in great proportion from the outer part of the crown. In one of the molars, the third (fig.1, B), the intervening part of the inmer side of the crown forms a small low prominence before inclining to blend with the main exterual cone. The molars increase in size to the third; then gain, perhaps, a little in basal breadth to the sixth; which, therefore, by the analogy of hinder decrease of size in the molars of Nyrmecobius Spalacotherium, I do not regard as the last. The traces in the fossil at the interval between $m b$ and the coronoid process would be, I think, rightly interpreted as those of a socket.

The molars and the last premolar form a series uninterrupted by any 'diastema.' 
The projecting front teeth are made to catch, the canine and premolars to kill, the molars to pierce and crush chitinous integument; and, by the analogy of Moles, Shrews, and Opossums of like size (Didelphys dorsigcra, e.g., p. 105, fig. 22B), we may guess the prey to have been Insects and other Annulosa.

The mandibular dentition of this little marsupial ferine may be formularised as :-

$$
i \cdot \overline{4-1}, c \cdot \overline{1-1}, p \cdot \overline{4-4}, m \cdot \overline{7-7}:=32 .
$$

The analogy of Myrmecobius checks any hasty conclusion as to there being precisely as many teeth in the upper jaw as in the lower one of Amblotherium.

The dental formula of Myrmecobius is:-

$$
i . \frac{4-4}{3-3}, c \cdot \frac{1-1}{1-1}, p \cdot \frac{3-3}{3-3}, m \cdot \frac{5-5}{6-6}:=52.1
$$

The mandibular dentition of Amphitherium is :-

$$
i \cdot \overline{3-3}, c \cdot \overline{1-1}, p \cdot \overline{6-6}, m \cdot \overline{6-6}:=32 \text {. }
$$

The multicuspid character of the molars of Myrmecobius, and the almost uniform small size of the cusps, are associated with a smaller relative size and a looser or more open arrangement of the teeth than in Amblotherium. The affinity of Amblotherium to Amphitherium is closer than to Myrmecobius. The present species, Amb. soricinum, as represented by the mandible with the full adult complement of teeth, above described, is smaller than any of the previously characterised species so represented.

Species 2-Amblotheridm mustelula, Owen. Plate II, fig. 2, 2 A.

The present specimen (Pl. II, fig. 2, nat. size, and 2 A, magn. 3 diam.) agrees generically in the character of the crown of the true molars (as exemplified by the tooth marked $m 3$, in fig. 2 A) with the type of Amblotherium, and it presents the same general configuration of the ascending branch and symphysial end of the jaw. The difference of size is such as to lead me to regard it as specific, and this conclusion is strengthened, if not confirmed, by modifications of shape and proportion of the hinder or ascending portion of the ramus.

The species Ambl. mustelula is represented by a right mandibular ramus, the inner side exposed, showing five or six of the molary series in sitû, but with crowns more or less mutilated; there are also some feeble indications of incisors.

The jaw has a larger ascending branch and coronoid process than in Amb. soricinum or in Amphitherium; remarkably larger than in Myrmecobius. The condyle (b) projects

1 Waterhouse, "Description of a new Genus of Mammiferous Animals from Australia," \&c., 'Trans. Zool. Soc.,' vol. ii (1836), p. 149, pl. xxviii. 
from above the level of the molars, apparently with a longer relative interval between it and the angle than in Amb. soricinum, but the outline is not so well preserved.

The anterior border of the coronoid, so far as preserved, is more vertical and less curved than in Amblotherium soricinum or in Amphitherium. 'The lower margin of the horizontal ramus is continued by a gentle convex line to the end of the symphysis, which is long, narrow, and very little raised from the horizontal level. The breadth of the rising ramus between the fore part of the base of the coronoid and the back part of the condyle almost equals the extent between the fore part of the base of the coronoid and the hind end of the symphysis $(r)$. In Amb. soricimm the same dimension of the rising ramus is equal to three fourths of the extent from the fore part of the base of the coronoid to the hind part of the symplysis (fig. $1, r$ ). In the present jaw, as in that of Amb. soricinum, the mylohyoid groove (fig. $2 \mathrm{~A}, g$ ) is represented by a fine linear one, extending from near the entry of the dental canal $(d)$ to the synuphysis. The ridge $(a$ ) retrogrades from that entry, and amgnents in depth, or inward inflection, as it approaches the angle $(a)$. The angle which the line of the ridge $\left(a^{\prime}\right)$ forms with the fore margin of the coronoid is more open than in Amb. soricinum.

The best preserved of the molar teetl ( $m$.3) shows the inner side of the crown divided into two tubercles answering to $e$ and $s$ in fig. 1 B : the anterior one, in like manner, being longer and inclined forward, from a higher level. The main cone rises vertically from the outer side and middle or body of the tooth. The hindmost molar in place seems to answer to $m 5$ in fig. 1, and, from its relation to the coronoid, should be the antepenultimate molar. There possibly may have been three teeth behind it, if they decreased in size, as in Spalacotherium, but this I think unlikely. An interval for one molar divides the tooth in place $(m 5)$ from the next in advance ( $m$ 3). The molar $\left(\begin{array}{ll}m & 2\end{array}\right)$ in front of that is obliquely tilted $и$. The one marked $m 1$ is obviously smaller : its two roots have slipped from the socket, and the crown is broken off. This would give seven molars, reckoning the last in sitû as the antepenultimate one. In advance of the first molar are three premolars, losing size as they advance in position. They are too much mutilated for any conclusion as to the relative length or height of the main cone. Each is implanted by two roots, and the base of the main cone gives indications of fore and hind cusps. The socket of one antecedent premolar is definable. Then conses the base of a small canine in its socket, and next, one of a small incisor, in advance of which there is space for two or three sockets of other incisors before the symphysis terminates anteriolly, where the extreme end seems to be wanting.

The lower border of the horizontal ramus deseribes a more marked convex curve than in Amb. soricinum.

The conclusions arrived at from close scrutinising of the indieations of teeth in this wellmarked form of mandible (fig. 2) are more favorable to generic conformity with the dental formula shown in Amb. soricinum than otherwise. I, therefore, limit myself to regarding the species it represents as being generically allied to the smaller type (fig. 1). 


\section{§ VIII. Genus-Peraldestes, ${ }^{1}$ Owen.}

The present genus, like Amblotherium, differs from Spalacotherium by a more marked distinction between the premolars and molars; the former being necessarily characterised, through the want of developmental evidence of these long-since extinct Mammals, by shape and relative size of crown.

In Spalacotherium, as in Amphitherium and Phascolotherium, it is difficult to draw the line between the members of the numerous unolar series, as may be appreciated by reference to the subjects of figs. $23,25,26,33, \mathrm{Pl}$. I. Here, however, the superior length of crown serves to determine the last and pennltimate premolars by contrast with the smallness of the tooth by which the molar division of the 'clieek-series' begins.

Species 1.-Peraliestes longlrostris, Owen. Plate II, figs. 3, 3 a, B, c.

Of the molary series of teeth evidence is given in the present species by instructive portions of the dentition of both upper and lower jaws.

Pl. II, fig. 3, represents of the natural size, in outline, a portion of the right upper jaw, which at $\mathbf{A}$ is figured, in tint, magnified 3 diam.; whilst at $\mathbf{B}$, the grinding surface of the preserved upper molars is represented on the same scale.

This specimen includes the external alveolar wall of the maxillary with the last premolar and six following true molars in sitú. As much of the upper jaw as equals in length the series of preserved teeth extends in advance of them : it is a fragmentary tract, but shows part of the bony palate and a few alveoli. A vacuity near the fore end of the palate, and a corresponding fissure on the outer wall of the jaw, may indicate the hind limits of a premaxillary; but this portion of bone is not entire anteriorly.

The interest and instruction afforded by this specimen lie in the demonstration given of the character of the crowns of the upper molar teeth, and especially of the configuration of their outer side.

In a direct side view of the exposed part of the specimen the outer wall or division of the crown shows but little vertical extent compared with the fore-and-aft, or with the transverse, diameter; but the inner half is developed into a longer cone. The front half of the outer wall presents the form of a smooth subhemispheric protuberance (a), from which the hind half extends backward at a lower level; its ontline being broken by a few slight notches dividing it into two or three minute tubercles $(b)$. The larger anteroexternal tubercle $(a)$ contracts to a low cusp (sharper in $m_{4}$ and 5 than in $m 3$ ), from which the grinding surface curves outward to the loftier or longer and more acutely terminated cone of the antero-internal lobe $(c)$. The post-external lobe or tract $(b)$ contracts as it extends inward, and ends there in a low cusp (ib, fig. 3 в, $d, d$ ) at the hind and inner part of the base of the long antero-internal lobe $(c)$. The horizontal section of

\footnotetext{
${ }_{\pi}$ mipa, pouch; $\lambda_{\eta \sigma \tau} \eta \dot{s}$, robber.
} 
the crown is triangular, with the base turned ontwards, and the apex formed by the anterointernal lobe: the anterior half of the base projects more ontward than the posterior half.

Of the six molars in situ showing the type above defined, the crowns increase in size from the first $\left(\begin{array}{ll}m & 1)\end{array}\right.$ to the third $(m$ 3) and decrease from the fourth to the sixth ( $m$ 6), which seems to be the least of all. Of this tooth the outer side is turned obliquely backward, the low posterior portion of that side being much curtailed: thus the foreand-aft dimension of $m 6$ is less than that of the antecerlent molars. Moreover, the outer surface of the maxillary runs inward behind the sixth molar withont appearance of fracture, and confirms the ascription of six molars, and not more, to the series on each side of the upper jaw.

The Mammal indicated by the present specimen is nearly allied to Amblotherium. It belongs, lowever, to a distinct genus, here represented by a species as large as Amb. mustelula. In extending the comparison to other genera known by the upper as well as the lower teetl, Stylodon alone arrests attention. But, besides the differences in the number of molars behind the long-crowned premolar, there are differences of configuration of the grinding-surface of the molar teeth, as conısared with the fossil upper jaw (PI. II, fig. 14, c.g.). True it is that this unique example presents the imner side of the maxillary teeth to view : but, though there be some increase of fore-and-aft breadth as the crown extends ontward, there is no accessory cusp in the molars of that specimen, answering to the one marked $d$, which is plainly shown at the middle of the hinder border of the crown in the molars of fig. 3 : the fore-and-aft extent of the outer part of the crown in fig. 3 is relatively greater than in fig. 14 .

The last premolar in Peralestes, with a fore-and-aft breadth not exceeding that of $m \mathrm{l}$, has a crown of twice the length. It is a long, sharp cone, and answers serially to the inner one in the true molars. A 'cingulnu' is indicated along the outer side of the base of the cone $(p$, fig. $3 \mathrm{~A})$ and derelops a mimnte cusp both before and behind that base, or at least belind it. 'Ihe front talon may be described as a mere thickening there of the cingulum. The onter tubercular wall of the crown in the succeeding teeth seems to be a derelopment of the cingulum. This premolar, like the succeeding molars, shows two external roots, the front one being the largest. 'The seven teeth are close-set.

An upper strip of the maxillary, in advance of these teeth, indicates a long and slendersnouted form of head, recalling that in Mryrmecobius and Perameles.

Sareophitus ursinus comes nearest in the character of its upper molars to the present species of Peralestes. 'The outer part of the crown (ib., fig. 3 c) is low in proportion to its fore-and-aft extent. It develops anteriorly a cusp, $a$, similar in its proportions and position to $a$ in $m 3$ and $m 4$, A. 'The hinder tract of the outer part in the second true molar of Sarcoplitus develops two cusps, the larger of which answers to $d$ in fig. 3 в. 'The immer cusp $(c)$ is the longest and sharpest cusp in hoth Sarcophilus and Peralesfes. 'The groundwork pattern is the same, with a generic distinction indicated by the accessory low inner batsal tubercle, and also by the minor number of molars in the large existing typodentate zouphagons Marsupial. 
Species 2.-Peralestes (Pilascolestes ?) Longirostris, Owen. Plate II, figs. 4, 4 A, B, C.

From the size and shape of the last two premolars and the contrast they present to the small succeeding nolars, together with the shape of so much as is preserved of the crowns of these, which show a corresponding similarity with the lower molars of Sarcoplitus, with that indicated in the upper molars of fig. 3, I am disposed to refer the specimen to be describerl (PI. II, fig. 4, nat. size, fig. 4 A, magnified 3 diam.) to the same genus; although, it is true, that there are indications of a greater number of true molars than in the upper jaw of Peralestes longirostris.

Since, however, in Mypmecobius, the only known existing form of multidentate Marsupial, there is one more true molar on each side the lower jaw than in the mper jaw, I am unwilling, especially as the actual teeth are not preserved in the mandible under consideration, to separate it from the genus slowing so niarked a resemblance in the proportions of the contiguons premolars and molars, and so close correspondence in the characters of upper and lower molars with those in Sarcoplilus. If an upper jaw slould eventually be found showing seven or eight true molars of Peralestian type, following the large cuspidate premolar, the generic name Phascolestes might be accepted for the species represented by the present mandible.

The specinen is the anterior half of a left mandibular ramus, showing the symphysis and inner surface with an impression of the posterior part as far as the beginning of the coronoid process.

The teeth in place are the forr incisors $(i, 1,2,3,4)$, the canine $(c)$, four premolars $(p 1,2,3,4)$, the basal part of the erown of five succeeding tecth $(m 1,2,3,4,5)$, and the impressions of three successive long and slender cones, which, if belonging each to a distinct tooth, would make the premolar-molar series twelve in number on each side of the lower jaw, which is that in Amplittlerium (Pl. I, fig. 23).

The present specimen is fully one fifth longer and is proportionably deeper at the corresponding part than the jaw of the type of Amplitherizm there figured (and in the work cited below $\left.{ }^{1}\right)$; it has a longer and larger canine, and also unequivocally shows four incisors in sitü, making eight in front of the lower jaw. These incisors, instead of being arranged transversely at right angles with the canine and molar series, as in Thylacinus and Dangarus, form a series of sockets curving gradually forward to that of the foremost, due to the symphysis, as in Amblotherium, Ampititherium, Phascolotherium, and Mymecobius. As in the latter Marsupial, also, the foremost incisor is the largest, and is subprocumbent in position. The last three incline rather forward, but less so than does the first. The second incisor is the smallest; the third and fourth increase without gaining the dimensions of the first. Each stands apart from the other by a short interval, as in Myrmecobius. They are 
set closer together than in Amblotherium, and the foremost is relatively larger. The crown of the counine $(c)$ rises vertically, with a slight backward curve to its sharp summit. It is relatively narrower, antero-posteriorly, at its base than in Myrmecobius. It shows a wellmarked longitudinal groove at the imer side of its basal half near the hind border. It is relatively longer and larger than in Amblotherium.

'The first premolar $\left(\begin{array}{ll}p & 1\end{array}\right)$ is minute, with a low indication of one main cone and a hind hasal production: it stands distant by more than twice its own fore-and-aft breadth from the canine. The second premolar $\left(\begin{array}{l}p_{2} \\ 2\end{array}\right)$ is one third larger than the first, with its main cone and hind talon better marked : it stands half its hrealth distant from the first. The

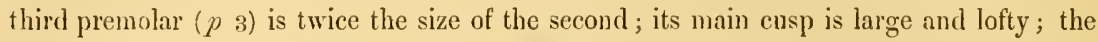
basal talon relatively low and small: it rises a little further from the second than does that hehind the first. The fourth premolar $(p 4)$ increases chiefly in vertical extent; its main cone is a long subcompressed piercer; the hind talon is feebly marked: it stands at the same distance from the third as that tooth does from the second premolar.

The hases of the five succeeding teeth indicate a more complex type of crown. An anterior as well as a posterior basal cusp is marked off from the main cone, and the anterior cusp is larger and higher than the posterior one. One may infer the main cone from the preserved impressions of the last three molars to have been long and slender; it rises chiefly from the onter side of the crown. Supposing each tooth preserved or indicated in this portion of mandible to have worked upon a maxillary fellow, its generic distinction from Peralestes wonld he established, and the dental formula of Plascolestes would he, $i \frac{t-4}{+-4} c \frac{1-1}{1-1} p_{t-4}^{t-4} m \frac{8-8}{5-8}=6 \mathrm{~S}$, heing four more than in Amplitherium, and fourtecn more than Myrmecobius. But, by the analogy of the latter genus, as above remarked, the number of the molar scries may have been less in the upper jaw. The lower contour of so much of the ramus as is preserved in the subject of fig. 4, Pl. II, is gently convex, curving gradually up to the incisive arcolar border. The symphysial articulation is long and narrow. There is a feeble indication of the notch which is present at the anterior border of the symphysis in Myrmecobius (Pl. I, fig. 24), and is conspicuous in Amplitherium Broderipii (ib., fig. 25). T'he anterior terminations of the linear groove ncar the lower margin of the ramus, shown in the imner side of most of these small mesozoic mammalian jaws, is here also visible. A fine line is continued from it to the lower end of the symphysis.

\section{Incerla sedis. Peralestes, sp. ?}

In the proportion of depth to length of jaw the fragment of the right ramus (PI. I, fig. 40 and $40 \mathrm{~A}$ ), figured in my original memoir on Spalacollerium, ${ }^{1}$ and referred to that genus, more resembles the present. Seeing, also, that the fore part of the ramus has becn broken off' behind the long symphysial articular surface, one might hazard a supposition that the teeth, there referred to a canine and anterior premolar, might be the

$$
1 \text { 'Quart. Journ. Geol. Sne.,' vol. x, p. 431, fig. } 12 .
$$


homologues of the last two premolars in Phascolestes. The molar series in Mr. Brodie's specimen are, however, in too mutilated a state to support more than the conjecture that it may belong to a Peralestian species.

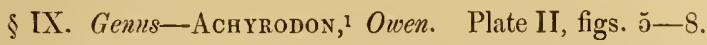

The present genus is represented by four more or less mutilated mandibular rami of small size (Pl. II, figs. 5-8), retaining molar teeth (fig. 7 B) of the general tricuspid type exemplified in Spalacotherium and Amblotherium, but with the externo-median or main cusp (ib., o) sharp and slender, longer in proportion to its basal breadth, and with the antero-internal cusp (ib., e) of similar shape and proportions, and of nearly equal height. The resemblance of these cusps to needle-points snggested the generic name. The postero-internal cusp (ib., s) retains the small proportions shown in fig. $1 \mathrm{~B}, \mathrm{Pl}$. II). The main cusp (fig. $6 \mathrm{~B}, o$ ), inclines slightly forward, and the front one $(e)$ in a greater degree, overlapping the hind cusp of the antecedent molar.

The specimens exemplifying this curious needle-toothed type of Marsnpial are less perfect than some of those exemplifying the preceding genera; but enough of the dentition and alveoli may be recognised to show that the genus enters into the polyprotodont and multimolar group of Entomophaga.

Species 1.-Achrrodon nanus, Owen. Plate II, figs. 5, $5 \mathrm{~A}, 6,6 \mathrm{~A}, 7,7 \mathrm{~A}$, and $\mathrm{B}$.

The first exemplar of this species is a right mandibular ramus mutilated at both ends, but including eight molars of the gencric type and two contiguous premolars (Pl. II, fig. 5, nat. size ; $5 \mathrm{~A}$, magn. 3 diam.). The inner surface is exposed. In advance of a vertical line dropped in front of the foremost of these premolars begins the symphysis $(r)$, and as much of the symphysial end of the ramus continues forward as forms the alveoli of two teeth, probably, also, premolars. The last two premolars, in place ( $p 3, p 4$, fig. $5 \mathrm{~A}$ ), have crowns higher than those of the sncceeding molars : that of $p 4$ is twice the height of that of $m 1$, and is rather higher than that of $p 3$. Both are conical, snbcompressed, with apices polished and a little blunted by use. A low cingulum crosses the base obliquely from before downward and backward. Both are implanted by two fangs. The coronal pattern of the molars is at once assuned. The long, slender, anterior cusp rises obliquely forward from the fore end of the cingulum. The longer main cone contrasts by its slenderness with that of the antecedent premolar: The low hind cusp is as well marked as in the succeeding teeth. These very gradually increase in size to the third $(m$ ), the seventh and eighth decreasing again.

As much of the fore part of the coronoid process as is preserved rises straight and slopes but little from the vertical: it resembles the corresponding part of the coronoid of Amblotherium mustelula (PI. II, fig. :), not the more sloping convexity of that in Ambl.

$$
\text { ' ¿хирus, acus : ódrvs, dens. }
$$


soricimm (ib., fig. I). The pterygoid fossa is hounded by a well-marked inwardly produced ridge, which has deelined to the lower border of the ramus at the hind fracture. 'The dental canal (ib., fig. $5 \mathrm{~A}, d$ ) begins at the fore part of the fossa, below that border of the coronoid. The mylohyoid groove $(g)$ begins in alvance of the lower hounding ridge of the immer fossa, and, if it lodged a nerve of that name, this must lave perforated the ridge anterior to the entry of the mandibular nerve-trunk, in order to cmerge upon the groove. The groove is well-defined, linear, and extends at first straight forward, then very slightly bends up to the back part of the symphysis $(r)$. 'This is narrow, long, and contimues the feeble convexity of the under border of the ramus. without any abrupt uphending from that contour. Below the last three molars the inner alveolar plate is subconvex vertically to the groove. Beneath the anterior five molars the bone is flatter: in advance of the premolars the inner surface bends inward as it sinks to the synphysis.

Achyrodon differs from Amblotherinm in the greater relative length of the anterior cone of the molars, which projects over the hind cusp of the antecedent tooth, exemplifying the closer, and as it appears interlocked, array of the molars in the present genns. Admitting that one molar may be wanting in the type of Amblotherium (Pl. II, fig. 1), the seven molars then would occupy the same relative extent as do the eight molars in Achyrodon. They are, nevertheless, in other respects so closely alike as to have led me long to hesitate, and repeatedly pass under comparative review all the Purbeck specimens showing this general slender-coned type of molar, before concluding to indicate the differences above defined by a generic name.

The specimen (Pl. II, fig. 6, nat. size, fig. $6 \mathrm{~A}$, magn. three diam., in tiut) might seem to be the left ramus of the same mandible as the right one last described, but that it appears more slender. Like that, it is mutilated at both ends, but in a less degree, retaining the two anterior premolars, and rather more of the reflected lower border of the 'ascending ramus.' There are five molars ( $m$ 1-5) and sockets for three, if not forr, behind the tecth in place. 'The crown of the best preserved teeth show the base of the long anterior cone and the smaller and lower posterior basal cnsp, mited by a low oblique smooth rising; external to which, or from which, aseends the principal cone, chiefly supported by the outer side of the cormal base. The molars are close-set; and, incleed, their bases seem, as in the right ramus (fig. 5), obliquely to overlap each other.

The apex of the main cone is broken in all, or more worn than in fig. 5. The last premolar ( $p$ 4) shows the usual simple type of one chief subcompressed pointed cone; which, though broken, evidently had the characteristic superiority of height over the snceceding true molar ( $m$ 1). It is implanted, as in fig. 5 , by two roots.

'The ramus is slender, almost straight. The slight curve of the lower border, and the inclications of the ascending ramus $\left(a^{\prime}\right.$ and $c$ ) repeat the characters in the mandible (fig. 5). 'the dcep pterygoid fossa leads to the entry of the dental canal $(d)$ which is below the 
anterior margin of the coronoid process, as in the right ramus (fig. 5). A well-marked linear groove $(g)$ traverses the whole length of the inner surface of the portion of the horizontal ramus preserved, about one third of the depth from the lower margin, ending at the hind part of the symphysis. Its curve and commencement in advance of the anterior boundary of the pterygoid fossa repeat the characters noted in the subject of fig. 5, Pl. II.

The left mandibular ramus (Pl. II, fig. 7, nat. size, 7 A, magn. three diam. in tint), wanting the ascending branch, lhas four well-preserved molars in place, the inner side exposed. The mylohyoid groove $(g)$ has the same commencement and course. The better preserved, long, narrow, almost horizontal symphysis $(r, s)$ shows that the slender ramus gradually tapers to the obtusely pointed anterior end.

The molars are closely arranged, and well display the anterior slender sharp-pointed cusp (fig. 7, в, $e$ ) rather inclined forward; next, a similar, but rather larger, longer, and more nearly vertical, main cone $(o)$, belind which is the basal cusp $(s)$ : a very minute accessory cusp could be detected at the inner and hinder part, near the base of the main cone.

There is space for one or two such molars, especially if the last one lost size, as in the type jaw (fig. $5 \mathrm{~A}, m 8$ ), behind those in place; the extent of the empty alveolar tract in advance of the molars indicates teeth in number according to those slown in fig. 6 .

The four molars in place answer to those marked $m 3-6$, in Pl. II, fig. $5 \mathrm{~A}$. If the proportion which those four teeth there occupy of the cxtent of alveolar tract from the fore part of the coronoid to the fore end of the symphysis be compared with the corresponding proportion in Amblotherium soricinum (ib., fig. 1), their superiority, both absolutely and in relative size to the jaw, in the present fossil, will be appreciated. But the difference of structure, according to the taxonomic value assigned by Mammalogists to the characters of true molars, is more than specific. The mylohoid groove $(g)$ describes a somewhat different curve from that in Amblotherium.

Species 2.-Achrrodon Pusilu,us, Owen. Plate II, figs. 8, $\mathrm{S}_{\text {A. }}$.

The mandibular character last referred to has not more than specific value, if so much. The curve, convex upward, of the hinder half of the mylohyoid groove (Pl. II, fig. $S_{A}, g$ ) in the portion of jaw showing in the few molars preserved the generic coronal characters of Achyrodon is, however, associated with other differences.

The specimen (ib., fig. 8 , nat. size; $8 \mathrm{~A}$, magn. 3 diam.) is the hiuder half of the horizontal portion of a left mandibular ramus with the inner side exposed, showing four molars in sitû, which I determine to be the third to the sixth inclusive, as in fig. 7; there are sockets of teeth, bcfore and behind those in place, indicative of the same excess of number as characterises the dentition of the preceding species of Achyrodon. I quote the 
notc originally made of the characters of these teeth, before the relations of this specimen to any other in the serics had been determined by comparison.

"The last two molars, seen from the inside, have a crown of two cnsps and a hind talon. The cusps are remarkable for their hight, slenderness, and sharpness, resembling needle-points. 'They do not rise straight $n p$; the anterior one curves gently forward before it ascends, retaining a slight forwarl obliquity; the second cusp is more nearly vertical, but little longer, and slightly inclines forward. The first and second of these teeth in sitû seem to consist each of one main cusp, which is long, slender, and pointed, with a fore and a hind basal cusp; they resemble the two hind molars, with the reduction of the anterior cusp to a talon; but the second of these teeth has suffered fracture, and the difference in both may be due to mutilation (as I subsequently satisfied myself was the case). The inipression of the fore part of the jaw indicates space for five or six molars or premolar's, besides a canine and three or, perhaps, four incisors. There is room for two molars behind the teeth in place, of equal size with them."

The best preserved teeth in the present mandible are rather less, both absolutely and in proportion to the clepth of the supporting part of the jaw, than in Achyrodon nanus; and, coupling this with the conrse of the mylohyoid groove, I venture to indicate the species represented by the present mandibular fragment as an Acluyrodon pusillus.

\section{Genus-Peraspalax, ${ }^{1}$ Owen.}

Species 1.-Peraspalax talpoides, Owein. Plate II, figs. 9, 9 a, B.

The molar teeth of this genus, agreeing in general character with those of Amblotherium, are more complex, inasmnch as they show a distinct cusp-like rising or prominence (Pl. II, fig. 9 в, n), from the inner side of the base of the main or exterual cone $(0)$. In this respect they make a nearer approach to the type of the lower molar in Didelphys (ib., c) than does any of the preceding Purbeck Marsnpials. The antero-internal cusp (ib., fig. 9 B, c) projects obliquely forward, and from a higher level than the shorter and smaller hind basal cusp (s), above which the anterior cusp of the following molar projects, giving an interlocked kind of disposition of the close-set series of molars, recalling that in Achyrodon.

The main cone $(o)$ is shorter and basally broader relatively than in Amblotherium, nuch more so, therefore, than in Aclyrodon. 'The molar tecth are also larger, and of a more robust character in proportion to the jaw. This character is well seen in comparison with Anblotherium mustelula (fig. 2, PI. II), a species of about the same size as that represented by fig. 9.

'The prescnt species is represented by a portion of the left mandibular ramus, with the inner side exposed, retaining six molars $(m 2-7)$ and one premolar $(p+4)$ in sitú. It shows the socket and impression of the first small molar $\left(\begin{array}{ll}m & 1\end{array}\right)$, and the impressions of the three

$$
1 \pi \dot{p} a, \text { pouch; } \dot{\alpha} a \pi \dot{\alpha} \lambda a_{n}, \text { mole. }
$$


anterior premolars and of a canine. The molars exemplify the generic didelphid modification of the multicuspid mechanism for insect-crushing above defined. They slightly increase in size from the first to the sixth; the third $\left(\begin{array}{ll}m & 3\end{array}\right)$ is a little displacel, exposing the two roots. The molars are close-set, and the anterior oblique lobe of one overlies the posterior talon of the tooth in advance; but it is much shorter, and more obtuse and procumbent than in Aclyyrodon (fig. 7).

The last premolar $(p$ ) , with the well-preserved crown, shows distinctly the front and hind basal talon, the main cone rises higher, and the whole tooth is larger than the three succeeding molars. It is divided by the socket of the small first molar from the second one. Impressions of the crowns of two or three anterior premolars, and of that of a longer, sharp, recurved canine, are preserved in the slab of the matrix.

\section{\$II. Genus-Peramos, ${ }^{1}$ Oven. Plate II, figs. 10-13.}

In this genus the teeth, implanted in a jaw characteristically long and slender, are large in proportion, and that in fore-and-aft extent rather than in height. The main outer cone in the true molars has a base almost equal to its height, and offers a marked contrast with the proportions of that of Achyrodon. There is an indication of an accessory internal cusp ( $n$, fig. 10, c, Pl. II), from the main cone (ib., o), distinct from the antero-internal basal cusp (ib., e), which, with the general proportions of the main cone, approximate Peramus to Peraspalax. But the five molars retained in the mandible (fig. 10) decrease in size in a greater degree than do those, $m 4-7$ (Pl. II, fig. 9 A), in the type of Peraspalax. Such indications have the greater value in the endeavour to interpret materials so minute and fragmentary and often obscure. It is certain that there is not sufficient evidence for the determination of generic conformity of the specimens above cited and compared in their dental system; and the marked difference in the form and proportions of the mandible, as exemplified in Pl. II, fig. 9 (Peraspalax) and fig. 10 (Peramus), sways with me in offering the present evidence for comparison with future possible acquisitions under the above generic name.

Species 1.-Peramus tenurostris, $O w$. Plate II, figs. 10,10 А, $10 \mathrm{~B}, 10 \mathrm{c}$.

This species is represented by three fossils. The first to be described is a left mandibular ramus (Pl. II, fig. 10, nat. size, and $10 \mathrm{~A}$ and $\mathrm{B}$, magn. 3 diam.), wanting the symphysial extremity (probably supplied by fig. 11), with the last four molars in situ, and sockets of five antecedent teeth. In the last three molars the main cone is high and boldly convex across, as in Stylodon, but is broader at the base, and lower than in that genus. The front border is shorter and more nearly vertical than the hind one, at the base of which is a short thick talon (fig. $10 \mathrm{c}$ ): the anterior basal talon (ib., $e$ ) is much smaller: the sharp apex of a small cusp (n) rising from the fore and inner part

\footnotetext{
I $\pi \eta \rho a$, pouch; $\mu \nu s$, mouse.
} 
of the base of the main cone iudicates an accessory part, which represents the anterointernal cusp in Peraspalax and Didelplyys. The three molars showing the above structure progressively, but slightly, decrease in size as they recede in position.

The main cone in the foremost of the fonr teeth in place $(m 4)$ has its outer surface less bulging or convex across, and its acute apex is on a lower level than that of the next molar ( $m 5$ ). The anterior cnsp is better marked; but the posterior basal cusp is still the largest, though less than in the succeeding molars. The antecerlent alveoli sufficiently show the multidentate character of the fossil ; but it wonld seem that the premolar shape and degree of coronal simplicity prevailed over a greater proportion of the molar series than in Peraspalax.

T'he coudyle $(b)$ projects backward on the level of the dental series. The angle of the jaw $(a)$ bends downward and backward, as a slort triangular proeess, in advance of the condyle and from a lower level. Working out the matrix with careful avoidance of disturbance or breakage of so rare a feature in the present series of small jaws, I got the evidence that the angular process was slightly inflected, as shown in the view from below, in fig. $10 \mathrm{~B}, a$. 'The fractured surface at the fore part of this process was probably due to the original exposure of the fossil. The dotted line in fig. $10 \mathrm{~A}$ indicates the proportion of the process which I suppose may then have been broken off. The crotaphyte depression is deep and extensive from behind forward; its fore and under boundary ridges are well marked. The ridge, continued from its anterior margin, curves forward midway between the molar alveoli and the lower border of the ramus, and, blending with the lower ridge, subsides in advance of the four teeth in place.

Peramus temirostris differs from Spalacotherium tricuspidens in the non-constriction of the mandible behind the molar series; in the sharper angle at which the external crotaphyte boundary-ridges meet anteriorly; in the lower position of the condyle (b); as well as in the deflected angle (compare fig. 10 with fig. 38 in Pl. I). Peramus also differs in the two last-defined characters from Amblotherium, and notably from Anblotherium mustelula, in the greater slope of the fore margin of the coronoid process.

Sufficient of the jaw of Achyrodon is preserved, in figs. 6 and $6 \mathrm{~A}$, Pl. II, to show a difference of contonr of the lower border of the ramus, but the generic distinction is more decidedly manifested in the forms and proportions of the molar teeth. The contrast which the mandible of Peramus presents with that of Amplitherium and Phascolotherium will be seen by a glance at figs. 23 and 26 in $\mathrm{Pl}$. I.

The next example of Percmus tenuirostris is the fore end of the left mandibular ranus wanting in the preceding speciunen. It is outlined of the natural size, Pl. II, fig. 11, and given in tint at $11 \mathrm{~A}$, magn. 3 dian. It includes the bases of three incisors, a canine, and five premolars.

'The jaw tapers in a singular degree to its fore extremity, the line of the incisive alveoli coming down to meet that of the symphysis, while this is nearly horizontal or slightly 
concave. It plainly indicates a produced and slender fore-part of the head, recalling the physiognomy of the insectivorons marsupial Bandicoots (Perameles) and Myrmecobians. This mandibular character suggested the 'nomen triviale' proposed for the present species.

Of the incisors (Pl. II, fig. $11 \mathrm{~A}, i 1,2,3$ ) it can only be said that their crowns have been slender, and were probably long; the first or foremost procumbent, the second and third progressively, thongh slightly, rising from the horizontal position. The canine $(c)$ is rather more raised, and shows its characteristic curvature to a sharp summit. A slight interval separates each of these front teeth from the other. At a similar interval from the canine rises the compressed sharply conical crown of a small premolar $\left(\begin{array}{ll}p 1 & 1\end{array}\right)$. The next ( $p$ 2) has been forced forward and turned round, the curved hind slope of the cone being pushed behind the base of $p 1$ : the divided socket of this two-rooted tooth is exposed. The third premolar is in place, and well slows the shape of the crown, with the convex front border and concave hind one, produced at the base without any cusp-like elevation of this part. The socket of the fourth premolar is vacant.

The fifth tooth $(p$ 5) shows a change of shape, approaching that of the first of the retained molars in figs. 10 and $10 \mathrm{~A}$. The fore and hind borders of the compressed cone slope or diverge from the sharp apex at almost the same angle, and each end of the base developes a minute cusp or talon. The body of the cone is markedly convex antero-posteriorly, as in the hinder molars. There is no indication, impressional or alveolar, of any premolars between the last ( $p$, if it be a premolar ?) in place and the molars in siti $i$ (in fig. $10 \mathrm{~A}$ ), suggesting the character shown in both upper and lower jaws of Peralestes. Otherwise it might be questioned whether the type of upper molars in Peralestes (Pl. II, figs. 3 and 3 A) might not probably be that of Peramus. But, even if Peramus had shown the marked superiority of height and size of the last two premolars over the succeeding true molars, the present must have been a different and smaller species from the Peralestes longirostris represented by figs. 3 and 4 in Pl. II.

Peramus tenuirostris (?). Plate II, figs. 12, 12 A.

This is represented by the anterior portion of a left mandibnlar ramus, with the outer surface exposed, and the symphysial end with its alveoli and teeth broken away: it also shows the premolars, which have suffered some displacement in the foregoing specimen. They accord in proportions and shape too closely with the dental characters of Peramus. to justify generic separation.

The first tooth in place is a premolar, two-rooted, with a simple subcompressed conical crown. The next tooth seems to show a lower conical crown, with the same fore-and-aft basal extent; but there is evident trace of mutilation by fracture. The third tooth gains in height and fore-and-aft extent. The fourth is similar in size to the third. The fifth 
seems to be smaller, but one cannot be sure that size may not be masked by matrix, which I lave thought it too hazardous to endeavour to clear away. The basal cusps are best marked in the fourth and sixtli teeth.

At the fractured fore part of this jaw is the crown of a small tooth, which slopes obliquely forward (as in $i 3$, fig. $11 \Lambda$ ); it is probably an incisor. The socket of a larger simple tooth follows, answering to the canine in fig. $11 \mathrm{~A}$.

Peramus tenuirostris (minor?). Plate II, figs. 13, 13 A.

The left ramus, wanting the ascending portion, of a long and slender mandible with the imner side exposed (Pl. II, figs. 13 and $13 \mathrm{~A}$ ), I refer, from its shape and the character of the few teeth it retains, to the same genus, if not species, as the two forcgoing specimens.

The angle at which the pterygoid depression terminates anteriorly suggestively resembles that of the outer depression in fig. $10 \mathrm{~A}$, and offers the same distinction compared with the immer surface of the mandible of Amblotherium, shown in Pl. II, fig. $1 \mathrm{~A}$, as has been pointed out in regard to that specimen. The mylohyoid groove is wide at its linder half and straighter in its course than in Amblotherium or Acliyrodon.

The preserved fore part of the base of the coronoid, and a neatly defined impression of the remainder, show a shallow emargination of the summit which may be due to fracture, as is donbtless the deeper notch there in the mandible (fig. $10 \mathrm{~A}, \mathrm{c}$ ). But the coincidence is noteworthy. If one could trust the part of the impression marked $b$, in fig. $13 \mathrm{~A}$, as showing the position of the condyle, it would seem to be relatively lighler, and divided by a shorter and more angular notch from the coronoid than in the type of Peramus tenuirostris (fig. $10 \mathrm{~A}, b$ ). The anterior part of the inward production of the lower border of the depression on the inner side of the ascending ramus indicates the marsupial character, but is not preserved backwardly far enough to show any downward extension of an angular process, as at $a^{\prime}$ in figure $10 \mathrm{~A}$.

The crowns of two molars are partially preserved, and the roots of two in advance are visible. A chief cone, and indications of smaller basal cusps, as in $m 4$, fig. $10 \mathrm{~A}$, are plainly shown.

The end of the symphysis has been broken and displaced slightly npward, so that one cannot satisfactorily or with certainty conclude as to a difference, or the degree of difference, from the shape of that part in fig. $11 \mathrm{\Lambda}$. If the mandibular ranus (fig. 13, P'l. II) should exemplify more than a sexual inferiority of size of Peramus tenuirostris, it might bear the specific name minor. I do not recognise grounds for generic distinction. 


\section{§ XII. Genus-Strlodon, Owen, 1S66.' Plate II, figs. 14-19; Plate III, figs. 1-4.}

The present genus of Mesozoic Mammal was founded on a portion of lower jaw with teeth (Pl. II, fig. 15, nat. size, $15 \mathrm{~A}$, magn. five diam.) submitted to the Author by his friend the Rev. Peter B. Brodie, M.A., F.G.S., by whom it had been obtained from the same locality and marly member of the Purbeck beds as that which became subsequently the scene of Mr. Beckles's explorations.

The results of the latter abundantly confirm the title of this, at one time, unique specimen, to the generic distinction assigned to it, and the later acquisitions instructively add to our knowledge of the dental and mandibular characters of Stylodon.

Species-Stylodon pusillus, Owen.2 Plate II, figs. 15,15 A, to 19,19 A.

I may be permitted to quote part of my original account of the type-specimen of the present species before proceeding to the description of those discovered by Mr. Beckles.

"The part of the lower jaw is imbedded in a small block of the matrix, with the onter surface exposed: it includes the portion of the ascending ramus supporting the coronoid process (a film of which only remaius in the depression of the matrix, mainly indicating its size and shape), and so much of the horizontal ramus as includes the alveoli of the nine posterior teeth, eight of which are in sitú. The articular and angular processes, and the fore part of the ramus, have been broken away, and there is no indication, in the matrix, of tlie entire ramus having been imbedded therein; it may be inferred, therefore, that the mutilation took place prior to imbedding. Enough, however, has been preserved to demonstrate the class-characters of the animal to which the fossil belonged, and to enable us to add another genus and species to the small category of Mammalia of the Mesozoic period.

"The continuous unity of bone at the part of the mandible which would show most of the sutures in a lacertian jaw-the height, breadth and contour of the 'processus coronoideus ' - and the implantation of one at least of the teeth by two fangs in a double socket, concur in testifying to the warm-blooded, air-breathing, viviparons, and lactiferous class of the animal. The base of the coronoid process shows the raised boundary of the lower part of the depression for the insertion of a temporal muscle of mammalian proportions. The lower margin of the ascending ramus has a degree of thickness and flatness suggestive of Marsupial affinities; but the angle itself is broken off. As, however, the alternative is the almost equally low 'lissencephalous' sub-class, to which the present little Insectivore must be referred, if it be not 'lyencephalous,' it adds another to the prevalent testimony of the low condition of the Mesozoic mammalian life.

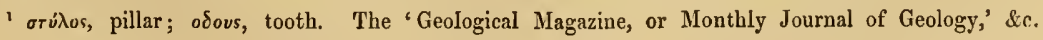
No. xxiii, May, 1866, vol. iii, p. 199, pl. x. figs. I and 2.

2 Ib. ib. 
"The crowns of the teeth, encased in lustrons enamel, are long or high in proportion to their breadth and thickness. They manifest this proportion, incleed, in a higher degree than do the teeth of Spalacotherinm; and, being rounded or cylindroid at the aspect exposed, have suggested to me the generic name Stylodon, signifying 'pillar-tooth.' The hindmost in place, supported apparently on a single columnar fang, which is partly protruded from the socket, and covered with a darker and duller cement, has a longish conical crown, with the fore part of the base rather more produced than the hind part: the crown of the next tooth is somewhat longer: that of the antepenultimate has a broader base, produced anteriorly into a minute angle, and slightly thickened behind, but not dereloped into a continuous cingulum. The apical half of the crown is broken off in the three teeth next in arlvance. Each has a small anterior basal 'talon,' and a single columuar root, so far as it is exposed; they are, likewise, severally smaller than the antepenultimate tooth. The seventh tooth, counting forward, is more abruptly smaller than the rest, with a simple conical crown, indicating only a feeble prominence of the fore part of the base. Then rises the crown of the largest tooth of the series, laniariform, subrecurved, or seeming to be so, from the convexity of the front border, and the minor concavity of the hind one, where the base is a little thickened and produced; this crown is supported on two divergent fangs. The convex surface of the jaw beneath these teeth is entire-shows no neurovascular outlets-the main anterior one has gone with the missing fore part of the ranus.

"Any attempt to determine the nature of the above-described eight teeth must be made on unsatisfactory and uncertain grounds. Guided by their shape and proportions, we might view the foremost as a 'canine,' the next four as 'premolars,' the last three as 'true molars,' and thus infer an example of placental diphyodont dentition. The objection to the two-fanged character of the canine would be met by the same mode of implantation of the canine of the common mole ( $T a l p a$ ), the proportion of which tooth to the succeeding premolar is rery sinilar to that presented by Stylodon.

"But the proportion of the preserved dentigerous part of the present fossil to the part behind indicates a greater number and size of teeth in advance of the laniariform tooth than the three small incisors of Talpa. The closer similarity of the narrow columuar hinder molars to those in the Cape Mole (Chrysochloris, Cuv.), and the very probable addition of an eighth such molar to the seven in place behind the laniariform tooth of the fossil, warn us of the deceptive character of the analogy of the dentition of the common Mole. It is more likely that Slylodon like Spalacotherium and Chrysochloris (unique in this respect among existing Insectivora), exemplified that excess of number of teeth which, in Marsupialia, as in Insectivora, is seen in a single known existing genus (Myrmecolius), but was common in the similar small insectivorous pouched Mammals of the older Oolitic deposits. Spalacollerium had ten molar teeth on each side of the lower jaw, of which the last six had tricuspid crowns, with proportions and spacing similar to 
those in the Cape Mole." 1 The corresponding teeth of the present genus and species are in closer contact with each other, and are of more simple shape, and apparently more simple implantation.

The first example which I have selected from Mr. Beckles's series (Pl. II, fig. 17) shows the generic character of the molar teeth of Stylodon; and, if they appear to be a little further apart than in fig. 15 , it is because more of the intervening matrix remains. Those who have experienced by how slight a touch of the finest needle-point the crown or part of the crown of a tooth flies off, in the attempt to develope these delicate fossils from their subpetrified mar]-bed, will appreciate the reticence which practice begets of being content when enough has been exposed for comparison and determination, and of "letting well alone."

The alternative of the Cape Mole suggested in my original Memoir as preferable to that of the common Mole for homologizing the teeth in place in the type-jaw, and the probable nearer affinity of Stylodon to Spalacotherium, is confirmed by the fossil now under description. The two-rooted tooth with a canine-shaped and canine-proportioned crown proves to be the last of the premolar series (as definable by shape).

The instructive specimen, figured of the natural size in ontline, and magnified three diam. in tint, is a left mandibular ramus, wanting the rising branch, but including the dental series, which may be formulised as-

$$
i \overline{4-4}, c \overline{1-1}, p \overline{4-4}, m \overline{7-7}=32 .
$$

The front or first incisor $(i 1)$, is procumbent, with a long and narrow spatulate crown. The second $(i 2)$, with a narrower crown, lies parallel with the first. 'The third $(i 3)$ is smaller, and more erect: the fourth $\left(i_{4}\right)$ is also very small, and is nearer to the canine than to the third ineisor. The canine $(c)$, with a longish slender obtuse crown (perhaps not entire at the apex), slopes forward, but less so than do the incisors. The outer side of the root shows a longitudinal fissure, indicative of division.

The first premolar $\left(\begin{array}{ll}p & 1\end{array}\right)$ is small, and near to but not touching the canine: the second $(p 2)$ rises, at an interval eqnal to its own breadth, from the first, and is also small. The third premolar ( $p$ s) shows a longish, subcompressed, subcurved, conical crown. The fourth $(p 4)$ is a similar but a larger tooth. Each premolar has two roots, one before the other.

The true molar series begins, as in Amblotherium, by teeth of inferior size, as if they had continued backward a series of deciduous teeth which the larger premolars had displaced. The first molar $(m 1)$ has a straight, vertical, smaller and more slender cone than $\nu 4$; it is also more convex antero-posteriorly, and with a cingulum extending into an anterior and a posterior basal cusp. The root, or outer root, supporting the girted crown, rises some way above the alveolus. 'These characters are repeated in the four 1 'Quart. Journ. Geological Society of London,' 1854, vol. x, p. 425. 
succeeding molars, with slight but progressive increase of height, not of breadth, of crown. The length of the exposed part of the third molar $\left(\begin{array}{ll}m & 3\end{array}\right)$ is equal to the entire depth of the ramus below the socket: the same may be said of the fourth $(m$ 4) and fifth ( $m$ s) molars; but the lower border of the jaw may not be fully exposed.

The crowns of the last two molars $(m 6, m 7)$ are partly broken away; and those of the last two incisors and first two premolars have suffered mutilation; otherwise, the whole mandibular series of teeth of Stylodon pusillus is instructively displayed in the present specimen. In comparison with the mandible of Amblotherium soricinum (Pl. II, fig. l) it well exemplifies the value of the dental characters showing generic distinction in these minute multidentate Marsupials of the Mesozoic period.

The next example supplies almost as much of the dental series of the npper jaw, as does the foregoing specimen of that of the lower jaw. The grounds for referring the specimen (Pl. II, figs. 14 and $14 \mathrm{~A}$ ) to Stylodon pusillus will be given, as might be looked for, in some detail.

In the existing Insectivores which show teeth, or at least the molar series of teeth, resembling those of certain species of small Mammals represented by fossil jaws and teeth from the Pnrbeck marl-beds, the longest and largest lobe or cusp projects from the inner part of the crown in the upper molars, from the onter part in the lower ones. This is well shown in Clerysocliloris, ${ }^{1}$ in which the inside view of the upper teeth and the outside view of the lower teeth present the form or character of crown closely resembling the type of that which suggested the generic name Stylodon. Somewhat of the same character is seen in the Tenrecs (Centetes), ${ }^{2}$ which more nenrly resemble Stylodon in the proportions of the incisors and canine. In Perameles, ${ }^{3}$ and Didelplys ${ }^{4}$ also, the longest cusps of the true molars project from the inner half or side of the crown in the upper jaw, and the reverse in the lower jaw. The tendency to adhere to this reversing of position, as it secms, of upper and lower molars in respect to outer and inner side-configuration of crown is discernible in the teeth of Sarcophilus ursinus, Pl. II, fig. $3 c$, and fig. $4 c$.

Upon these considerations, and after close and repeated scrutiny of the teeth, which a successful application of the needle-point has exposed in one of Mr. Beckles' slabs, affording, at first sight, small promise of such result, I conclude them to belong to the upper jaw.

The apparent continuation of the jaw-bone $(a, b$, fig. $14 \mathrm{~A})$ directly down, or vertically, from the alveolar margin of this specimen, at first suggested a mandibular character. But the cracks and fissures (ib. $a, a$ ) close to that margin, and the thinness of the osseons plate

1 Fr. Cuvier, genre Chrysoclore, 'Annales du Muséum d'Histoire Naturelle,' tom. xii (1808), p. 49, pl. iii, figs. 1-5. Ib., 'Dents de Mammifères,' 8 ro, 1825, p. 63, pl., no. 18. (The line-engraving in the original memoir is better than the lithograph in the subsequent work.)

2 Ib., p. 46 ; and ib., p. 69, pl, no. 19.

3 Ib., p. 7l, pl. no. 23, A.

${ }^{4}$ Ib., p. 73, pl. no. 23 , c. 
itself, show it to be part of a bony palate, broken and bent. up into its present position by posthumous pressure. The part $(b)$, moreover, continued from the sockets of the three last molars, retains an inward curve or bend therefrom, suitable to its palatal character, and not in accordance with the disposition of either the inner or outer plate of the ramus of any mandible in the present series of small mammalian fossils.

With this determination the general curve of the molar series also accords : it inclines outward from the canine, and, after a straight course, bends inward at the end of the series, the hinder half of which is thus convex outwards or horizontally. Vertically the series presents, as in the upper molars of Marsupials and Insectivores, a slight sigmoid disposition.

Assuming then that we have-or rather are detecting-in the present specimen, the dentigerous part of the left upper jaw, it exposes the inner side of the teeth, and also the working surface of the last three molars $(m 5,6,7)$. The teeth, in situ, are the canine $(c)$, and eleven of the premolar-molar series.

Of the incisors nothing can be said, satisfactorily or confidently, beyond the fact that there are, in the portion of crushed bone, $d$, anterior to the camine, feeble indications of their alveoli.

The canine $(c)$ is a formidable tootlr; its crown is more than twice the length of that of the longest molar; it is gently bent, as it descends, backward and a little inward, is strongly indented at the middle of the inner side of the base, the indent widening to the socket, as if indicative of a division, or disposition to divide, into two roots. A like indication was noted in the lower canine of Stylodon pusillus.

Close behind the canine projects the crown of a minute premolar $(p 1)$, of a simple, subcylindrical, obtusely pointed form. After an interval there is an indication of a sinilar minute premolar ( $p 2)$. Then follows a premolar $(p 3)$, having for its crown a broader based conical cusp with a minute tubercle before and belind: this tooth is not longer than the first, but is much broader from before backward; it is implanted by two roots. Immediately follows a much larger and longer premolar $(p 4)$, the conical crown of which does not show the basal tubercles. The next tooth $\left(\begin{array}{ll}m & 1\end{array}\right)$ presents the form of the exposed inner surface common to the rest of the molars; viz., that of a cylindrical column truncate atop: this terminates internally a crown which expands slightly as it extends outward; the inner cusp does not reach the level of the apex of the antecedent premolar, and the sudden loss of size in $m$ I significantly recalls that character in the type mandible (Pl. II fig. 15). The second molar ( $m 2$ ) in the upper jaw (fig. 14) is merely augmented in size: it shows more of the dark-coloured cement-covered base before the bright amber-coloured enamel begins. The following molar $\left(\begin{array}{ll}m & 3\end{array}\right)$ is similar. The fourth of these molars $\left(\begin{array}{ll}m & 4\end{array}\right)$ shows a slight outswelling of the enamelled base of the crown and the summit of the inner column is less worn, rising to an obtuse point. The fifth, sixth, and seventh molars $(m 5,6,7)$ decrease progressively in length; they slightly expand to the outer side, which is divided by a mid-longitudinal cleft (fig. 14, $\mathrm{B}, c$ ) into two low cusps. The grinding 
surface sinks as it slightly expands from the produced sharp summit of the imner cusp, and is concave from within outwards: it is very smooth and polished. The series of grinding surfaces of these antero-posteriorly compressed tri-cuspidate molars describes lengthwise a moderate convexity downward or toward the mandible, which curve, with the horizontal outward bend of this part of the dental series, confirms the determination of these teeth, as belonging to the upper jaw.

The maxillary molars of Stylodon show most resemblance to those of Chrysochloris, but they are close together, and, indeed, obliquely overlap each other. Being broadest transversely, and extending from within slightly backward as well as outward, a small part of the hinder surface, as well as the narrow columnar side, of one tooth stands clear of the crown of the following tonth.

If, as is most probable, one of the minute premolars has dropped from the interspace between the first $(p 1)$ and the next $\left(\begin{array}{l}p \\ p_{2}\end{array}\right)$ in place, we may reckon five premolars according to shape, and seven molars by the same character, twelve in all, on each side the upper jaw, besides the canines and an unknown quantity of small incisors. The indication of premaxillaries $(a)$ testifies to a greater extent of dentigerous jaw anterior to the canine than exists in the Cape Mole.

In the outline of the natural size, $\mathrm{Pl}$. Il, fig. 14 (and in fig. $14 \mathrm{\Lambda}$, magn. nearly four diam. in tint), I conclude, therefore, on the foregoing grounds, is represented a great part of the left upper jaw and dentition of Stylodon pusillus.

To the same genus and species I refer the left mandibular ramus, with five molars in sitü, opposed by portions of the crowns of the corresponding upper teeth (PI. II, figs. 16 nat. size; $16 \mathrm{~A}$, magn. 3 diam.). A few of the premolars are more or less perfectly preserved in the part of the mandible in advance of the lower molars.

The ascending ramns and the symphysial end of this mandible are broken off; the inner surface of the preserved part with teeth is exposed. The longitudinal groove on the imer side of the ramus is relatively wider than in most other genera of small Mesozoic Marsupials, showing that groove.

Fragmentary portions of the maxilla to which the portions of upper molars belonged are discernible in the matrix below the mandibular ramus, but too much crushed for working ont to any purpose.

In the subject of fig. 18, Pl. II, we have acceptable confirmation of the dental characters of the lower jaw shown in figs. 15 and 17. It consists of the two rami of the nandible separated in such a way that the left presents an outside view, and the right turns its lower border to the surface of the slab; part of its outer surface has been exposed by removal of matrix.

It is evident that the skull was crushed, together with the jaw, prior to being imbedded in the lacustrine or fuviatile marl. Parts of the basioccipital and basisphenoid, showing 
their 'barmoniæ,' are recognisable, but I am unable to determine any other cranial element in the remaining mass of crushed fragments.

The lower border of the mandible, as shown in the left ramus, magn. 3 diam. in fig. 1S A, slopes from below forward and very gradually upward to the socket of the first or front incisor, as in the specimen, fig. 17, and in Peramus, fig. 11. The foremost tooth is preserved in both rami : it is the largest of the incisors; the crown is shaped like the bowl of a narrow spoon; it expands beyond the root, slightly bends upward and terminates in a rounded edge; it is moderately convex across, externally. Three teeth of smaller size and more slender crown, follow; they are implanted each by a single root, at intervals rather more than their own brealth, save the second, which is closer to the first incisor.

The fifth tooth by resumption of size of crown, thongh it be less broad than the first incisor, suggests a canine; but it seems to be implanted by two fangs. After an interval of rather more than the coronal breadth of the canine, there is a small simple-crowned premolar; after a shorter interval there is a second still smaller premolar. Then follows an alveolar tract, which may have accommodated four or five teeth of larger size. The molar series is resumed by six successive teeth, which terminate it. The exposed outer side of the crown in the three teeth where it is entire shows the character of the true lower molars of Stylodon, with the type-specimen of which (fig. 15) the present one agrees in size. It yields valuable accession to the evidence of the characters of the fore part of the mandibular dentition of the genus. 'The cement-covered outer or main fang of the largest molars rises a short distance above the alveolar, and swells into a low quasi-cingulum forming the base of the enamelled crown. The ultimate and last molars seem progressively to decrease in length in a degree not shown in the last two molars in place in the type specimen. Does this indicate an additional or eighth molar? There are two anterior outlets of the dental canal, the foremost of which opens beneath the interval between the canine and the anterior premolar.

In Pl. II, figure 19 gives the nat. size, and $19 \mathrm{~A}$ a view magn. 3 diam., of a portion of a left mandibular ramus, with the base of the ascending ramus, the last two molars, and the sockets with roots of the six antecedent teeth. This specimen is chiefly valuable as showing the outer part of the crown in the last two molars in place. The tooth rises some way above the socket, and then swells out to form the base of a long and narrow-pointed cusp or cone, which terminates, outwardly, the crown of the tooth; but this, as it extends inwards, expands in fore-and-aft diameter, and develops a minute inner basal cusp. Something of this kind is shown in the ante-penultimate molar of fig. $15 \mathrm{~A}$, which tooth may have been rotated slightly from its natural position. The sockets of the six antecedent molars indicate teeth of the same relative size as those which are in place in the type specimen of Stylodon pusillus.

The proportion of the mandibular ramus preserved in the present fragment corresponds pretty closely with that of the type specimen; only the crowns of the molars anterior to 
the penultimate one are more or less broken away. The basal half of the crown of the long and large terminal premolar $(p 4)$ shows its two roots one before the other. If the succecding teeth have their root divided, the fangs must stand on the same transverse line, one on the inner side of the other. The fore part of the base of the coronoid projects, ridge-like, curving forward to subside upon the onter surface of the ramus, as in the typejaw (fig. $15 \mathrm{~A}$ ). 'The base of the ascending branch extends straight backward to a like degree, and there is a similar slight indent at or above the angle $(a)$, dividing this from the ridge (b), which would end in the condyle.

The size is the same in both specimens.

The apparent slenderness and separation of the crowns of the molars (in the figure) is due so much to the degree of exposure of the specimen that I do not feel the ground safe for proposing specific distinction.

In Pl. III, fig. 2, nat. size ( $2 \mathrm{~A}$, magn. 3 diam.), are shown the onter side of a portion of the left mandibular ramus of Stylodon pusillus, with the seven molars and part of the last premolar. This specimen gives another example of the mandibular molar characters of the present genus and species. I figure it because it shows better than in any of the foregoing specimens the angle at which the fore part of the coronoid process arises in this species. The last two molars progressively diminish in size; the crowns of the fourth and fifth are the highest.

The Becklesian collection, containing the counterpart slab with the impression of the above fossil, indicates its fragmentary state when imbedded in the fresh-water marl, and confirms the idea which was derived from inspection of the type-fossil. ${ }^{1}$

Another variety of Stylodon pusillus is exemplified in the portion of the left mandibular ramus, showing the outer side, with the last premolar and six following molar teeth in situ, forming the subject of Pl. III, fig. 3, and fig. $3 \mathrm{~A}$.

The second and sixth molars have longer crowns, for example, than in fig. 2. The generic and specific characters of the type-jaw (Pl. II, fig. 15) are, however, instructively repeated in the extent of the dentition here displayed.

There is a small outlet of the dental canal below the interval between the penultimate and last premolars and another foramen in advance.

Species 2.-Strlodon robustus, Owen. Plate III, figs. 1, 1 ^.

The present example (Pl. III, fig. 1, nat. size; $1 \mathrm{~A}$, magn. 3 diam.) shows a Stylodon with a deeper and more robust character of jaw than the preceding specimens. It consists of a left mandibular ramus, mutilated at both ends, with ten of the molary series in sitú, one only wanting the crown; the outer side is exposed. The foremost

$$
\text { 'Geol. Mag., lec. cit., p. } 199 .
$$




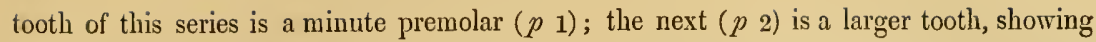
part of the two fangs above the socket, and the conical subcompressed crown rising rapidly or vertically to the apex of the fore part, and sloping more gradually backward. The third premolar ( $\left.\begin{array}{ll}p & 3\end{array}\right)$ shows more equal fore and hind borders of the cone, with an indication of an anterior basal cusp. The crown of the fourth premolar is, as above noted, wanting; its base was larger than the third, and it probably showed the characteristic height of crown indicated by the dotted line in fig. $1 \mathrm{~A}$ of the last (fourth) premolar, as compared with the first true molar. The succeeding seven teeth exemplify the Stylodont type of true molars; but the hindmost is here preserved, showing a greater inferiority of height to the penultimate tooth than appears in the type specimen. We have here the signs of individual variation which may have been repeated in generations, as a zoological species.

Incerta sedis [? Leptocladus dubius]. Plate III, figs. 4, $4 \mathrm{~A}$.

After repeated scrutiny and comparison I decided to make the specimen about to be described the subject of a lithograph, the ultimate result impressing me with a belief in its having most claim to affinity with Stylodon. It is, however, with diffidence that I offer this remark; and the fossil is made known rather, or chiefly, as a guide for comparison with future discoveries of better specimens, which may prove the present to be indicative of a distinct genus and species.

Pl. III, figs. 4, and 4 A, magn. 3 diam., represents a left mandibular ramus, with the outer side exposed, wanting the ascending branch, with nine teeth in place, the socket of a canine, and two sockets of incisors. 'The lower contour is almost straight; the alveolar one slightly rises along the middle third, and sinks or is concave, but in a very feeble degree, both before and behind. The vertical extent of the ramus is the same behind and before the premolar-molar series. The symphysis curves rather abruptly from below the canine to the incisor-alveoli. The teeth, however, are too much mutilated to yield satisfactory generic characters of the present multidentate Marsupial.

The crown of the best preserved molar consists of one chief cone, which is high and sharp; a basal ridge or 'cingulum' swells into a minute prominence anteriorly, and extends with the base of the crown further back, to form a low hind cusp. The cingulum subsides at the middle of the outer convex part of the base of the main cone, and rises as it recedes therefrom, forward and backward, to form the accessory cusps. The above structure is more or less traceable in the last three teeth in situ in the present specimens. There is space for one or two such molars between the hindmost and the rising base of the coronoid process.

The tooth anterior to the foremost of the three molars, by the inferior height of the chief cone in proportion to its breadth, suggests that it may be the last of the premolar series. The minnte anterior cusp and the low backward production of the base of the 
main cone are well marked. Four teeth of like type precede the above premolar; they decrease in size, especially in basal fore-and-aft extent as they advance in position; but this decrease is most marked in the foremost. Each is implanted by two roots.

From the size of the socket the antero-posterior diameter of the canine must have excecded that of the largest molar; its crown was probably of the usual proportional length. The incisors, which appear not to have exceeded three in number, were minnte; they were close-set, and not divided by an interspace from the canine. All the other teeth stand a little apart, as in Spalacotherium and Chrysochloris. The intervals are certainly wider than in Stylodon pusillus.

The outer side of this minute slender jaw is unusually convex vertically. There are two anterior dental foramina, one $\left(f^{\prime}\right)$ beneath the fourth, another $(f)$ beneath the first, premolar.

If other discoveries should better demonstrate a generic type of teeth in a mandible with horizontal rami of the form and proportions here exhibited, perhaps the name Leptocladus ${ }^{1}$ might be accepted for the genus here indicated. For the convenience of registration I have marked the fossil as Leptoclaclus dubius.

\section{$\S$ XIII. Gemus-BoLodon, ${ }^{2}$ Owen.}

'This genus is founded on characters of the maxillary teeth, as shown in two specimens (PI. III, figs. 5 and 6 ).

Seeing the rarity of an upper jaw as compared with a lower jaw in the mammalian fossils from Mesozoic beds, one is disposed strongly to surnise that some of the many mandibles in the present series must belong to the same species or genus which has left the spccimens about to be described.

But there are, amongst the few examples of upper jaw, maxillary teeth with patterns of crown which do permit their association with previously recognised mandibular teeth, as, for example, those of Peralestes, Stylodon, Triconodon.

I find, however, no mandibular ramus with teeth which exemplify the same kind or degree of conformity with the three remarkable ones, which have suggested the generic name signifying 'lump-tooth ;' and I have, therefore, no alternative but to describe them as indicative of the genus and species, described in the present section.

Species 1.-Bolodon crassidens, Ow. Plate III, figs. 5, 5 A, 5 в.

In Pl. III, fig. 5 represents, of the natural size, and figs. 5, $\mathrm{A}$ and B, magnified 3 diam., the right maxillary, with the outer side exposed, showing the beginning of the zygoma $(z)$, and part of the lower rim of the orbit (o). A fossa anterior to the maxillary process or

\footnotetext{
$1 \lambda \epsilon \pi \tau \dot{s}$, slender; $k \lambda a ́ \delta o s$, ramus.

$2 \beta \bar{\omega} \lambda o s$, lump; òduis, tooth.
} 
root of the zygoma may include the antorbital foramen $(f)$. The outer wall of the upper jaw in advance of this is remarkable for its height and verticality, and for the arched convexity which defines it above, the thick or broad hind part of which arch may be due in part to a nasal bone combined with the maxillary. A crack, fissure, or sutural 'harmonia' runs from the interspace between the second and third teeth in place some way upward where all trace of it is lost. The determination of the teeth depends on the demonstration of the character of this fissure which the present material does not afford. If it be a suture the two anterior teeth are in the premaxillary; if it be an accidental crack, the premaxillary may be wanting at the fore part of the specimen and the foremost tooth would be a canine. Under this doubt I shall merely indicate the six teeth in place, as they follow from before backward, by consecutive numerals, although the last four with complex crowus are 'molars,' by the character of shape.

The laniariform tooth (1), if a canine, is umusually large among the small Purbeck Mammals : the crown is robust, and terminates somewhat obtusely, retaining its thickness nearer to the apex than usual; in section it is a very full oval, much less compressed than in the canines of any other Mesozoic Mammal. The imner side is Iess convex across than the outer. The enamel there shows two or three low linear longitudinal risings. There is an indication of a rugous talon behind the base of the crown. This tooth is implanted by a single thick root.

The succeeding tooth (2) is of much less size; it is also implanted by one large root, which expands into a low stumpy bulging crown, consisting of one chief thick cone, with a small anterior and posterior ridge-shaped cusp. The enamel is rugous; it swells out beyond the smooth fang to form the base of the crown, without, however, defining a distinct cingulum. This tooth is contignous to No. 1 .

An interval of the breadth of the tooth (2) divides it from the next (3); the alveolar part of the jaw is there broken, or seems so, if the fissure be not sutural. The outer side of the crown of the tooth (2) developes a low thick stumpy cone $(a)$ : the inner side divides into two similar cones. The outer cone $(a)$ is the largest, the antero-internal one $(b)$ the smallest, but the difference is slight. Of the two imner cones or tubercles, one is rather in advance of the outer cone, the other is on the same transverse line therewitl. The enamel forming the low apex of each cusp or cone is rugous; it is smooth and polished where it covers the outer bulging convex base of the crown. The rugosity is due to ridges converging toward the apex.

The next tooth $\left({ }^{4}\right)$ in close contiguity with the last is of similar size and shape; but the antero-internal cusp $(b)$ is rather larger. In both teeth a low ridge passes from the back part of the base of the external cusp $(\alpha)$ to that of the post-internal cusp (c) counecting them. The succeeding tooth $(s)$ seems not quite to have ' come into place.' The external cnsp is below the level of that of the antecedent tooth, and so are the just visible apices of the two internal cusps; it evidently has a crown of like size and character with that of the foregoing teeth; but fracture interferes with a satisfactory appreciation of the modifications 
of this molar. The longitudinal rugosity of the enamelled summits and the shining smootlness of the outer convex base of the crown are repeated.

The last tooth in place (6) is a larger one with some modification of the crown. This is not longer, vertically, but is more extended from before backward, than in the preceding teeth. This extension is due to a ridge or talon continued from the hind basal half of the main outer cone; the summit of which, as well as those of the two inner cones, have suffered fracture. The basal part projects ontwardly with a polished coat of enamel; but the bulge is less than that in the antecedent teeth; and, instead of being continued into one cusp, it divides, after inclining inward, into two smaller cusps, with the rugous enamel. The hind lobe of the tooth is less prominent externally than the front one, and terminates in a notched enamel border.

There seems to be a socket of a smaller molar behind the above-described tooth, and the zygomatic process of the maxillary indicntes that socket to terminate the molar series.

A portion of the delicate bony palate extending from the inner side of the alveolar tract of the maxillary is exposed in the marly matrix.

On the hypothesis that the crack is a suture defining the premaxillary, the tooth (1) would be an incisor of a proportion reaching that in Diprotodonts, and the next singlerooted tooth (2) would be a smaller incisor.

It is remarkable that the only other specimen with teeth of the Bolodont type shonld also be maxillary. It is represented in Pl. III, fig. 6, nat. size; $6 \mathrm{~A}, \mathrm{~B}$, magn. 4 diam. The specimen is a crushed portion of upper jaw with three teeth of the right and two of the left molar series. The latter includes the tooth corresponding to the foremost of the right side and one in advance; the right series, accordingly, has two teeth posterior in position to those shown on the left side. By the obliquity with which the posthumous crushing force has pressed upon the fossil, the left teeth show their outer side, the right teeth their inner side. The bony palate is entire between these right and left teeth, and shows its median suture.

In the oblique view of the two molars of the left maxillary (fig. $6 \mathrm{~A}$ ), the outer side, which is chiefly seen, shows one chief cone, the summits of the two inner cones also coming into view; the three molars of the right maxillary (fig. 6 в) show more clirectly the two main cones of the inner side; the summit of the main outer cone also coming into view in the second of these teetl.

The main onter cone answers to that marked $a$ in the molars numbered 3,4 in fig. 5, $\mathrm{A}$ and $\mathrm{B}$; the two main inner cones in fig. 6 B, answer to those marked $b$ and $c$ in figs. $5, \mathrm{~A}$ and $\mathrm{B}$.

But the teeth in the present specimen show some minor features, not so recognisable in the preceding one.

The outer main cone $(a)$ in the second left tooth developes from the hind part of its base a talon or thick ridge $(e)$ which inclines obliquely inward, and joins the hind part of 
the base of the hinder inner cone $(c)$. A less thick ridge extends from the fore part of the outer lobe $(a)$ from its base half way or more to its summit, and bounds the fore part of the crown, being continued to the base of the front inner lobe $(b)$; this anterior talon or ridge $(d)$ is less developed in the anterior than in the posterior of the two molars of the left side; the hiud ridge or talon is also less developed, and it is to the diminution of the accessory parts ( $d$ and $e$ ) that the smaller size of the anterior of the two left molars is chiefly due. The two best preserved molars of the right maxillary are more equal in size and similar in character; they show the convex bulge of the inmer surface of the two main inner cones. The third molar, which may be the hindmost, is not sufficiently entire for useful description, but the indication of the division of the inner wall of the crown into the two main cones is unmistakable.

The same characteristic sculpturing of the enamel which was noted in the preceding specimen is conspicuous in the best preserved teeth of the present, viz. the vertically ridged summits of the chicf cones, the ridges being comparatively thick, few, and converging toward the apex. The sides of the main cones turned toward each other are shorter and less vertical than those forming the outer and inner surfaces of the crown. The inner side of the outer cone extends a short way between the outer sides of the two inner cones.

Again and again have I gone over all the mandibular specimens and fragments of lower jaws in quest of teeth approximating sufficiently in character with the well-marked upper molars above described, but in vain. Had there occurred any Purbeck mandibular specimen allied to the Oolitic Stereognathus, it might have suggested a relationship to the maxillary evidences of Bolodon crassidens.

Incerta sedis. Plate III, figs. 14,14 A, 14 в, 16 A, 16 в, 20 .

The subject of fig. 14, Pl. III, is a portion of a right mandibular ramus, with parts of two molars $(a)$; with the interveniug sockets of, seemingly, the last premolar and the first and second molars, and with a mutilated premolar in advance of that $(b)$ in place.

The chief value of this specimen is its demonstration of a broad triturating surface, such as might be produced by attrition against upper molars of the breadth of those in the preceding specimen. But the antero-posterior length of the best preserved molar $(a)$ in the present mandible forbids a reference to Bolodon. The last molar, or what seems to be such $(c)$, is about one third the size of the antecedent tooth $(a)$, with a low one-lobed cromn, the enamel of which is feebly wrinkled on its ontside near the grinding surface. It may answer to the small tubercular in Thylacoleo and Plagiculax. The premolar (b) has a low but sharp-pointed chief cone, thick, convex externally in proportion to its height; the hind cusp is well developed. The state of this specimen forbids me to 
hazard a generic or specific name, and I cannot certainly refer it to any of the wellcharacterised species.

The subject of fig. 16, nat. size, $16 \mathrm{~A}$, magn. 3 diam., Pl. III, is a considerable portion of a left mandibular ramus, apparently showing the contour of the lower half of the ascending branch, with a few fractured molars $i$ sitú. The symphysial end is broken away.

Fig. 20, Pl. III, shows the impression, with two small portions, of the left mandibular ramus. The anterior (ib., a) part of the bone contains the eanine, the crown of which is long, strong, subrecurved, and rather obtuse at the apex ; it is supported on a root of twice the length of the crown, which seems to bifurcate at its implanted end. The impression on the matrix sliows the fine ridge which was moulded on the usual longitudinal linear groove of the inner side of the ranus. The impressions of the same side of the molar teeth indicate a middle principal pointed conical lobe, and anterior and posterior smaller, but similar lobes. Of these impressions six may be counted, leaving space for premolars between them and the canine. The hind portion of preserved bone is from the lower part of the ascending ramus.

\section{§ XIV. Gemus-Triconodon, Owen, 1860.'}

In the typo-dentate section of polyprotodont Marsupials a generie form is as well marked in the Purbeck series as is that typified by Phascolotherium in the Lower Oolitic stage.

But at the Purbeck period the principle of differentiation manifests itself in the present genus by the abrupt assumption of the definite and well-marked triconodont character of the molars (Pl. III, fig. 7, $m 1,2,3$ ) as contrasted with the premolars; and the molars, as defined by shape, are three in number, a reduction rare in the Marsupial order, and unique in association with the four antecedent premolars as, similarly, defined by shape of crown.

S'pecies 1.-'T'riconodon mordax, Owen." Plate III, figs. 7, 7 A.

PI. III, fig. 7 , represents of the nat. size, and fig. 7 A, magn. 2 diam., the original speeimen on which was founded the present genus and species.

The generic name relates to the form of the erown in the three last teeth $(m 1,2,3)$, which is subcompressed, antero-posteriorly extended, and divided into three nearly equal cones in the same longitudinal line, the mid cone being very little larger or longer than the front and hind cones; there is no cingulum on the outer side of the crown, but I may add

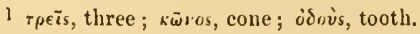

2 'Enc. Brit.,' vol, xvii, 1859, Art. "Palæontology," p. 161, fig. 86; 'Palæontology,' 8vo, 1860, p. 318, fig. 91 . 
to the original description that at the posterior margin of the posterior cone a rudimental talon is feebly marked off by a short vertical indent from the rest of the outer surface of that cone.

'The first of these teeth (fig. $7_{\mathrm{A}}, m_{1}$ ) is very little less than the others; the fore ridge of the base of the coronoid $(c)$ screens part of the last cone of the third molar $(m 3)$ from view.

The last premolar $(p 4)$ seems to have slipped some way from its socket, exposing its two roots, and bringing the base of its crown on a level with the apices of the cones of the succeeding molars. The crown of $p 4$ has a principal subcompressed cone, with a small and low anterior basal cusp, and a larger and higher posterior one. The two divisions of the socket of the premolar in advance $(p 3)$ inclicate a tooth of rather inferior size. The next premolar $\left(\begin{array}{ll}p_{2} & 2\end{array}\right)$ is much less, but of like character; the main cone, however, is much reduced in proportion to the basal cusps. The indications of teeth anterior to $p 2$ are obscure; they show, however, the socket of a minute two-rooted anterior premolar $(p 1)$, the apex of an emerging crown of a canine $(c)$, and one, or perhaps two, of the sockets of the small incisors.

An outlet of the dental canal opens beneath the socket of $p 1$, midway between the upper and lower borders of that part of the jaw.

The symphysis rises rather abruptly from the lower border, sloping at an open angle therewith, more resembling that part in Sarcophilus than in Thylacinus, where it tapers forward more gradually.

The lower border of the ramus is nearly straight, very feebly wavy, from the convexity below the molars, which is repeated rather less feebly below the crotaphyte depression : it is obtuse, rounded, losing thickness as it recedes to beneath the rising branch. The crotaphyte depression is there bounded by a low ridge $\left(a^{\prime}\right)$, extending backward to the outer and under side of the condyle (b), as in Thylacinus, only more depressed, so as to cause the slight convexity of that part of the lower contour of the jaw. In advance of the cretaphyte depression a more shallow longitudinal one extends some way forward, just above the rounded lower border of the ramus.

The condyle $(b)$ is large, convex both transversely and vertically, most extended in the latter direction; it projects from a level a little below the outlets of the alveoli. The notch between it and the coronoid process gives the condyle a subpedunculate character (this is better marked in the larger species of Triconodon). So much of the coronoid process as remains does not extend back so far as the hind part of the condyle, but the process might have done so when the apex was entire.

From the relation of the last molar $\left(\begin{array}{ll}m & 3\end{array}\right)$ to the fore margin of the coronoid, and the degree of protrusion of the crown of the canine, this specimen may be concluded to have come from an individual not quite fully grown.

I am led to the same inference by the appearance of the less complete specinien 
figured, of the natural size, in Pl. III, fig. 8. This also consists of a left mandibular ramus with the onter side exposed, but wanting the hind haif of the ascending branch and the fore part, if not the whole, of the symphysis. It shows well the three triconodont molars and the sockets of the anterior teeth as far as that of the first premolar. Beneath it is a 'foramen mentale,' and belind, under the second premolar, is another outlet of the dental canal; the inlet of this may be seen at the hind fractured part of the jaw. The anterior boundary of the outer crotaphyte depression is well marked; it is angular anteriorly, the corner just rounded off; the lower horizontal boundary projects as it recedes, recalling a character of the mandible of Thylacinus. The outer plate of the ramns falls sheer from the alveoli, not swelling out first, as the inner plate does. 'Two thirds down, the outer plate begins to swell out and curve to form the thick convex lower border of the ramus.

T'he bone is marked by fine longitudinal striæ. There is no trace of the longitudinal depression shown in fig. 17. The three molars occupy an alveolar tract slightly exceeding that in the type-specimen. Like it, I suspect the present jaw may have come from an animal not fully adult.

In the magnified view ( 3 diam.) of the crown of $m_{2}$ (fig. $S_{A}$ ) the vertical indent is shown at the hind border of the hind cone, and a minute notch and prominence appears at the fore part of the base of the front cone, which the specimen (fig. $9 \mathrm{~A}$ ) shows to be due to the begimning of the inner 'cingulum.'

Triconodon mordax (?). Plate III, figs. $9,9 \mathrm{~A}, 10,10 \mathrm{~A}$.

The specimen, Pl. III, fig. 9, nat. size, $9 \mathrm{~A}$, second molar, magn. 4 diam., is a part of a right mandibular ramus, with the three molars and the sockets of the four premolars, showing the inner surface. In exposing the triconodont molars the fore part of the first $\left(\begin{array}{ll}m & 1\end{array}\right)$ flew off, leaving, however, a distinct impression of its two anterior cones.

The cingulum traversing the base of the inner side of the crown of $m 2$, and turning up to the fore margin of the first cone and the hind margin of the last, is here instructively displayed (fig. $9 \mathrm{~A}$ ), as is also the continuation of the cingulum into a small hind basal cusp of the last molar ( $m 3$ ). The cingnlum thus limited to the inner side of the lower molars is here minntely tuberculate. The crown of the second premolar $(p 2)$ shows a main median cone with the apex slightly recurved, and a fore and hind basal cusp, the latter being the larger.

The symphysis begins belind at the vertical line dropped from the interspace between the first and second premolars. The inner part of the lower border of the ramus is produced to form the lower boundary of the longitudinal groove extending forward from near the entry of the dental canal.

In size, especially in the extent of the three molars, this specimen shows a slight 
inferiority as compared with the type-jaw (Pl. III, fig. 7) and the subject of fig. 8 . But both this difference of size and some slight modification of the shape of the cones, as viewed from the inner side (fig. 9 A) and outer side (fig. 9 A), may well come within the sexual and other variations of a species. The limitation of the cingulum to the inner surface of the base of the molars is generic. In subsequent specimens I shall show the reverse position of it in the upper molars of Triconodon.

The next specimen (Pl. III, fig. 10, nat. size, and $10 \mathrm{~A}$, teeth, magn. 3 diam.) yields confirmatory evidence of the characters of $p 4$ and $m 1$, as shown in the type-specimen (fig. 7). It consists of a right mandibular ramus, with the outer side exposed, wanting part of the ascending branch, of which the form is indicated by a smooth impression on the matrix.

The alveolar tract includes the last premolar $\left(\begin{array}{ll}p & 4\end{array}\right)$ and first true molar $\left(\begin{array}{ll}m & 1\end{array}\right)$, in sitú; it shows the empty sockets of the second and third molars, and of a third and second premolar, each of which is two-rooted. The socket of the first premolar retains the base of the crown of that tooth $(p 1)$; it is preceded by a larger socket of a single-rooted canine, and by the sockets of three small incisors.

The fore part of the depression for the insertion of the crotaphyte muscle is shown on the part of the ascending ramus preserved. The impression on the matrix shows that the angle of the jaw was inflected, in a way and degree from which may be inferred the marsupial nature of the species.

The true molar (fig. $10 \mathrm{~A}, \mathrm{~m}^{1}$ ) consists of three principal lobes and a small posterior talon. Each lobe is a subconpressed sharp-pointed cusp; the mid one rather the largest and highest, but the apices of the three rise nearly to the same level. 'The 'talon' is also pointed, and ends about half way up the third lobe. The fore-and-aft extent of this tooth much exceeds either its height or breadth, the latter being the least dimension. No cingulum appears on the side of the tooth exposed. The crown is implanted by two roots.

The crown of the last premolar has one conical, subcompressed, pointed lobe, with a minute basal cusp in front and a larger one behind; the fore-and-aft extent of this premolar is nearly equal that of the succeeding three-coned molar. It is implanted by two

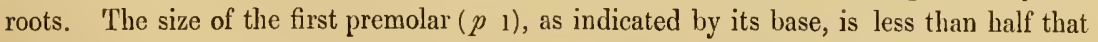
of the last $\left(\begin{array}{ll}p & 4\end{array}\right)$. The canine must have had an antero-posterior breadth of base nearly equal to that of the last premolar. The incisors were the least of all the teeth. There was no break, or 'diastema,' in the dental series.

Along the outer side of the ramus near its lower border runs a linear fissure, but this may be accidental; above the back part of this fissure appears a shallow longitudinal depression, as in the type-jaw (fig. 7).

As compared with Phascolotherium ${ }^{1}$ from Stonesfield Oolite, with the same clental

1 'History of British Fossil Mammals,' 8ro, 1846, p. 61, fig. 20. 
formula, Triconodon differs in the close and unbroken array of the several teeth in the same ramus. 'The mandible is shorter in proportion to its depth; it maintains this depth more equably from the ascending ramus to the symphysis: the anterior contonr bends up abruptly from the lower one, instead of the gradual rise and continuation forward to the end of the symphysis, as in all the known Stonesfield Nammals, ${ }^{1}$ and as in the existing Myrmecobius (Pl. I, fig. 24). ${ }^{2}$

The clief valne of the specimen (Pl. IlI, fig. 10, nat. size) lies in the repetition of the characters of the symphysial angle, and the almost straight course, or feeble undulation, of the lower border of the mandibular ramus, as in that of the type-jaw (fig. 7) of Triconodon mordax.

'T'riconodon (?). Plate III, figs. 15, 16, 20.

'I'he subject of fig. 15, Pl. III, is part of a right mandibular ramns of a young Mammal allied to and perhaps of the genus last described. T'he main cone of a premolar $(p)$ is rising into place. The tooth marked $m 1$, but which might be the last of the premolar series, has a low main cone, boldly convex externally, with a low anterior basal cusp, and a large posteriorly produced hind cusp, making the fore-and-aft length of the crown exceed its height. The foremost compressed cone of the succeeding molar and part of the succeeding cone of the same tooth are preserved. Near the fractured fore end of the ramus two or three outlets of the dental canal are discernible.

The inferiority of size, as compared with fig. 9 or with the type of Triconodon mordax (fig. 7), seems to be more than individual immaturity would account for, and I hesitate either to affirm or deny its specific identity.

The more mutilated ramus (Pl. III, fig. 16), of the same size as the preceding, and with a like straight contour of the lower border of the jaw, is figured and here noted with the view chiefly of calling attention to similar better preserved specimens, in the event of such being obtained, capable of throwing light upon the true nature of the subjects of figs. 15 and 16.

Fig. : 0 is chiefly an impression of a similar sized ramus, with a well-preserved canine and impressions, which at the hind part of the molar series recall a 'Triconodont character.

'T'riconodon (?). Plate IV, figs. 5, $5 \mathrm{~A}$.

The subject of Pl. IV, fig. 5, $a$ and $b$, nat. size, and 5 A, magn. 3 diam., is a portion of a right maxillary bone, with the antepenultimate and penultimate molars, and

\footnotetext{
1 1b., figs. 15, 17, 19 .

2 Ib., fig. 18.
} 
the socket of the last molar. A portion of the bony palate and the beginning of the zygomatic or malar process of the maxillary are preserved; the outer side is exposed.

The molars in place are worn down nearly to the cingulum, which extends along the outer side of the base of the crown; its division into the three compressed lobes is just traceable; the grooves on the inner side of the crown indicate the action of the lobes of the lower molars. In size the molurs in the present specimen are rather less than those of the smaller sized example of Triconodon mordax (Pl. III, fig. 9).

'I'riconodon, sp. ind. Plate IV, figs. 6, $6 \mathrm{~A}$.

The subject of Pl. IV, fig. 6 , nat. size, with the three molars magnified 3 diam. at A, is part of a right mandibular ramus, with the three molars and sockets of the premolars. 'The lower portion of the ramus, as well as the fore and hind ends, are mutilated, and the specimen is chiefly valuable as showing the characters of the inner side of the true molars.

There is a progressive increase in antero-posterior extent from the first $(m 1)$ to the third ( $m$ 3) molars; the cones show an inclination backward, not observable in Pl. III, figs. 7, 8, and 9. Moreover, the cingulum is not tuberculate or crenate, as in Pl. III, figs. 9 and 11, and it extends into and developes a larger posterior basal prominence or talon in each molar.

The correspondence in general size or extent of the series of three molars is very close between the present specimens (Pl. IV, fig. 6) and the subject of Pl. III, fig. 9. But the above-defined differences in form and proportions lead me strongly to incline to see in the specimen here described the indication of a distinct species of Triconodon.

Triconodon, sp. ind. Plate III, fig. 21.

The subject of Pl. III, fig. 21, is the fore part of a right mandibular ramus, with the first and fourth premolars, part of the first true molar, and the crushed socket of a canine, nat. size. The molar $(m$ l $)$ has a compressed antero-posteriorly extended crown of the triconodont type, but with the mid cone only entire; the front one, as in fig. 12, was obviously lower, the hind one more nearly equal to the mid one. The last premolar consists of a main cone with a fore and hind basal talon, the apex of the cone rising higher than that of the mid cone of the contiguous molar. The small anterior premolar $\left(\begin{array}{l}p \\ 1\end{array}\right)$ is too mutilated for characterising. All the premolars and the molar were inserted, each by two fangs.

The teeth agree in size with those in Triconodon ferox (figs. 12 and 13). 'T'he ramus of the jaw beneath the first and second premolar is less deep and more convex externally 
than in that species. There are two anterior outlets of the dental canal, one beneath $p$, the other beneath the socket of $p 2$. The onter alveolar wall descends at once from the sockets to the ontward swelling of the ramus, two thirds down toward the thick rounded lower horder of this part of the mandible. The angle at which the symphysial end scems to rise from the lower border resembles that in Triconodon mordax.

The subject of Pl. IV, fig. 4, nat. size, is a portion of a left mandibular ramus, with the inner surface exposed, showing the symphysis and the broken bases of the third or fourth premolars. The faint linear groove along the inner part of the thick under border of the ramus does not answer to that called 'mylohyoid' in fig. 11, PI. III; it may be a trace of the line of confluence of the osseons encasing of the prinitive mandibular cartilage. But the mammalian unity of the bone is well exemplified in this portion of jaw.

The extent, shape, and the angle of the long axis of the symphysial surface with that of the horizontal ramus, are the same as in Triconodon mordax (PI. III, figs. 7 and 10).

Species 2.-Triconodon ferox, Ow. Plate III, figs. 11, 12, 13, 17, 18, 19. Plate IV, fig. 1.

The size of the specimen about to be described might be deemed to represent that of the jaw of a full-grown Triconodon mordax, admitting the evidence of immaturity shown by the type-specimen (fig. 7). But although the jaw-bone would grow and bring into view the three main cones and hinder talon of the last molar clear of the coronoid process, yet the crowns of the teeth, once completed, do not grow. Now, the extent of the three molar's in sitú in the sulject of Pl. III, fig. 11, nat. size, exceeds that of the same teeth in fig. 7 by two millimeters or one line. The extent of the whole molary series in Triconodon mordax is nine lines, in the present jaw it is ten and a half lines.

Does this inclicate a mere sexual superiority of size?

It is certain that the molars of the female Thylacinus are smaller than those of the male, concomitantly with her general inferiority of size. I should be unwilling, seeing the general conformity of the dentition in the present and preceding specimens, to refer the subject of fig. 11 to a distinct species, believing rather that it might represent a male of Triconodon mordax, were it not for the difference in the shape of the mandibular ramus itself, to which I shall next ask attention, the present specimen agreeing more closely in this respect with Phascolotherium than with Triconodon mordax.

There is, however, an important character in which the agreement with the smaller species of Triconodon is closer, and which may be in generic feature.

Among existing manmals with a dentition for animal food certain marsupials, $e . g$. Thylacinus, Sarcophitus, have the articular condyle of the mandible on as low a level as the alvcolar tract. This eharacter is repeated in the Phascolotherium of the Stonesfield 
Oolite. ${ }^{1}$ But in the present jaw, as in the type-specimen, the condyle projects backward below the level of the alveolar apertures, and the lower border of the ascending ramus, which it terminates behind, does not curve up to the condyle so much as in Phascolotherium.

It represents, in position, the angle of the jaw ; but on the inner side, in the present specimen, is a fractured surface (fig. $11 \mathrm{~B}, a$ ), indicative of a part projecting inward, and which would be the true homologue of the inflected angle of the Marsupial jaw. The articular surface of so much of the condyle as is preserved is smoothly convex, both transversely and vertically.

A deep notch, rounderl at the bottom, but narrower than in Phascolotherium, and also narrower and deeper than in figs. 7 and 10 , divides the condyle from the large, lofty, and antero-posteriorly broad, coronoid plate. The depth of the notch gives a perlunculate character to the low-placed condyle in a greater degree than in Triconodon mordax.

The exposed (inner) surface of the coronoid $(e)$ is flat, with a shallow depression at its fore and inuer part, where it passes into the horizontal ramus. Below this depression is the narrow canal, leading from a few lines in advance of the peduncle of the condyle, and sinking, as the 'dental canal,' into the substance of the ramus at a vertical line dropped from a little behind the last molar tooth.

A very feeble and rather broad longitudinal impression $(g)$ is continued from the entry of the dental canal forward along the inner side of the ramus, as far as below the last premolar. This condition of the mylohyoid groove repeats that in Myrnecobius. The lower border of the ramus describes one uninterrupted gentle curve, convex downward from the condyle to the fore end, as in Phascolotherium. The symphysis follows, with a low slope upward and forward, carrying on and terminating the fore part of the curve. This is markedly different from the contour of the symphysial or fore part of the mandible in the two specimens of Triconodon mordax, in which that part of the jaw is preserved (figs. 7 and 10$)$.

The inner alveolar plate projects a little from the sockets before sinking into the inner surface of the ramus. The whole molar series, four premolars, and three true molars arc in place, with the base of the canine.

The shape of the jaw, with the same extent of the three molars, in the subject of Pl. 1II, fig. 12, nat. size, leads me to refer it to the same species (Triconodon ferox), as fig. 11 . It consists of a left mandibular ramus, inner side exposed, with the ascending branch in part shown by an impression, and with the symphysial end crushed and mutilated.

The portion of the bone preserved contains the last three molars, with the fore ends of the upper and lower ridges of the coronoid or those bounding the pterygoid depression.

The first molar is rather smaller than the second, and its mid cusp, being entire, shows

${ }^{1}$ Pl. I, fig. 26; and 'Brit. Fossil Mammals,' p. 61, fig. 20, $a$. 
it to rise a little higher than the first and third cusp of the same tooth. In the second nolar the apex of the mid cusp is broken off, and in the third molar both this and the hind cusp are wanting. Some traces of sockets are visille anterior to the molar series.

The impression of the angle and lower margin of the ascending ramus shows them to have been slightly inflected. The ramus has a slight general curve, convex downward, from the hind to the fore part, as in the type Triconodon ferox. The lower border of the mandible is moderately thick and rounded.

The subject of Pl. III, fig. 13, nat. size, is the hinder half of a left mandibular ramus, outer side exposed, with the three molars and last premolar.

The coronoid process is preserved. In its height, breadth, and backward curve it resembles that in Phascolotherium, which is like that in most zoophagous Marsupials. Unfortunately the lower border of the ascending ramus with the angle is broken off. The transverse rounding of the thick lower border of the preserved part of the horizontal ramus is rather oblique, descending from the outer toward the inner surface.

In this portion of jaw the mid cusp is entire in the third molar, showing the three cusps to be of equal height. The last premolar $\left(\begin{array}{l}p \\ -4\end{array}\right)$ is represented by its main cone and small hind basal cusp; the front one, probably present in the entire tooth, has been broken off. The cone, which constitutes the chief part of the crown of the premolar, is subcompressed, pointed, rising ligher than the level of the summits of the cones of the succecding molars. A fine groove indents the onter side close to the front border of the cone. The first molar, mutilated in the present specimen, shows the same degree of inferiority to the sccond molar as in the right ramus (fig. 11), where it is entire.

Although the depth of the ramus below the last molar is markedly greater than in fig. 11, the three molars are not larger nor do they occupy a greater longitudinal extent. I conclnde, therefore, that the subjects of figs. 12 and 13 exemplify a larger and stronger individual of Triconodon ferox.

T'he fragment of the right mandibular ramus (Pl. III, fig. 19), with the last molar and a portion of the penultimate molar in situ, shows well some of the characters of the outer surface of the last molar in Triconodon ferox.

T'lue hind lobe of $m 3$ (fig. $19 \mathrm{~A}$ ) has a shallow oblique depression, marking off a low basal talon. 'The onter and fore part of the base of the front lobe is similarly marked by an oblique cleft defining a low cingulum, beginning at the fore part of that lobe. Its non-extension along the base of the tooth to the hind talon shows the aspect presented to he the onter one.

There is a slight vertical notch at the hind part of the last cone of the penultimate molar ( $m$ 2), marking off a better dercloped basal talon than in $m$ 3. This talon or ridge terminates posteriorly the inner basal cingulum.

The lobes or cones of the homologous tecth are higher and sharper than in Triconodon 
mordax. In size this third molar somewhat exceeds that in the last-described specimen of Triconodon ferox, but not so much as to justify a reference to a distinct species.

The following exemplificatious of the generic characters of upper or maxillary teeth of Triconodon seem, from their size, to have been afforded by $T r$. ferox rather than by $T r$. mordax.

The subject of Pl. III, fig. 18, nat. size, fig. 18 A, magn. 3 diam., and B working surface of teeth, magn. 3 diam., is a portion of a left maxilla, with the last two premolars and the first two molars.

The molars show much wear. A cingulum extends along the outer side of the base of each ; it is impressed by many small vertical grooves or notches, and is thickest as it curves toward the summit of the anterior and the posterior lobes at the two ends of the tooth. The three lobes incline inward toward their summits; but these have been much worn down. The posterior fang of the second molar $\left(\begin{array}{ll}n & 2\end{array}\right)$ is exposed at the hinder fracture. The main cone of the last premolar $\left(\begin{array}{l}p \\ p_{4}\end{array}\right)$ has its apex worn away, not broken off; but this extends beyond the level of the working surface of $m_{1} 1$ and $m 2$. There is a hind basal cusp, as well as a basal ridge, or 'cingulum' which ends behind in a slight projection beyond the 'talon' of $p$ 4. The penultimate premolar $\left(\begin{array}{l}p_{3} \\ 3\end{array}\right)$ has a slightly retroverted main cone with a front and hind basal talon, the latter being most prominent. The alveolus and two roots of the second premolar $\left(p_{2}\right)$ are included in this fragment of upper jaw, showing a decrease of size corresponding to that of the homotypal teeth of the mandible.

A portion of the bony palate is preserved ( $a$, fig. 18), extending inward from the alveoli of $p 1, p 2:$ this thin, inferiorly concave, bony plate is entire to its fractured margin. There is a depression or smooth groove $(0)$ in the maxillary bone, a short way above the sockets of $p_{2}$; it may indicate the position of an antorbital canal outlet.

In P]. III, fig. 17 represents of the nat. size, and fig. 17 A magn. 3 diam., a portion of a right maxilla, with the last two premolars, the first molar and the fore part of the second molar, in situi, the inner side being exposed with a contiguons portion of the bony palate. The teeth agree in size with those in the maxillary specimen of the opposite side last described.

The penultimate premolar ( $p$ 3), in like munner, shows a clief cone, with an anterior and a posterior basal cup, each of the latter being girt by a ridge which almost subsides at the prominent mid-part of the main cone; the hind basal cusp is the largest. The last premolar $(p 4)$, with increase of size shows plainly the continuation of the cingulum, with a tubercular character, from below the fore and hind talons, across the base of the main cone, with a narrow median interruption, where the main cone seems to be longitndinally impressed. The posterior basal cusp is relatively larger than in $p 3$. 'The apex of the main cone extends beyond the summit of the contiguous molar cones. In the 
anterior nolar the foremost of the three cones or divisions of the crown is less than either of the other two eones. The eingulum is more interrupted and wore feebly developed than in $p 4$, or than along the onter side of the crown of $m 1$ (see fig. $15 \mathrm{~B}, m 1$ ); it crosses obliquely the fore part of the front cone; it also appears on part of the base of the mid cone, and on the fore part of that of the hind cone, but feebly. The cones are low, and worn; the transverse breadth of these upper molars is greater than in their lower lomotypes, yet the eharacteristic extension of the tooth in the antero-posterior direction concurs, with the trifid erown, in proclaiming the genus to which the present and preeeding portions of upper jaw are referable.

'The tendency to turn, as it were, the outer side of the upper molars to the inner side in the lower molars is exemplified in the partial development of the cingulum, as shown ju fig. $17_{\mathrm{A}}$ compared with its integrity in fig. $15 \mathrm{~B}$.

Confirmation of the ascription of fig. 17 to Triconodon ferox is afforded by the subjects of figures $1,1_{A}, B, C$, P'l. IV. Figure 1 gives the natural size of portions of an upper waxillary of a right mandibular ramus (fig. 1 в, magn. 2 diam.), with the inner surface exposed, and a similar anterior portion of the left mandibular ramus (fig. $1 \mathrm{c}$, ı1agn. 2 diam.), with the outer side exposed, of the same skull.

A portion of the bony palate projecting from the matrix is erushed down below its level, so as to obscure the inner surface of some of the teeth. The erown of the molar (fig. I A, magn. 4. times) slows the thickness of the cingulum traversing the outer side of its base, characteristic of the upper molars of Triconodon. A more interrupted growth of 'cingulum' on the inner side increases the transverse basal breadth. The inferior height of the auterior cone indicates this to be the first molar $(m 1)$. Of the premolars two are preserver, showing a principal cone, a hind smaller one, and the additional basal cusj) due to the further extension backwards of the cingulum, as in $p$, fig. 17, Pl. III.

The portion of right mandibular ramus, in contact with its maxilla (Pl. 1V, fig. $1 \mathrm{~B}$ ), is mainly instructive in showing a second incisor ( $i$ 2) in place; it is the tootl in advance of that shown in fig. 7, Pl. III; it is smaller in size but similar in shape to the third incisor $(i 3)$.

The canine $(c)$ has the usual laniary shape, slightly recurved; the apex is wanting, it appears to be worn down; there is a longitudinal basal indent at the inner side of the crown here exposed. The first premolar and its socket are crushed out of view; the crown of the second premolar $\left(\begin{array}{l}p_{2} \\ 2\end{array}\right)$ is in place, showing the ehicf cone with a short subvertical fore margin, a long sloping hind margin, provided with a basal cusp, which exteuds the cinguluus. The latter feature is more strongly marked along the imner side of the base of the third premolar ( $p 3$ ) ; its fore cud, as it circumscribes that part of the base of the main eone, simulates a small basal talon; the hind end similarly projects beyond the true basal eusp or talon at that part of the main cone. The two-cham- 
bered alveolus of the last premolar indicates the usual progressive increase of size. Part of a similar socket, with the hind root and portion of the crown of the first molar ( $m 1$ ), is definable; it is followed by the first and second cones of $m 2$. The basal cingulum is shown in both teeth.

In the fore part of the left ramus, showing the outer surface (Pl. IV, fig. $1 \mathrm{c}$ ), the characters of that side of the crown of the canine are seen ; it is more convex than the inner side, and has not the longitudinal basal depression. The anterior ontlet of the dental canal is beneath the alveolus of the first premolar. Part of the crown of the second $\left(\begin{array}{l}p_{2} \\ 2\end{array}\right)$ is preserved. The third ( $p$ ) shows the height of the main cone, which wants the apex and the right ramus. The last premolar and the first true molar $\left(\begin{array}{ll}n & 1\end{array}\right)$ are represented by the basal parts of the crown. The interruption or partial development of the cingulum is here noticeable. The mandibular rami in the present specimen show the convex lower ontline and the gradual curve upward to the incisive alveoli, which appears to be characteristic of Triconodon ferox, or at least to differentiate it from Triconodon mordax.

Species 3.-Triconodon occisor. Plate IV, figs. 2, $2 \mathrm{~A}, 2 \mathrm{~B}$.

I next enter upon the description of the partially dislocated rami of the same mandible (PI. IV, tig. 2, nat. size; A and B, teeth magn. 2 dian.), showing the formal characters of the mandible in Triconodon mordax, but belonging to an animal too superior in size to be referable to that species; from which also the present more decidedly and instructively differs in a minor relative size of the first molar $\left(\begin{array}{ll}m & 1\end{array}\right)$ as compared with the other two molars.

At first sight the left ramus (fig. $2, l$ ) seems identical, answering as it does, in both size and shape, with the type of the genus (fig. 7, PI. III). But if the first two molars be compared in the two specimens, those of the present show a marked increase of anteroposterior extent, notwithstanding the smaller proportion of $m_{1}$ to $m_{2}$. This differential character comes out well in the figures of each mandible which are magnified in the same degree in Pl. IV, fig. 2 B, and Pl. III, fig. 7 A respectively. Furthermore, although some signs of immaturity are recognisable in the type of Triconodon mordux, the mandible, here conpared, of Triconodon occisor is of a still younger individual ; only half of the last molar (n $\left.\begin{array}{ll}n & 3\end{array}\right)$ has advanced into view beyond the base of the coronoid, and not more than two thirds of the crown of the canine $(c)$ and of that of the last premolar $\left(\begin{array}{l}p_{4} \\ 4\end{array}\right)$ have risen above the socket.

The fully grown animal of the present species would equal in size that of Triconodon ferox, but the shape of the mandible and the proportions of the molars forbid a reference of the present specimen to that species.

I cannot, with a recognition of the above defined characters, withdraw from the 
undesirable duty of signifying them by adding another specific name to the present well-marked genus.

I give my original notes on the type specimen of $T r$. occisor.

"Botlı rami, somewhat mutilated, of the same mandible, the left $(l)$ showing the outer side, the right $(r)$ (good for molars) the imner side; and the latter more complete, having a fore-and-aft extent of coronoid process preserved for nine lines behind the last molar. Part of the inflected ridge or angle $(a)$ is shown. In advance and above this is the entry of the dental canal $(d)$, the condyle itself is broken away. 'The longitndinal linear groove is seen to terminate near the symplysis. The thicker imner alveolar plate is here well contrasted with the thinner outer wall of the sockets in 7 . The minutely tubercnlar ridge along the base of the immer side of the crown is well shown in the first molar" ( $m$ 1, fig. 2 B); "also the vertical groove close to the anterior border of each cone (most clearly shown in the first and second cones). The hind basal notch or talon comes well out on the outer sicle of the left $m 1$ and $m 2$ " (fig. $2 \mathrm{~A}$, Pl. IV).

"The last molar is not quite in place, its lindmost cone has not emerged or come forward from its alveolus, where it is exposed in the right ramus" (fig. 2, $r$, and $2 \mathrm{~B}, m 3$ ). "The last premolar" ( $p 4$, fig. $2 \mathrm{~A})$ "has not risen into place; its apex is on a level with the base of the first cone of $m 1$. The third premolar" $(p 3$, fig. $2 \mathrm{~B})$ " is in place in the right ramus, and shows the basal ridge along its inner side, together with the large posterior talon; the anterior talon is feebly indicated.

"Both auterior and posterior talons are more conspicnous and more equal in the second premolar" (fig. $2 \mathrm{k}, p 2$ ), "which is much smaller than the third, chiefly throngh the minor development of the main cone, which is less acute than that of $p 3$. The first premolar ( $p$ 1) has a still smaller main cone with an anterior and a posterior cusp. The premolars, like the molars, are inserted each by two roots."

So much of the crown of the canine as has risen into place shows a less recurved shape than in Triconodon ferox. The anterior border of the jaw rises at an open angle with the lower one to the incisive alveoli, as in Triconodon mordax. It does not ascend or curve gradually up as in Triconodon ferox.

Speeies 4.--Triconodon major, Ow. Plate IV, fig. 3.

In a block of stone, from the part of the Middle Purbeck marked 'Feather', in fig. 4,

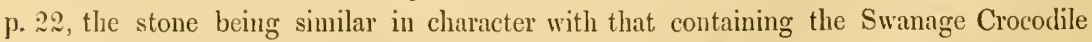
(Goniopholis), Turtles (Plcurosternon, \&c.) and Fish (Microdus', \&c.), and which the masons were sawing up, their attention was canght by the appearance of a fossil in the line of scction. The process was stopped, and the portion of stome with the fossil cut out. It was purchased for the British Musenm, and, after careful development of the 
fossil, the part of a right mandibular ramus was exposed, which is represented, of the natural size, in Pl. IV, figure 3.

The preserved molar $\left(\begin{array}{ll}m & 2)\end{array}\right)$ is of the Triconodont type ; but the size of the specimen is fully one third larger than the largest of the previously described species of Triconodon. The animal to which it belonged would probably be of the size of the 'Native Cat' of Australia (Dasyurus Mangei, Geoffroy). I estimate the length of the lower jaw of Triconodon major, when entire, according to the analogy of Triconodon ferox (Pl. III, figs. 7 and 8), to have been two inches and a half, and the jaw attains that length in the male of the spotted species of Dasyure above cited.

The tooth preserved, which lacks only the apex of the anterior cone, answers to the second of the three molars in Tr. ferox (Pl. III, fig. 12). It shows the nsual absence of continuous cingulum along the outer side of the base of the crown. There is no trace of anterior or posterior talon. The coronal clefts seem to be rather less deep than in the smaller species. The socket and remnant of the first molar shows it to have been, as in Tr. ferox, smaller in proportion to the second molar than it is in Tr. mordax. The last premolar $(p 4)$ shows the same relative antero-posterior extent of crown as in the smaller species : the two fangs supporting the base of the crown are partially exposed, but the rest of the tooth is broken off. The socket for the two fangs of the penultimate premolar $\left(\begin{array}{l}p 3 \\ p_{1}\end{array}\right)$ is preserved, anterior to which the jaw is broken off, exposing the anterior root of that tooth and the cavity of the ramus (fig. 3 a).

The two-celled socket of the molar following the one in place indicates a tooth of equal size; and the position of the outer buttress-like beginning of the fore part of the coronoid process shows $m 3$ to have been the last. The stone-saw has removed an extent of two lines between the begiming of the coronoid and the rest of the rising branch. This gives a basal fore-and-aft breadth of the coronoid of eight lines; the apex or upper half of the process is wanting. A similar notch between the hind border of the process and the condyle, as in Pl. III, figs. 6 and 10, gives the same pedunculate character to the upper part of the condyle; the joint projects at a lower level than the alveolar outlets. From its lower end a ridge (a) projects outward, but in a less degree than in Dasyurus, defining below the crotaphyte fossa.

The fractured fore part of the jaw exposes the anterior cell or division of the socket of the third premolar, filled with matrix, and the cavity of the ramus itself similarly occupied. The bone has suffered a longitudinal fracture towards its hind part. 


\section{$\S \mathrm{XV}$. Genus-Triacanthodon, ${ }^{1}$ Oven.}

Species 1.-Triacanthodon serrula, ${ }^{2}$ Ow. Plate IV, figs. 7, 7 a, S, S a.

This genus and species are exemplified in two slabs, counterparts of the same split block of Purbeck Shale, with the left mandibular ramus of a young individual.

One portion or slab (Pl. IV, fig. 7, nat. size, and 7A, magn. 2 diam.) inclucles the ascending ramus, the last molar tooth in its formative cell, and an impression of the rest of the bone and teetls; the other portion (fig. 8 , nat. size, and $S_{\mathrm{A}}$, magn. 2 diam.) includes the part of the ramus and teeth anterior to the penultimate molar, and the impression of the hinder part of the jaw with those of the last two molars. The portion of the ramus including the penultimate molar, which intervened between the fractures in figs. 7 and 8 , had been lost before the specimen came into my hands; it is well represented, however, by the impressions of its outer and inner surfaces in the counterpart slabs.

The fore part of the ramus in fig. 8 shows the outer surface, the hind part in the opposite slab (fig. 7) shows the inner surface, of the mandible.

In the fore part of the jaw the outer incisor (fig. $S_{A}, i 3$ ) is preserved; it is small, conical, thick, outwardly convex, with a sub-obtuse apex; there is a feeble indication of two shallow longitudinal linear impressions bounding a middle tract of the outer convexity, near the base of the crown. The canine (ib. $c$ ) is long, large in proportion to the incisor, strong, sub-recurved, sharp-pointed, with a longitudinal indent near the basal part of the outer side of the crown, indicative of a tendency to division of the implanted root. 'The canine follows the incisor without any diastema. The concave line of the hind border of the crown is arrested three fourths of the way toward the base by a slight hinder projection-a quasi feeble 'talon.'

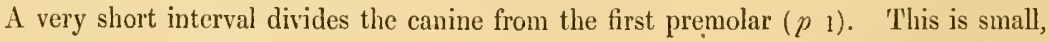
two-rooted, sub-compressed, with a hind cusp almost equalling the main cone, and with a small anterior basal cusp; the whole crown is low in proportion to its fore-and-aft extent.

The second premolar ( $p_{2}$ ), similar in form to, but somewhat larger than, the first, has a more elevated main or mid cone; the front cusp or talon is rather more developed than in $p$.

The third premolar ( $\left.\begin{array}{l}p \\ 3\end{array}\right)$ shows a markedly larger size, especially in the relative height and breadth of the main cone. 'The anterior basal cusp is low ; the posterior cusp

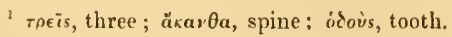

2 Serrula, little saw, suggested by the row of denticles formed by the five three-spined teeth. 
is higher, and it is followed by a minute basal 'talon,' probably the termination of an internal ' cingulum.'

This tooth is followed by $p 4$ or $d 4$, approaching the Triconodont or true molar type ; but with the basal cusps, especially the front ones, better developed than in any of the succeeding true molars. The mid cone is also relatively bigher in proportion to the first and third cones; but the whole crown is lower in proportion to its fore-and-aft extent than in the succeeding molars. The apex of the mid cone reaches only to half the heiglit of the main cone of the antecedent premolars. The crown is entire; no main cone is worn or broken away. If it be the homologue of $p 4$ in Triconodon it shows widely different proportions and form. The superiority of the middle to the fore and hind cusps favours its reference to the premolar series; unless, indeed, it may belong to the deciduous series; the symbol of $d 4$, in fig. $8 \mathrm{~A}$, is to be taken suggestively in reference to the alternative above proposed. I have not felt justified to hazard this unique and brittle eridence by burrowing after a possible hidden germ of a successional tootb. Behind $p+$ or $d 4$ is a tooth $\left(m_{1}\right)$ of the more usual 'Triconodont or Triacanthodont type, the anterior and posterior cones, especially the latter, rising more nearly to equality with the mid cone : there is neither fore nor hind talon. The crown of this tooth stands at a higher level than that of the preceding, but rises not quite to a level with the apex of $p 3$.

The next tooth ( $\left.\begin{array}{ll}m & 2\end{array}\right)$, of the same type as $m_{1}$, slightly exceeds it in size; it is equally devoid of trace of 'cingulum' on the onter side here exposed. A minute tubercular prominence at the fore part of the base may be the anterior end of an inner 'cingulum :' there is no trace of hinder talon. The next two molars $(m 3, m 4)$ are indicated by impressions of their crowns in the present slab, that of the hindmost $\left(\begin{array}{ll}m & 4\end{array}\right)$ being wholly within the impression of the coronoid process. It is preserved in the opposite slab, with that process (fig. $7_{\mathrm{A}}, m_{4}$ ). The penultimate molar, with the supporting part of the jaw, as before stated, has been lost.

Before quitting the survey of the slab (fig. 8), I may note that the outer wall of the socket of the canine is prominent, and that in the depression between it and the less prominent alveolus of the succeeding premolar the foremost and largest of three outlets of the dental canal opens. These three foramina are in the same longitudinal line, mid way between the upper and lower borders of the ramus, pretty closely following each other. The outer' surface of the bone is finely punctate and longitudinally striate. The outer alveolar border is serrate through the low angular processes rising into the intervals of the teeth and their fangs; the wall sinks at once from the alveolar outlets a short way, then slightly swells outward before inbending to the thick lower border of the ramus, making the lower half convex vertically. The symplysial contour forms, as in Triconodon mordax, an open angle with the lower border of the ramus; but this is continned in an uninterrupted gentle curve to the condyle $(b)$.

In the opposite slab (fig. 7) the crown of the last molar ( $m$ 4) is exposed, incompletely developed, in a formative alveolus at the fore part of the base of the coronoid pro- 
cess; the calcificl summits indicate a conformable character with the antecedent molars. In Macropus and most diphyodont Placentals the hidden and incomplete condition of the last molar would imply, or be coincident with, a like condition of the last premolar.

The coronoid process (fig. $7 \mathrm{~A}, e$ ) is subrhomboidal, is broad, high, reclinate; its apex is continued backward to the same vertical line as that touched by the hind part of the condyle which projects below the level of the alveolar ontlets. The condyle $(b)$ is pedunculate at its upper part throngh the oblique deep notch between it and the coronoid. It shows well the carnivorous mammalian convexity, the lower part of which is contimned into the lower border of the ascending ramus. This border is inflected, and part of it is retained in the grooved impression left on the slab (fig. $8 \mathrm{~A}$, at $a^{\prime}$ ). 'The inflected border, representing the 'angle of the jaw,' bounds the shallow longitudinal chamel leading to the entry of the dental canal.

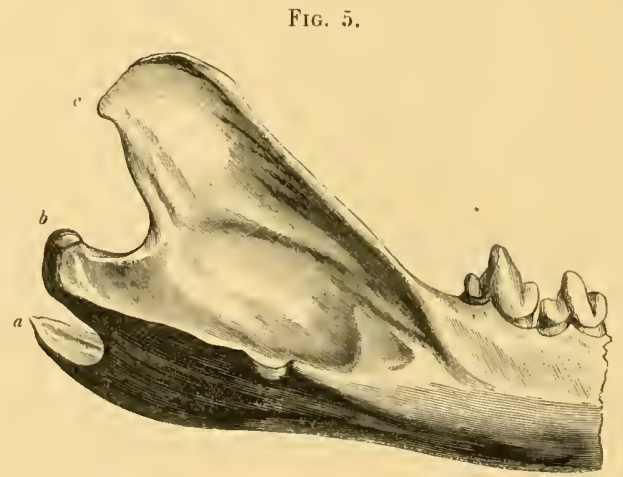

Hind part of mandible of Thylacinus ( $\frac{2}{3}$ natural size).

The 'Thylacine (fig. 5), amongst known living zoophagous Marsupials, offers the nearest approach to the indications of predatory nature given by the lower jaw and teeth of Triacanthodon. But these indications are exaggerated in the concentrated carnivorous character of those parts in the genus next to be described. 


\section{$\$$ XVI. Genus-P'iagiaulax, Falconer, 1857 .}

Species 1.-Plagiaulax minor, Falconer. ${ }^{2}$ Plate III, figs. 9, 9 А, 9 в.

This species is represented by the dentigerous portion of the right mandibular ramus with the teeth in sitû (Pl. IV, fig. 9, nat. size; 9 A, magn. 3 diam.; B, molars magn. 6 dianı.). The lower border of the hind part with the ascending ramus is broken away.

The teeth are the incisor $(i)$, four premolars $(p 4-2)$, and two molars $(m 1,2)$. The incisor is long, large, laniariform, more rounded or convex externally than in the larger species (see Pl. IV, fig. 11, A, i) ; the anterior end is broken off, but the impression left on the matrix shows it to have been pointed, and also indicates a shallow longitudinal groove on the inner side of the tooth, nearer the fore than the hind border $\left(a i^{\prime}\right)$. The length of the exposed part of the tooth or 'crown' equals the fore-and-aft extent of the entire premolar serics. The direction of the crown is upward and forward, at an angle of $120^{\circ}$ with the alveolar line of the succeeding teeth: the convexity of the antero-inferior border and a slight concavity of the postero-superior border give the appearance of a curve in the same direction.

The first premolar abuts against the fore part of the second. It rises at a distance from the incisor equal to the breadth of the base of that tooth. It is minute, with a crown longer or higher than its fore-and-aft breadth. Slightly bulging at its base, above the single root, it becomes flat externally with the summit obliquely truncate.

The crown of the second premolar ( $p 2$ ), larger and more compressed, swells out rather more abruptly above the fang, from which protuberance the crown expands and flattens as it rises, and again contracts to abut upon the fore margin of the next tooth. The apex of the crown of $p_{2}$ is marked by three fine short ridges directed from before upward and backward; below these the enamel is smooth and flat to the bulging base. The height of the crown is greater than its fore-and-aft breadth, the extreme of which is about half way to the angular summit; this shape is due to a truncation in the same direction as in the first molar, viz. from above downward and forward, which gives to the crown a rhomboidal figure.

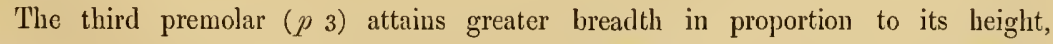
though the latter dimension of the crown still predominates: the thickness of

1 “An abbreviation for 'Plagiaulacodon,' from $\pi \lambda \alpha^{\prime} \gamma$ 'os, oblique, and $a^{\tilde{n}} \lambda a_{u}^{\tau}$, groove, having reference to the diagonal grooving of the premolars,' see 'Description of Two Species of the Fossil Mammalian Gelius Plagiaulax from Purbeck;' by Hugh Falconer, M.D., F.R.S., F.G.S., in 'Quarterly Journal of the Geological Society of London,' vol. xiii, p. 261.

2 Ib., p. 264, and p. 281, fig. 15. 
the crown is but little increased. The rhomboidal form prevails; the upper angle being in contact with the upper and anterior angle of the more quadrate crown of the last and largest premolar, and the trenchant border slopes therefrom downward and forward to that of $p_{2}$. The lower angle of the rhomboid is formed by the smooth shining bulge of enamel above the fang, or the chief anterior fang. Above that the surface expands and flattens, with the slightest degree of concavity lengthwise, and the feeblest indication of a ridge along the hind border. Two, or at most three, oblique ridges mark the trenchant summit of the crown, whence they run a short way downward and forward.

In the last premolar ( $p$ 4), with a slight increase of height of crown, the anteroposterior diameter prevails withont increase of thickness. The anterior root, above which is the enamelled swelling, is more plainly a sulhordinate support, instead of being the chief or the sole one. The onter surface of the crown rises more directly from the posterior insertion as a flattened tract. A feeble vertical ridge holds the same distance from the anterior thickened border of the crown as does that which, in the preceding premolar, marks the posterior horder. The flattened part of the crown behind the short vertical rising in $p$, thus seems to be a superadded part of the tooth, and may indicate the tooth, so symbolised, to be a carnassial true molar ; but the test of devclopment eamnot, with present evidence, be applied. The oblique ridges, six or seven in number, continued downward and forward from the serrations of the trenchant margin, are linited to the upper half of the crown. The lind part is lower than the fore part ; the serrate border sloping from before downward and backward; that border of the fonr closely contiguous premolars describes an unbroken convex curve, like the edge of a circular saw. The four trenchant teeth constitute two thirds of the molary series.

The first tubercular molar ( $m$ 1) has an oblong crown, with the long diameter from before hackward. Its vertical diameter is less than half that of the fore part of the antecedent tootl. The grinding surface (Pl. IV, fig, $9 \mathrm{~B}, m \mathrm{l}$ ) is divided by an anteroposterior depression into an outer and an inner division, the imer wall rising highest; this presents three obtuse cones, the foremost being smallest, and the other two further apart. The outer division is cleft into three more equal, smaller, and lower tubercles. Below these the outer surface of the crown is not impressed or indented, but presents a snooth moderate convexity from hefore backward. The three pairs of peripheral tubercles. in this minute lower molar recall the character of those of Stereognathus (PI. I, fig. 29), though the resemblance is not so close as to the lower molar (PI. I, figs. 6-12) of Vicrolestes.

The last molar $\left(\begin{array}{ll}m & 2\end{array}\right)$ loses in antero-posterior and vertical extent ; its middle depressed surface is broader, and is bounded by narrow ridge-like low walls of enamel, with feeble indications of a tubercular character, the inner and fore angle being most elevated. In hoth molars the height of the crown is inconsiderable compared with the other dimensions.

The outer and fore root of the coronoid process projects external to the alveolus of the last molar, and slows the fractured surface, and the most prominent part of the onter 
surface of the horizontal ramus is thence continued in a gentle curve below the alveoli of the premolars, forward, to the upper part of the socket of the incisor; the prominence is not well defined, but it gives a vertical bulge or convexity to the outer side of the jaw.

The alveolar border rises in well-marked angles into the interspaces of the premolars, or of their roots.

The crown or exposed part of the incisor formed, when entire, two sixths of the total extent of the dental series; the premolars two fifths; the molars one fifth.

Fig. 9, Pl. IV, gives the natural size of the specimen. If the ascending ramus of the jaw be restored after the type of that of the larger species of Plagiaulax (ib. fig. 10), the length of the lower jaw, including FIG. 6. the incisor, would be seven and"a lialf lines, as in the woodcut, fig. 6 .

\section{Species 2.-Plagiaulax Becklesil, Falconer. ${ }^{1}$ Plate IV, figs. 10, 10 а, 10 в, 11,11 а.}

The type of this species is preserved in the connterpart slabs of a split block of Purbeck shale, of which one contains the hind half of the right mandibular ramus, with the impression of part of the fore lialf (PI. IV, fig. 10, nat. size ; $10 \mathrm{~A}$, magn. 3 diam.); the other contains the fore half of the same ramus with the teeth and the impression of the major part of the rest of the bone (ib. fig. 11, nat. size; $11 \mathrm{~A}$ magn. 3 diam.). The inner side is exposed of the hind half, the outer side of the fore half.

The fore half contains the incisor (fig. $11 \mathrm{~A}, i$ ) and three premolars (ib. $p 2,3,4$ ); the hind half shows the shallow sockets of two small molars (fig. $10 \mathrm{~A}, m_{1}, m_{2}$ ).

The condyle of the jaw (figs. $10 c, 10$ B) is unusually large, especially in the vertical direction. It extends to the lower border of the ramus, the angle-almost a right onebeing formed by their meeting or intersection at $a$. A narrow tract of fracture indicates the homologue of the angular process to have been thence directly inflected as a thin plate, the base of attachment of which was continned forward below the pterygoid depression, to the entry of the dental canal $(d)$.

The condyle $(c)$ is convex transversely and vertically, the articular surface curving from before backward, downward, and again slightly forward, to the extent of nearly a half circle : its breadth rapidly increases from the upper end to one third down, then gradually decreases to near the angle. The smooth articular surface is best marked upon (and was, perhaps, confined to) the upper broader part of the condyle, the lower boundary, as in Thylacinus, not being defined. The narrowing is chiefly from the inner side; so that the outer contour of this vertical condyle (fig. $10 \mathrm{~B}, \mathrm{o}$ ) is uniformly

I Op. cit., pp. 262, 278, 279, figs. 1-5, 7-14. 
convex; the imer contour (ib. $i$ ) is convex at the upper half, concave at the lower one; the imner border is sharply defined, as in Thylacinus. The representative of the angular process of the jaw in other Mammals is here directly and abrnptly inflected inward, at the level of the lower end of the condyle, as a horizontal ridge $\left(a, a^{\prime}\right)$, which extends forward from the inner side of the lower margin of the ramus to the entry of the dental canal $(d)$, in front of which the ridge curves and rises vertically with some subsidence and blunting to the back part of the molar socket ( $m$ 2), which is partly within, and is below the anterior part of the base of the coronnid process (b). The inflected part of the lower. border of the ramus is not much produced, but is most so near the angle, where the margin, broken off from the slab under scrutiny, is preserved in that containing the fore part of the ramns with the teeth (fig. 11). The line of the inflected lower border of the jaw runs nearly straight from the terminal condyle to beneath the dental canal.

From the upper end of the condyle the hind margin of the rising branch ("ramus ascendens,' ' perpendicular portion or ramus,' Anthropotomy) dips down before curving forward and upward to rise almost vertically, or with a slight backward curve, to the summit of the coronoid process $(b)$. The concave curve from the condyle is deep and bold, giving a pedunculatc character to the joint, at least at its upper part. The inner margin of the condyle is produced beyond the level of the inner surface of the rising ramus, circumscribing that surface behind, as does the ridge anterior to the dental canal in front. The apex of the coronoid process, if it were entire, would probably not extend further back in relation to the condyle than in Thylacinus, fig. 5 .

From the summit of the coronoid the anterior margin of that process curves with, at first, a bold convexity, subsiding near the base to change into the gentle concave line by which the process commences, anteriorly, on the ontside of the hind socket or hind part of the socket of the last molar tooth.

The tract of line forming the inner surface of the broad (antero-posteriorly extended) and high coronoid, with that of the 'ranus ascendens' below, is almost flat on the inner side of the jaw here exposed. It is vertically concave through the production of the inner part of the lower border, near that border, and is very feebly convex in the same direction along the base of the coronoid; in the fore-and-aft direction the flatness of the relatively extensive tract of the inner surface of this part of the nandible is less affected. The immer alveolar wall of the last socket makes an obtuse projection (below $m_{2}$, in fig. $10 \mathrm{~A}$ ), and it is thicker than the onter alveolar wall. In the horizontal plane the inner border of the socket describes a more convex curve than does the onter border. The eitire border is obtuse; the socket is a full longitudinal irregular ellipse, and less deep than its length, recalling the shallow bed in which rests the hind tubercular of Thylacoleo and Felis. A part of the sockct of the anterior molar $\left(\begin{array}{ll}m_{1} & 1\end{array}\right)$ is preserred, in front of which is the impression, in slab, fig. 10, of the large premolar $(p 4)$.

The fore part of the ramus with the teeth is almost as deep as it is long, the depth or height of the ramus increasing from the incisive alveolus to the hind fractured part. A 
prominence (fig. Il A, b) a little below the hind part of the socket of the last premolar leads backward to the broken origin of the outer part of the auterior border of the hase of the coronoid process, and a feebler bulge or vertical convexity of the line extends forward below the premolar alveoli to near the outlet of the socket of the incisor. The concavity (a), deepest at the back part of this portion of jaw, gradually shallows and contracts to end bclow the alveolus of $p 2$. The second vertical convexity $(c)$ of the outer surface of the ranus, forming the lower boundary of the concavity $(a)$ is continued into the thick rounded under border of the jaw.

The ramus loses depth as it advances and terminates anteriorly in the socket of the large subcompressed laniariform incisor (fig. 11,i). The crown of this formidable tooth is directed upward at an angle of $110^{\circ}$ with the line of the premolar alveoli; the tooth as it advances contracts or loses fore-and-aft breadth, and is slightly curved upward to its pointed extremity. The transverse breadth, which is small, is maintained nearly to the apex. The onter side of the basal third shows a shallow medial longitudinal impres sion, contracting to lose itself in the uniform subconvex level of the rest of the outer surface. This depression recalls that at the corresponding part of the base of the canine in Triacantiodon ( $p, \mathrm{Pl}$. IV, fig. $8 \mathrm{~A}, c)$. The anterior border of the incisor is blunt to near the apex; the posterior border shows a narrow flat tract with sharp margins; the entire crown is invested by enamel. It is implanted, as far as the socket is exposed, by a single cement.clad root, which slightly contracts as it sinks into the bone.

The incisor is relatively as long as in Plagiaulax minor (Pl. IV, fig. 9), but is broader antero-posteriorly, less convex, and less uniformly so externally, more recurved toward the apex; in other words, more fitted for piercing as might become a larger and stronger species.

The three compressed lamelliform premolars progressively increase in height and, in a greater degree, in fore-and-aft extent, as they recede in position. The crowns of the three teeth $(p 2,3,4)$ are in very close contact, and are so coadjusted as to give to their trenchant borders a continuous convex outline, acting as one great carnassial.

The first premolar (fig. $11 \mathrm{~A}, p_{2}$ ) is the least. It arises about twice its own breadth from the ontlet of the incisive alveolus, leaving a distance of that extent between it and the incisor. The height of the crown is twice its breadth. The fore part of the base swells into a smooth convexity. The contracting summit bends slightly back and abuts against the middle of the fore part of the second premolar. The onter side of the upper

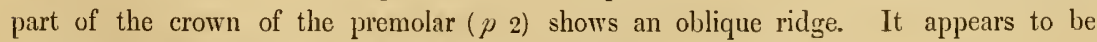
implanted by two fangs, an alveolar process rising to their interspace.

The second premolar $(p 3)$ is implanted by a large anterior and a small posterior fang. The outer side of the anterior root swells out at the base of the crown into a smooth convex protuberance. The outer alveolar wall rises in an angular form between this and the more inwardly inserted small hind root. The crown, narrow transversely, expands from before backward, and then contracts to a subconvex trenchant border. Of this the cutting power 
is cnhanced by a fine serration at the hind half, formed by four fine points of enamel, from which, ridges extend obliquely forward and downward, leaving intervening parallel narrow groovcs. The height of the crown of the second premolar is rather more than its foreand-aft breadth.

In the last premolar $(\mu 4)$ the increase of size is considerable, as in $\mathrm{Pl}$. minor. The two roots are nearly equal, the hind one exceeding. Both swell out slightly before they coalesce and expand into the crown, but the anterior protuberance is most marked. The fore-and-aft extent of this trenchant tooth exceeds its lieight. The serrate margin is moderately convex. It is formed by eight enamelled points, from each of which a ridge extends obliquely downward and forward, parallel with the course of the four in the antecedent tooth, and to the same extent down the crown; but both ridges and grooves are more strongly marked in the present premolar. The outer surface of the crown is flat, and slopes at once to the trenchant edge, unbroken save by the oblique ridges on its upper half. The hindmost of these is fecble, and runs below that from the hindmost denticle forming the posterior angle of the crowu. There is no trace of the short vertical rising noted in $p 4$ of Plagiaulax minor.

As each specimen is delineated, or outlined, of the natural size, admeasurements are not given in the text. Dividing the length, in a straight line, of the present mandibular ramus, from the apex of the incisor to the back part of the condyle, into uine parts, five of these include the dentition and four the ascending ramus belind the last molar. Of the five parts, including the dentition, a little over four fiftls are occupied by the incisor and premolars, and the rest by the two molars. The teeth occupying the fonr fifths of the dentary tract are expressly and very effectively modified for piercing and cutting: those lodged in the hind fifth of the alveolar tract we may infer, by aualogy of other specimens, to have been two small and low tubercular molars adapted for pounding.

The piercing, holding, and tearing power is limited to one large sub-erect, sub-recurved, laniariform tooth, which by position in the jaw is technically an incisor. The cutting or dividing function is allotted to three teeth, so proportioned and coadjusted as to act as one large carnassial, working by a sub-convexly curved, trenchant, and finely serrate edge, as a slicar-blade on a tooth, or aggregate of teeth, of probably like carnassial form or character in the upper jaw. 'The strengthening oblique ridges and resultant serration of the cutting edge seem well adapted to the division of the tough and dry integument of Saurians.

The position, shape, direction, and relative size of the condyle, witl the size, shape, and duration of the coronoid process, indicate the power and line or direction of work of the mandible, which by the analogy of the Thylacine (fig. 5) and Ursine Dasyure (fig. 20) I conclude to have been the work mainly of biting and cutting, with a little crushing or pounding of the divided substances before their final deglutition. The comparisons, however, with the jaws and teetlo of other mammalian species will be deferred till the descriptions of the specimens of Plagiaulax are completed. 
Plagiadlax Becklesil (?). 1 .Plate IV, figs. 12,12 A, 12 B.

The specimen (Pl. IV, fig. 12, nat. size, $12 \mathrm{~A}$, magn. 3 diam., B, grinding surface of molars, magn. 3 diam.) referred to this species ${ }^{1}$ is a fragment of the right mandibular ramus with the beginning of the fore part of the base of the coronoid process (fig. 12 $\mathrm{A}, c)$ : it includes two tubercular molars in sitû, with the inner side exposed, and the impression of the obliquely ridged trenchant crown of a premolar (ib. $p 4$ ) in relative superiority of size to the tuberculars corresponding with that indicated by the tooth in place $(p 4)$ and the molar alveoli in the precediug specimen (ib. fig. $10 \mathrm{~A}$ ). To the species represented by that specimen I should refer, without doubt, the present fragment, but that the distance from the hind margin of the last premolar to the back of the socket of the hind molar is relatively greater in the present specimen; yet not to such a degree as to forbid the reference, with some indication of doubt, of the present specimen to the Plagiaulax Becklesii. Accepting this determination, we can complete herewith the description of the mandibular dentition of that species.

The penultimate molar (fig. $12 \mathrm{~A}$ and $\mathrm{B}, \mathrm{ml}$ ) presents a low oblong crown, the foreand-aft extent exceeding by one fourth the transverse diameter. The outer half is worn lower than the inner half of the grinding surface, and the outer side of the higher inner border is worn vertically smooth to a shallow groove, traversing the working surface from before backward, and dividing the inner from the onter part of that surface.

The inner surface, swelling out above the two roots of the tooth, presents a low obtuse conical rising anteriorly, with an anterior basal low ridge. 'The posterior lalf of the inner side of the crown is lower, and presents two small risings, divided by a shallow longitudinal indent. The outer and lower worn-down side of the crown shows two or three feeble risings.

In the last molar (ib. $m$ 2) the inner half of the crown is higher than the outer one, toward which it also presents a smooth, straight, sheer, or vertically worn, surface. But it is on a lower level than $m 1$, the enamel being detached or broken away, which gives the appearance of the tooth having been worn down more nearly to the fangs than is the penultimate molar. This, however, is the result of accident. Sufticient of the inner half of the molar remains to show the vertical surface presented to the lowcr outer half; and such surface, indicative of vertical abrasion by an upper molar, would be, probably, as high as in the penultimate molar $(m \mathrm{l})$, had the enamel of the inner half of the crown been preserved in $m 2$. The outer half of the crown retaius its enamel covering; has a convex outline from before backward, with an almost flat, slightly concave, working surface. The outer and fore part of the base of the coronoid is external to the posterior two thirds of the last molar.

1 By Dr. Falconer, loc. cit., p. 279, figs. $7-10$. 
Sinall as is this fragment, some useful inferences may be drawn from it. Firstly, that the two molars in situi were small, not to say minute, in relation to the entire mandible; and occupied not much greater extent-if any - of the dental series than do the alveolar indications of such molars in the former specimen (fig. $10 \mathrm{~A}$ ). Secondly, that the line of action in which they worked upon the upper molars was more vertical than horizontal; conld hardly have been transverse, seeing the sheer wall by which the inner half of the crown rises above the onter half. The two molars are plainly of the character of the tuberculars terminating the carnassial series of flesh-feeder's, adapted for pounding and squneezing out the juice of imperfectly divided aniusal tissues; not fitted, for the rotatory griuding actions by which vegetable substances are rednced, with salivary admixture, to a pulp; but taking that share in the dividing work which the larger of the two small mandibular molars does in Thylacoleo curnifex.

Plafiaulax Becklesil, Falconer. Plate $\mathrm{IV}^{\top}$, figs. $13 a, \mathrm{~A}, 13 \mathrm{~b}$, в.

'Ihis species is, again, represented by the fore part of the right mandibular ramus with the implanted base of the broken incisor $(i)$, part of the first $\left(p^{2}\right)$, the second $(p 3)$, and the fore part of the third $\left(\begin{array}{ll}p & 4\end{array}\right)$ premolars. The inmer side of the specimen is represented in Pl. IV, fig. 13, nat. size, $13 \mathrm{~B}$, magn. three dianı, : the outer side of the specimen is represented in fig. $13 a$, nat. size, $13 \mathrm{~A}$, magn. three diam. In hoth figures the parts wanting, but preserved in the preceding specimens, are restored in ontline.

'The symphysial surface (fig. $13 \mathrm{~B}, s, r)$, extends upward and forward at an angle of $147^{\circ}$ with the lower line of the mandible $(r, a)$. It is indented behind, the part $(s)$ above the entering notch snddenly expanding. A linear groove extends from the notch forward across the symphysial surface, dividing the upper broad from the lower narrower part of the articular surface. The immer surface of the ramus is slightly swollen behind the upper part of the symplysis by the corresponding wall of the long socket of the laniariform front tooth $(i)$, and the vertical convexity of that swelling changes to a concavity as the inner surface descends to the thick rounded lower margin.

The crown of the second prenolar ( $p 3$ ) swells ont on the inner side (fig. $13 \mathrm{~A}$ ) above the roots, with a concavity or notch, which divides the swollen base into two smooth protuluerances, the anterior being the most prominent. Above this the inner surface is flat to the trenchant margin, not defining a cingulum. The flat inner surface of $p 3$ is traversed by four linear ridges extending from above downward and forward, each ridge being confinued from the summit of the low projection, the succession of which gives a fine serrate character to the trenchint border of the tooth.

'l'he lamus has been fractured across the third premolar $(p 4)$, showing the length of the implanted fang (fig. $13 \mathrm{k}$ ); the degree of ontswelling of the base of the crown both 
externally and internally, and the proportion of the transverse basal breadth to the height of the crown. In this section the tooth is spear-shaped.

Externally as well as internally the lower swollen border of the crown is notched, indicative of the division of the root, and the part in front of the notch is more prominent than the one behind; it is also lower placed. The onter side of the crown (fig. $13 \mathrm{~A}, p 4$ ) is flat from the base to the cutting edge, and no indent marks the base of the crown as a cingulum.

The small anterior premolar $\left(\begin{array}{l}p \\ p_{2}\end{array}\right)$ repeats the character of the fore part of the succeeding premolars, in the smooth enamelled tuberosity by which the crown rises from the root. The narrow crown slopes backward, and is applied like a buttress against the fore part of the next premolar.

The grooves are limited to the upper half of the outer surface of the crown of $p 3$ (fig. $13 \mathrm{~A}$ ), but descend a little lower on the inner surface (fig. 13 в). The anterior denticle of the serrate cutting edge bounds the foremost short groove; the second ridge commencing below the first denticle runs along a greater proportion of the cutting edge before terminating in the second denticle. The third ridge beginning near the fore margin of the crown extends obliquely upward and backward to the third denticle near the hind part of the cutting edge. The fourth ridge terminates in the hiud angle of that edge. The groove below the fourth ridge is completed by a fifth, parallel with the others, and terminating a little below the hinder angle of the crown.

In the third or last premolar $(p 4)$ four grooves on the upper half of the outer surface have directions nearly parallel with those of $p 3$. The foremost clenticle at the anterior angle of the crown bounds the first short groove. The four succeeding ridges all begin at or close to the anterior margin of the crown.

The accentuation of the outer surface of the fore part of the mandibular ramus is well shown in this fragment. A low ridge $(t$, fig. $13 \mathrm{~A})$, one fourth of the depth of the ramus from the alveolar margins, bounds above a shallow depression at the middle third of that surface which narrows to a point forward beneath the fore part of the first premolar $(p 2)$. Auterior to this point, or angular end of the depression, is a single well-defined circular outlet of the dental canal $(d)$.

The incisor is subcompressed. The section of the base of the exserted crown is a long ellipse with the anterior and posterior rounded ends similar in breadth; but the inner medial side is rather flatter than the outer one.

\section{Plagiaulax Becklesil (?). Plate IV, figs. 15, 15 A.}

To this species I refer, with doubt, a specimen of part of the crown of the incisor, a small part of the anterior premolar $\left(p_{2}\right)$, the penultimate $(p 3)$ and major part of the last premolar $(p 4)$ apparently of the left side, imbedded in their natural relative positions in a portion of the Purbeck shale, with the outer surface exposed (Pl. IV, fig. 15, nat. size. 15 A, magn. 3 diam.). 
The enamel of the apical half of the crown of the incisor, here preserved, shows a fine longitudinally wrinkled character. 'The section or fracture of the crown indicates its inner side to have had a shallow longitudinal groove. The basal part of the crown has left a partial impression indicating the diustema between it and the premolars not to have been so long as at first sight appears.

Part of the root of the small anterior premolar $\left(\begin{array}{l}p_{2} \\ 2\end{array}\right)$ is preserved. The penultimate premolar ( $p$ 3) shows the usual four oblique ridges on the upper part of the crown. Six ridges are discernible on the corresponding part of that of the broader last premolar $(p 4)$. The width of the interspace of the two diverging roots of this tooth, and the transverse breadth of the base of the crown, are well shown in this specimen. It has belonged to an animal quite as large as the type of Plagiaulax Bceklesii, and it most probably belongs to that species. This specimen does not appear to have ccme under the notice of Dr. Falconer.

Species 3.-Piagiaulax Falconert, Owen. Plate IV, figs. 16 and 16 a.

This species is represented by the fore part of the right mandibular ramus, with the incisor and premolars, showing their outer surface; followed by the impression of two smaller molars, and part of the ascending ramus (Pl. $1 \mathrm{~V}$, fig. 16 , nat. size, $16 \mathrm{~A}$, magn. 3 diam.). The preserved part of the jaw is rather less deep than in Plagiaulax Becklesii; the incisor is less broad in proportion to its length, especially at the base; it is also more convex on the outer side, and devoid of the longitudinal channel there (fig. $16 \mathrm{~A}, i$ ); but it is similar in length, position, curvature, and laniary character. The longitudinal ridge or prominence $(t$, fig. $16 \mathrm{~A}$ ) of the ramus (answering to $t$ in fig. $13 \mathrm{~A}$ ) is here situated half way between the alveolar ontlets of the premolars and the lower border of the ramus; it is further from that border in Pl. Becklesii (fig. $11, a, b$ ), and is less definitely marked; the longitudinal channel below is less prolonged anteriorly. A single outlet of the dental canal opens at a line dropped from the middle of the diastema between the incisor and premolars.

The first premolar ( $p$ 2, fig. $] .6 \mathrm{~A}$ ) is larger than in Pl. Becklesii; its crown developes the smooth protuberance above the fang, before flattening and expanding; at two thirds toward the apex it contracts thereto. The apex shows one short ridge dividing two grooves; it rises to the anterior angle of the crown of the succeeding premolar; the form of the crown is rhomboidal. The upper and posterior border is in contact with the anterior border of the next tooth. The upper and anterior border slopes forward and downward from the apex; the two lower borders converge, as they descend, to the basal protuberance. The height of the crown is one third more than its fore-and-aft breadth. The sniall hind root is visible at its base.

The second premolar $(p$ 3) has a subquadrate crown; but the outer enamelled surface is rhomboidal; the lorrer apex being formed by the basal protuberance. The upper and 
posterior border is applied to the next tooth $(p 4)$, the anterior angle of which is reached by the apex of the present tooth. The upper and anterior border of the rhomb forms the free trenchant part of the crown and slopes down to the angle of the antecedent tooth $(p 2)$. This border presents four dentations, from which as many ridges are continued downward and forward, but subside before they reach the middle broadest part of the crown. The beginning of the posterior root is shown. This tooth is less than its homologue in $\mathrm{Pl}$. Becklesii (fig. $11_{\mathrm{A}, p} 3$ ).

The last molar (fig. $16 \mathrm{~A}, p$ 4) presents the usual subquadrate form, with the hinder root the largest. Eight denticles arm the trenchant border, from which the ridges traverse in the usual oblique course the upper half of the crown. There is a slight protuberance above each root, the rest of the crown being flat. A minute short vertical ridge is on the fore half of the crown, below the oblique ridges; and a similar short vertical ridge may be discerned near the hind part of the penultimate molar $(p 3)$, recalling the structure seen in Plagiaulax minor; and of which there is no trace in Pl. Becklesii. An impression of the bituberculate inner wall of the crown of a small molar $\left(\begin{array}{ll}m_{1} & 1\end{array}\right)$ is visible on the matrix belind the last premolar; it is followed by the impression and also part of the inner wall of a second molar $\left(\begin{array}{ll}m & 2\end{array}\right)$. This appears to be more even in character than the first ; it is not developed into two tubercles so large and well marked; it is of the same, generically, small size. Beyond the last molar rises the impression of part of the beginning of the coronoid process $(b)$.

Dividing the dental series of this specimen from the tip of the incisor to the back part of the last molar into fifteen parts, the incisor occupies five parts, the premolars five parts, the diastema two parts, and the molars ( $m 1$ and 2 ) three parts.

If the only differences between the present specimen and the type of Plagiaulax Becklesii had been in the less robust mandible and more slender incisor, such characters might have been interpreted as sexual; but the difference of the configuration of the outer surface of the jaw, and more especially in the proportions of the premolars, point to a derivative stage which would support a distinct specific entry in Zoological Catalogues. It is instructive to discern in the differences supporting a Plagiaulax Falconeri evidence of an intermediate position between $P l$. Becklesii and Pl. minor. In size the present species, which I dedicate, as of right, to the Founder of this most singular and interesting genus, is the same or but very little inferior to the type of Pl. Becklesii.

The specimen (fig. 16) does not appear to have come under the notice of Dr. Falconer.

Plagiadlax medius, Owen. (Cut, fig. 7, p. 86, and fig. 12, p. 90, magn. 4 diam., after Falconer.)

'The subject of fig. 14, p. 2S9, of FALConeR's ‘ Original Memoir' (loc. cit.), I have failed to find after rigorous and reiterated search in the series of specimens of the Becklesian Collection transmitted to me for description. It was not in that portion including the 
subjects of all the other illustrations of his 'Memoir,' marked as ' returned' by the anthor. T'the foregoing specimen (Pl. IV, fig. 16), not described by FALConer, comes the nearest to it, and at first I suspected that it might be such original from which the ascending ramus and condyle had been accidentally broken away. But Falconer describes his specimen as "Fig. 1, Plagiaulax Becklesii. The left ramus of the lower jaw, nearly perfect, showing the outer surface, magnified 4 diameters," (loc. cit., p. $280^{1}$ ). But the subject of my Pl. IV, fig. 16, is clearly the fore part of the right ramus of the lower jaw ; it differs also in the proportion of the premolars, in the relative depth of the ramus supporting them, and more decidedly in the shape, size, and direction of the incisor.

Dr. Falconer refers the specimen, fig. 14, p. 250, of his original Memoir, tom. eit. and fig. 1, Pl. XXXIV, of the undercited work, to his Plagianlax Becklesii, and it will be observed, in the copy of that figure, in Cnt $12, \mathrm{p} .90$, that the premolar $\left(p_{2}\right)$ bears the same proportion to $p 3$ as in the type of Plagiaulax Becklesii, Pl. IV, figs. 11, 11 A.

The mandibular ramus with the incisor of Plagiaulax minor, restored according to the analogy of Plagianlax Becklesii, is, as we have seen, $7 \frac{1}{2}$ lines in length (fig. 6, p. 76). 'The original of the fig. 1.t, p. 280 , of FALconer's 'Memoir,' magn. 4 dians., must have been $\delta$ lines in length (fig. 7 ); it is nevertheless referred to Plagiaulax Becklesii (Pl. IV, figs. 10-14), which is 14 lines in length (fig. 8).

Trusting, as we may confidently do, to the accuracy of FALconer's figure, it will be seen that this differs not only, notably, in size from the type of the species to which that minute and careful Observer refers it, but in the size of the premolar teeth. The series of three in the type of Plagianlax Becklesii (fig. 8 ) has a longitudinal extent of 3 lines, but in Plagiaulax medius (fig. 7) of $2 \frac{1}{4}$ lines. 'The shorter incisor (ib., i), tapering from the exposed part of the base to the apex, might be interpreted as a stage in the derelopment and protrusion of the tooth; and this probably led Dr. FaLconer to suggest that "the specimen would seem to have belonged to a young individual of Pl. Becklesii."

FIG. $:$.

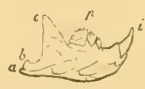

Plagiaulax medius. The subject of Falconer's Plagiaulax Becklesii, fig. 11, loc. cit., reversed and reduced to the nat. size.

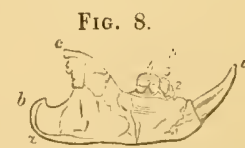

The type of Plagiaulax Becklesii, F. Nat. size.

But the crowns of the premolars are fully formed and in place, that of the anterior one

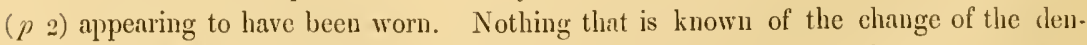
tition of the Marsupialia wonld support the inference that the premolars in fig. 7 were of the deciduous series, restined to be displaced by permanent ones of the size of those

I See also 'Palæontological Memoirs and Notes of the late Hugh Falconer, A.M., M.D., \&c.,' Sro., 1868, vol. ii, p. 417 , pl. xxxiv, fig. 1.

2 Loc. cit., p. 271 , and 'Palæontolugical Memoirs, \&c.,' 1868, voI. ii, p. 421. 
in Plagiaulax Becklesii, fig. 8. Repeated researches have failed to bring to light any other instance of a vertically replacing tooth ('dent de remplacement,' Cuv.), save that 'premolar,' by development as well as by shape, which displaces the second or the first and second of the primary or deciduous molar series in the Poephaga.'

This premolar ( $p 4$, figs. 13,14, p. 92), which assumes an antero-posteriorly extended trenchant and vertically ridged character in Hypsiprymnida, may be the homologue of $p 4$ in Plagiaulax, but the proof from developmental character is wanting. I deem it most unlikely that any of the premolars in fig. 7, p. 86 should be destined to be displaced and replaced by a vertical successor of larger size and similar character. There then remains the possibility, assuming the trenchant, serrate, ridged teeth in Plagiaulax medius to be permanent or non-deciduons primary ones, that they belonged to a female Plagianlan Becklesii, in which the incisor was not fully risen into place. The difference in the shape of the coronoid process $(c)$ may depend upon some marginal defect of that plate in the small and delicate fossil. ${ }^{2}$ The condyle $(c)$ may likewise have lost so much of its prominence as would have brought it to the vertical parallel of the angle of the jaw $(a)$, as in fig. 8 and Pl. IV, fig. 10.

If the parts as figured by Dr. FALCONER were natural, they wonld indicate, with difference of size, a difference of slape of jaw, which, as compared with that of the type Plagiaulax Becklesii, should be interpreted as specific. They undoubtedly show the same low position of the condyle, viz. depressed below the level of the molar alveoli-lower, indeed, than in the type-specimen (fig. S, p. S6). The figure also shows the wide emargination between the base of the coronoid $(c)$ and the condyle (b), like that which is seen in the mandible of Thylacinus (fig. 5, p. 74), and to which the term 'neck' or 'peduncle' of the condyle is sometimes applied.

From the seemingly more distinct and prominent angle (fig. $7, a$ ) a ridge is continued forward and upward, bounding below the external crotaphyte hollow, at a higher level than the inverted angle and lower margin of the jaw bounds the internal or pterygoid hollow in Plagiaulax Becklesii (Pl. IV, fig. 10). ${ }^{3}$

In the well-preserved 'ascending ramus' of the jaw of Plagiaulax Becklesii (Pl. IV, fig. $10,10 \mathrm{~A}$ ) there is no trace of a solution of continuity effecting a communication between the external and internal crotaphyte depressions near the entry of the dental canal, as

1 Owen's "Fossil Marsupialia from the Cares of Wellington Valley," May 8, 1838, in Mitchell's 'Three Expeditions into the Interior of Eastern Australia,' Svo, vol. ii, p. 360, pl. 30. 'Classification of the Marsupialia,' 'Proceedings of the Geological Society of London,' Jan. 8th, 1839.

2 Dr. Falconer, who describes this fossil, in a P.S. to his original paper, as "a fifth specimen of Plagiaulax" received since that paper was written, states, "The true molars, if present, are concealed by the flap formed by the anterior margin of the coronoid process. This part of the jaw has been slightly crushed."-Loc. cit. (1857), p. 271, op. cit. (1868), p. 421.

3 "The base of the coronoid is occupied by a deep depression bounded on the lower side by a raised ridge, which sweeps round from the inferior part of the condyle, to be continued into the anterior margin of the coronoid process."-Falconer, loc. cit., 1857 , p. 271 , tom. cit., 1868, p. 421. 
in the poephagons and rhizophagous Marsupials. Dr. FALConer states, "So far as can be seen" (in fig. 7) "the depression wonld seem to be more limited" than in Mypsiprymnus, where the "crotaphyte depression terminates in an excavation common to it and the dentary canal." 1

I conclude, therefore, that, in this 'fiftl specimen,' as in the type of Plagiaulax Becklesii, the ascending plate or 'ramus' is entire, as in Dasyurus and Thylacinus, with a like carnivorons character of coronoid and condyle.

\section{$\$$ XVII.-Taxonomic Deductions.}

In the non-production of an angular process of the mandible downward and backward below a condyle low-placed as in Plagiaulax, in the inflection of the part corresponding to the angular process in placental Carnivora and its continuation with a similarly inflected lower border of the 'ascending ramus,' with a corresponding outwardly produced ridge deepening and bounding below the outer crotaphyte depression, I see, with Dr. FALCONER, characters of the mandible of Plagiaulax which "are clearly marsupial." "

In this ancient extinct marsupial genus the mandibular dentition is :-

$$
i \overline{1-1}, c \overline{0-0}, p \overline{4-1}, \text { or } \overline{3-3}, m \overline{2-2},=\overline{14 \text { or } 12} \text {. }
$$

In this formula the 'premolars' are defined by 'shape.'

Now, the Marsupialia show two leading modifications of the anterior mandibular teeth: in one, several pairs of incisors intervene between the right and left canines; in the other, one pair of incisors of large size are present, and no canines. The first condition characterises the 'polyprotodont section,' the second the 'diprotodont section." ${ }^{3}$ The existing representatives of the latter group of pouched Mammals are confined to the Australasian arca. Some of the former group are American.

In both sections there are modifications of dentition, digestive organs, and limbstructures, which in an interesting degree run parallel with each ofher; the arborcal diprotodont Phalangers and Petaurists, e.g., with the Opossums and Phascogales; the saltatory Bandicoots and Choeropods with the Potoroos and Kangaroos: the gradatory carnivorous Polyprotodonts have no known existing Diprotodont correlatives. Plagiaulax belongs to the diprotodont section of Marsupialia, and the next step is to determine, so far as the mandible and mandibular dentition may support a deduction, to which of the minor groups or families of that section it shows the nearest affinity.

1 Loc. cit., p. 271 , and tom. cit., p. 421.

2 Loc. cit., p. 271 , and tom. cit., p. 421.

3 OwEN 'Anatomy of Vertebrates,' vol. iii, p. 293. 
No existing Diprotodont offers the mandibular formula of Plagiaulax. In the Phalangers a subtrenchant tooth (fig. 9, $p 4$ ), in contact with the true or tubercular molars, and with a crown reaching to the same level, is reckoned as the last or hindmost premolar, and as the homologue of the similarly developed and situated tooth in Phascolarctos and in most 'Poeplaya.' I view the last and largest of the premolars of Plagiaulax as the homologue of this tooth, and symbolise it as $p 4$.

In Phalangista Cookii (fig. 9) three small teeth intervene between the last premolar $(p 4$. $)$ and the incisor $(i)$. Two of them are held to be $p 3$ and $p$ 2-the homolognes of those so symbolised in Plagiaulax FIG. 9.

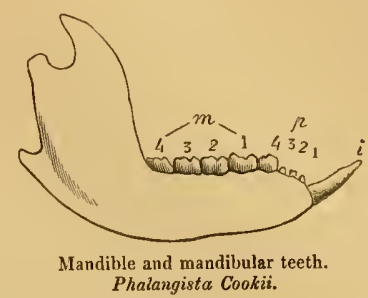
Becklesii (fig. S). With respect to the anterior small tooth, it may be questioned whether it be the homologne of $p \mathrm{1}$, in Plagiaulax minor, or the rudiment of a lower canine. At any rate, as regards number of mandibular teeth between the incisor and the true molars, it is only in the Carpophagous family of Diprotodonts that species are known corresponding with the species of Plagiaulax. In Petaurus (Belideus) flaviventer four denticles intervene between the functional premolar and the incisor. ${ }^{2}$

Some zoologists have founded subgeneric divisions, with names, on the difference in number of the small premolars, and would, on like grounds, place in distinct genera Plagiaulax Becklesii and Plagiaulax minor. A better ground for such distinction is afforded, among existing Carpopliaga, by the small volant species, Petaurus (Acrobata) pygmans, in which the true or tuberculate molars are reduced to three on each side of both jaws; whilst between these and the incisor in the lower jaw are interposed four teeth; add thereto the shape of the last premolar, which has exchanged the trenchant for the acuminate character. Mere form, however, of one or more premolars is not enongh to determine the reference to, or the removal from, such a group as Carpophaga of a species proved by more important characters to belong to that group or to one of like value in the diprotodont series.

In some Poephaga, for example, the tooth answering to $p 4$ in Plagiaulax resembles it in size and trenchant shape, being also grooved; yet the Poephaga depart further than do most Carpophaga, in having no tooth interposed between $p 4$ and the large procumbent incisor of the lower jaw.

The Hypsiprymidae or Rat-Kangaroos, with a ridged and trenchant $p 4$, have it followed by four molars with massive triturating crowns. Of these the first three have " a

1 This term, applied in 1839 to the diprotodont family including Hypsiprymnus, Macropus, and their subgenera, is preferable to the subsequently propounded one, Macropoda, of Van der Hoeven; because the latter is equally applicable in its descriptive sense to the long-legged saltatory Polyprotodonts. See Owen, Classification of the Marsupialia, in 'Transactions of the Zoological Society of London,' 4 to, vol. ii, p. 315.

2 See Art. Marsupialia, 'Cyclopædia of Anatomy,' vol. iii, 184l, p. 264, fig. 89. 
quadrate form, presenting four equidistant blunt tubercles, which are joined in pairs by transverse ridges, but with these ridges less elevated than the points of the tubercles: there

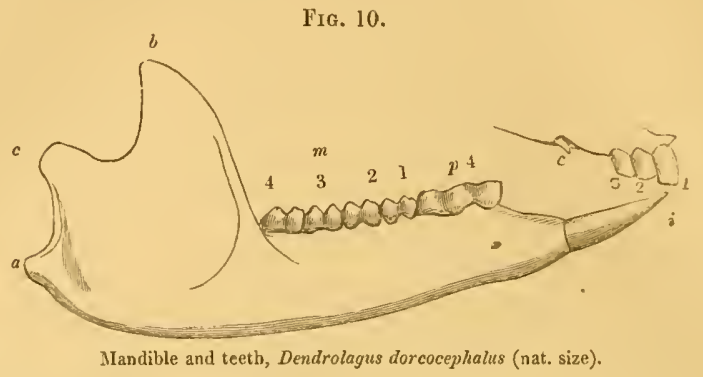

is a slight trace of the band of the tooth ("cingulum' of my "Odontography") "on the front and back part of each molar, as in Macropus. The hindermost molar is generally small, almost round." I

In those vegetable-eating Marsupials the molar teeth adapted to such diet are never fewer and commonly more in number than in the most typical placental Herbivora. In relation, apparently, with the drier and tougher vegetable fibres of Australia, the premolar is trenchant, and in the smaller Poephaga is strengthened by vertical grooves and ridges. In one of the New Guinea Tree-Kangaroos (Dendrolagus dorcocephalus, fig. 10) this trenchant tooth is proportionally larger than in the Australian Potoroos and Bettongs, but the light-giving teeth-the true molars-are conformable with the macropode type.2

FIG. 11.

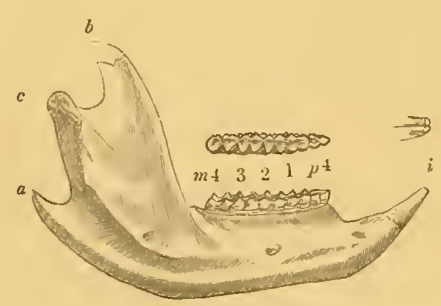

Mandible and mandibular teeth, $\frac{1}{2}$ nat. size, Phascolarctos fuscus.

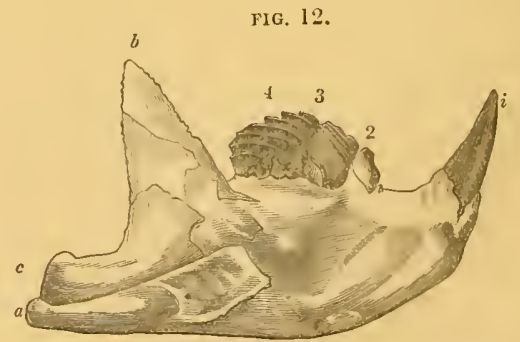

Mandible and mandibular teeth, Plagiaulax (medius, milhi) Becklesii, Falc., magn. 4 diam. (after Falconer). ${ }^{3}$ Reversed.

A greater contrast in the Diprotodont series is seen in the mandible and mandibular teeth of the Koala (Plascolarclos, fig. 11) and Plagiaulax, fig. 12.

' Waterhouse, "A Natural History of the Mammalia (Marsupialia)," 8vo, IS45, p. 194."

?lb., p. 182, pl. 10, ligs, 5,5 a.

3 'Quarterly Journal of the Geol. Soc.,' vol, xiii (1857), p. 280, fig. 1t; also 'Palæontographical Memoirs, îc.', rol. ii, p. 416 , pl. 34 , fig. 1 . 
The premolar (fig. $11, p_{4}$ ) is reduced in size, and begins to assume the triturating structure and breadth. In the true molars the four lobes have each the shape of a threesided pyramid, with the inner side of the inner pair of lobes undulated or indented in a manner recalling the ruminant type of grinders.

The lower incisors in Phascolarctos and Hypsiprynnus show, as in Rodents, an abraded surface (fig. 11, i) indicative of habitual and long continued gnawing actions. The mandible, by its lofty condyle (ib. $c$ ), its short, narrow, recurved coronoid (b), and the low relative position in which the inflected angle $(a)$ is prodnced, concurs with the herbivorous type of dentition in all Carpophaga and Poeplaga.

In IIalmaturus the mandibular incisor is procumbent; its long pointed crown is depressed, rather expanded or spatulate, with an outer trenchant edge, the inner side more or less flattened by pressure against its fellow, and the upper side showing, for some extent behind the point, the plane of attrition produced by action against the three opposing incisors of the premaxillary. Thie trenchant premolar, though relatively larger and more compressed than in Macropus, especially in such large extinct Wallabees as Halmaturus Atlas, forms but a small part, one ninth, of the dental series. It is followed by four molars with large cubical bilophodont crowns, with superadded longitudinal and transverse ridges. Each molar averages three fourtlss of the fore-and-aft extent of the trenchant premolar.

In IIypsiprymmus the long pointed incisor (fig. 14, i) is likewise procumbent, but is trihedral. 'The outer side is convex across, the inner and the npper sides are narrower and are flat, but are not divided by so sharp an angle as that which bounds the onter facet. The upper surface of the incisor shows a plane of attrition from action upon the upper incisors for one third of the extent from its apex, and the enamel is wanting on this surface. The trenchant premolar (ib. $p$ 4) has a low crown with a straight cutting subserrate edge. The outer and imer sides meet at a much less acute angle than in Plagianlax. The inner side shows five or six vertical ridges, the first and last being broad. The outer side is worn smooth in old individnals. This tooth forms one seventh of the longitudinal extent of the entire dental series. It is succeeded by four molars (ni 1-4) with large cubical massive crowns, the grinding surface of which, characterised as described by Waterhouse, ${ }^{2}$ become, by age, worn down to a flattened, more or less irregular, triturating surface, exemplifying the habitnal horizontal, rotatory, or alternate crushing action of the mandible upon the upper jaw.

There is but little variation in the rise from horizontality of the lower incisor in the known Potoroos (fig. 14) and Bettongs (fig. 13); in none is the upper contour of the exserted part of the tooth (i) raised above the parallel of the alveolar border of the lower molars.

In a skull of the Brush-tailed Bettong (Bettongia penicillata, fig. 13) now before me, the scalpriform character of abrasion of the upper surface of the pointed ends of the 
incisors extends half way toward their base. The ridges and grooved trenchant premolars FIG. 13.

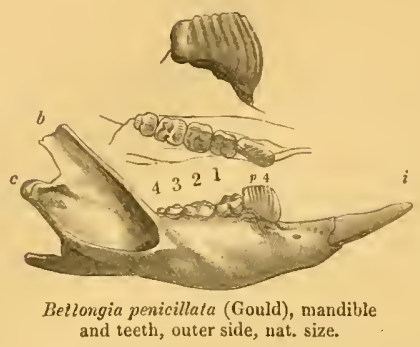

Fig. 14.

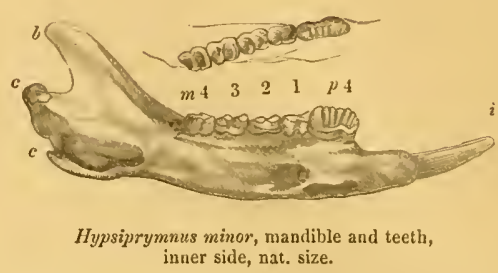

occupy rather more than one sixth of the dental series. They are followed by four molars resembling those of Hypsiprymmus, and equally adapted for vegetable diet.

"'The premolar in II. Gilbertii is but little longer than the foremost true molar, whilst in $I J$. murinus it is equal in length to the first true molar tooth added to that of the second."-W'Taterhouse, op. cit., p. 230.

In all Marsupial Pocpliaga the mandible presents corresponding modifications for the movements required in the cropping and mastication of vegetable food. The major part of the condyle is horizontal ; and extended transversely, flattened, or with a feeble convexity from before backward, which is its least diameter (Pl. IV, fig. 10, c). The condyle (figs. 13, 14, c) is raised above the level of the grinding teeth, abont equidistant from the inflected angle below (ib. $a$ ) and the summit of the coronoid process above. This process (ib. $b$ ) is relatively narrow, slort, and much inclined backward. The vertical line from its summit to the condyle is less than half the same cliameter of that part of the ramns. A wide vacuity at the fore and onter part of the 'ascending branch' receives the dentary canal from the imner surface, and is contimned forward into the substance of the horizontal ramus.

In the absence of this external vacuity or perforation, and in the presence of every character of jaw and teeth showing adaptation for animal diet, Plagiunlax (fig. 12) differs from the Potoroos (ITypsiprymnus), Kangaroos (Macropus), and every other known recent or extinct form of poephagons Marsupialia.

We should have no ground for surprise if, in the long ages since the diprotodont condition was first manifested, forms now exemplifying it had departed too far from the primitive type to be zoologically associated therewith more nearly than as Marsupials with lower incisors linited to a single pair. If we ask :-where is the living Marsupial that retains the typical number of premolars with a reduction of the true molars to two and of the incisor to one, on each side of the lower jaw ?--the answer is 'Nowhere.'

In the case of the Amphitherium or of the Spalacotherium, \&c., with the excessive number of molars, Mr. Waterhouse's discovery of Myrmecobius indicated the Marsupial 
still retaining that anomalous character of dentition which the small Mesozoic quadrupeds manifested in a land geographically now that of England.

So, with regard to the Plugiaulax with its clefective molar formula, we must also travel to the antipodean continent of Myrmecobius to find the forms most nearly allied, in dentition, to the Purbeck genus. But even there they are no longer amongst the existing Marsupials.

The incisors of Thylacoleo (fig. 15, i) in size, position, direction, and shape closely resemble those in Plagiaulax, nuch more closely than does the lower incisor of any poephagous, carpophagons, or rhizophagous species of Marsupial : the crowu is completely sheathed by enamel. But the laniary modifications are exaggerated or carried further out in Thylacoleo; the tooth is more compressed, its hinder trenchant edge is finely serrate, as in Machairodus; the crown is slightly recurved, as in Plagiaulax Becklesii and Pl. Falconeri; and the outer surface shows a very shallow and wide longitudinal depression at its basal half.

The last premolar $(p 4)$ is trenchant, and occupies two fifths of the longitudinal extent of the dental series; it is preceded by three small and early shed premolars; it is followed, as in Plagiaulax, by two small, tubercular molars ( $m 1$ and 2 ), which, together, are limited to one sixth of the dental series. The first of these, again, indicates the more strictly carnivorous character of Thylacoleo by the elevation and compression of the fore part of the crown, detracting in the same degree from its triturating power and character. The second lower molar is low,

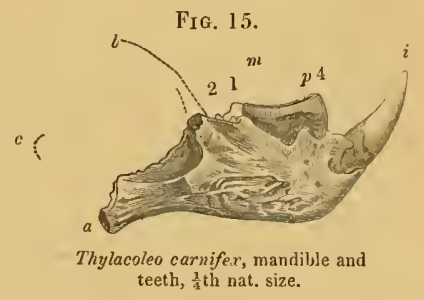
tubercular, one third the size of the first molar, implanted by one short thick root. We know that the two small teeth sncceeding the carnassial in the lower jitw were opposed to a single transversely extended tubercular molar above, in Thylacoleo.

The large carnassial premolar in Thylacoleo (fig. $15, p$ ) forms the same proportion of the dental series as do the close-set three or four trenchant premolars in Plagiaulax. The antero-posteriorly extended crown of the Thylacoleo's premolar has the enamel at the basal part of the inner surface vertically and finely undulated, one cammot say grooved or ridged. The worn margin demonstrates the trenchant or shear-blade mode of working upon the similarly shaped and developed upper carnassial. The smooth even surface slopes obliquely down the outer side of the lower and the imner side of the upper carnassial in Thylacoleo, showing the same relation of these teeth to one another transversely, as in the Lion and other Felines.

In Thylacoleo the outer wall of the mandibnlar ramus bulges ont, as in Plagiaulax, below the socket of the premolar. The outer crotaphyte depression is entire and imperforate. The dentary canal begins at a corresponding part of the inner or pterygoid depression From the continuation backward and slightly downward of the lower border 
of the onter crotaphyte depression, and from the concomitant extent of the fractured base of the coronoid process in the least mutilated mandible of Thylacoleo, which has yet reached me (fig. 15), I infer a breadth and general development of the coronoid process, and a position of the condyle corresponding, more or less, with those characteristic of Plagiaulax, Sarcophitus, and Thylacynus.

The dentition of the upper as well as of the lower jaw of Thylacoleo being ascertained, its formula gives :-

$$
i \frac{2-2}{1-1}, c \frac{1-1}{0-0}, p \frac{4-1}{3-3}, m \frac{1-1}{2-2} ;=28 .
$$

Thus, so far as the dentition of Plagiaulax is known, it more closely resembles that of Thylacoleo than of any other Marsupial.

From the characteristic rednction in size and number of the molar tecth, I have associated them as members of a 'pancidentate' family or Section of Diprotodonts.

In this section may be discerned an interesting illustration of the Law or Tendency from the General to the Particular as species approach the present time in geological position.

The extinct ponched Carnivore of the Neozoic period has the functional or carnassial premolars rednced to a single tooth on each side of the lower jaw; the extinct pouched Carnivore of the Mesozoic period retained, in one specics, three premolars of the carnassial type, in another species four-the normal number-on each side of the lower jaw.

The parallel runs very close with that which the placental Carnivora show within the limits of Tertiary time; as when, e.g., we compare the Miocene Hycnodon and its three lower carnassials with the modem Hycena, where they are reduced to one; or when we conpare the Miocene Amphyeyon with its three upper tuberculars with the modern Ursus, where they are reduced to two.

The alleged 'well-ascertained' conchusion as to the herbivorous nature of Plaginulax allowed only the contrast with the rich and well-adapted series of grinding teeth in the Poephaga and placental Herbivores to be thought of, and blinded the Objector to the suggestive instance of ancient adhesion to type ${ }^{1}$ which the carnassials of Plagiaulax, viewed as a Carnivore, force upon the attention.

Because certain saltatory vegetable-feeding Marsupials have one trenchant and vertically ridged mandibnlar premolar, occupying a small proportion of the entire molary series, it is not admissible that three or four trenchant and obliquely ridged mandibular premolars, forming a large proportion of the entire molary series, afford adequate grounds for conchuding the limbs to be 'macropodal,' and the beast to be herbivorous and a "Marsupial form of Rodent." a

A life's experience in the lahour of restoring, from fragmentary evidences, an extinct

I Falconer, 'Quarterly Journal of the Geol. Soc.,' vol. xiii, p. 2j6; also, 'Palæontographical Memoirs, Sc.,' vol. ii, pp. 421, 427.

2 Ib., ib., vol. xviii, p. 349, and 'Pal. Mem.,' vol. ii, p. 425. 
species has left me under the conviction that what has been above submitted to Palæontologists in the attempt to determine the affinities of Plagiaulax is near the truth: and that having the lower jaw and its entire dentition to work from, the Palæontologist ought to be able to indicate, approximatively, its place in the Natural System.

I should not have presumed so far if my material had been a solitary premolar; supposing even that the last and largest of the series had been the sole indication of what we now know as Plagiculax.

If it had resembled a premolar of a Rat-kangaroo as much as it differs from one; if its crushing edge had been straight and vertically notched, instead of being curved and obliquely notched, or 'serrate;' if its ridges had been vertical instead of oblique; no inference as to the number and kind of teeth with which such premolar had been associated, in the otherwise unknown Oolitic beast could be safely or scientifically drawn; still less could the Palæontologist be justified in jumping at the conclusion that the old user of this solitary evidence of its dental tools had been a saltatory herbivore! If one desired to have it believed that a Macropodal or Poephagons Marsupial had existed in Triassic or Oolitic antiquity, he might indeed substitute for scientific reasoning confidence of assertion. ${ }^{1}$

With a fossil premolar as like that of Hypsiprymnus as the last premolar of Plagiaulax is unlike,-I will not insult the common sense of Zootomists by citing the microlestian denticle (Pl. I, fig. 16) as a parallel case,-the competent Palæontologist viewing such premolar would call to mind instances where similar premolars are associated, in the Mammalian class, with very different molars, canines, and incisors. A premolar does a part, but not the whole, nor commonly the main work, of the preparation of the food for deglutition and digestion, \&c. A premolar may show, as in Hypsiprymnus and Plagiaulax, an admirably fitting instrument for dividing by cutting or by sawing. But such a fossil instrument cammot, by itself, teach the nature of the substances to the division of which it was applied by the living animal ; still less cal it justify a conclusion as to the kind of locomotion with which the beast carried itself to its food or prey.

The great master and founder of Palæontology las been held by some to have hazarded over much in estimating the amount of inference that could be drawn from a solitary fossil tooth. But this at least all subsequent experience has confirmed, that he selected the class of teeth which best justifies his axiom. I proceed, next, to consider the physiological deductions which may be drawn from our knowledge of these light-giving elements in the dentition of Plagiaulax.

1 Thus, Mr. Boyd Dawkins affirms:- "The presence of the Macropoda (Van der H. = Poëphaga, Orwen) is proved by the discovery of the Kangaroo-rat allies : namely, in the Purbeck beds, of the Plagiaulax, the true affinities of which have been so amply demonstrated by Dr. Falconer ('Quart. Journ. Geol. Soc., vol. xiii, p. 261 ; vol. xviii, p. 348); in the Rhætic bone-ked, of the Microlestes of Frome and Diegerloch, closely allied, according to Professor Owen, to Plagiaulax ('Palæont.,' p. 303); and, lastly, in the strata below the bone-bed, by the discovery of the Hypsiprymnopsis Rhaticus of the Watchet shore." "Quarterly Journal of the Geological Society of London,' vol. xx (1864), p. 412. 


\section{$\S$ XVIII. Phrsiological Deductions.}

From the shape of a tooth may be inferred its work; a pointed one to pierce, a trenchant one to cut, a hroad kuobled or ridged crown to bruise. But the kind of substances to be pierced, cut, or ground demands other considerations than that of mere shape to determine. The chief of these is the kind of teeth with which the piercers, the cutters, or the pounders may be respectively associated, more especially the first two. If the Palæontologist has no other part of the skeleton than a jaw with teeth to work from, the guiding principle of correlation is correspondingly limited in its applicability. Cuvier's choice of tooth or class of teeth as heing of highest correlative valne, or as throwing most light on the food and habits of an mknown and extinct Mammal, still commends itself to my experience as the best.

Guided by his rule, my first attention was paid to the molar teeth of Plagiaulax. These are too few, too small, and occupy too short a space in the dental series to perforn the effective kind and amount of mastication required for the preparatory act of digestion of vegetable substances.

Known only as they exist in the lower jaw, the analogy of Thylacoleo teaches that they would not be in greater, were more likely to be in less number, in the upper jaw ; accordingly, the inference of their functional relations to food may be legitimately drawn.

Every known instance of a like condition of tubercular molars points to the modifications of the rest of the dental series for predatory life and animal diet. And this, as regards the mandibular dentition of Plagiaulax, we have seen to be the case in every species and variety.

A pair of teeth, placed favorably at the fore part of the jaw, manifest the length, strength, sub-compressed, sub-recurved, pointed form of the laniaries of the Carnivore, and suggest the application to seizing, piercing, lacerating, slaying. The major part of the alveolar tract is occupied by teeth of the trenchant carnassial or shear-blade type.

There are few instances in which the sagacity of Cuvier in directing primary attention to the 'dents molaires' is better exemplified than by the small extinct Mlesozoic Marsupial under consideration.

The Musk-deer has a pair of canines almost as formidable for lethal purposes as the upper ones of Machairodus. The Gorilla has canines in shape and proportion like those of the ordinary large Carnivora; the Baboon adds to them the secondary feline characters of longitudinal grooves and the trenchant ridge; but the tyro taking these teeth only for his guide or basis of plysiological reasoning would be led astray.

The light-giving teeth in each case, by their massive cubical crowns, complex configuration and structures, number, and large proportion contributed by them to the

1 "La première chose à faire dans l'étude d'un animal fossile est de reconnoître la forme de ces dents molaires ; on determine par la s'il est carnivore ou herbivore."-Cuvier, 'Recherches sur les Ossenens fossiles,' 4to (1822), tom. iii, p. 1. 
dental series, bespeak plainly the secondary or subsidiary function of the associated long and large laniaries, as weapons, viz. of defonce or of sexual combat.

The true molars tell a similar story in every species of carpophagons and poephagous Marsupial. Detached lower incisors of the Kangaroos are long, pointed, and sharp-edged; in the Bettongs and Potoroos their tapering ends begin to manifest scalpriform modifications.

The procumbent, in many Kangaroos almost horizontal, position of these teeth warns against the conclusion that they were made to pierce as weapons, offensive or defensive: closely looked to and compared with true laniaries, such as those in Potamogale (figs. 16, 24) Thylacoleo (figs. 15, 18), and Plagiaulax (fig. 12), characters of shape and structure, besides those of direction or position, are discerned in the incisors of Pocphagans (figs. 10, 13,14 ) which relate to other ends than stabbing and tearing; to uses which require opposing teeth of a different character and in greater number than in pancidentate Marsupials.

The premolars of Plagiaulax are plainly made to cut; the strengthening of the blade by enamel-ridges, and the serration of the cutting edge, due to their oblique course, suggest an occasional application to tougher tissues than merely muscular. In the trenchant and vertically grooved premolars of Potoroos and Bettongs the margin is notched, but it has not the true serrate character which the oblique and unequally bordered dentations give to the cutting edge of the camassials of Plagiaulax. The three or fonr such premolars in this gents combine their oblique serrate margins into a curved line like that of part of a circular saw; the notched edge of the single premolar in Hypsiprymnus is straight.

The many and large molar teeth and procumbent sub-scalpriform incisors associated with the trenchant premolars of Potoroos and Bettongs, show the kind of substances these were destined to cut. We know it to be tough, dry vegetable substances, such as the coarse grasses of the Xanthorrhaea, the tegument of the Cycadeous Macrozamia, rootfibres, \&c.

The few and snall molar teeth and suberect laniariform incisors associated with the serrate premolars of Plagiaulax show that they operated upon animal tissues; the evidence of the many and varied kinds of small Saurians coexisting with Plagiaulax significantly indicate the tough integument which such modified carnassials would be well fashioned to divide.

Trenchant premolars need not the ridged and serrate structure "for chopping up fruits or succulent vegetables ;" 1 the very perfection and strength given to the carnassials of the little saurivore indicate the nature of the nutritive substances they operated on, and the needlessness of supplemental pounding or masticating teeth in greater number or of greater size than Plagiaulax possessed. Roots and grass "chopped up" by the premolars of

"Flower, Prof. Wm. Henry, F.R.S., "On the Affinities and probable Habits of the Extinct Australian Marsupial, Thylacoleo carnifex, OwEN," in 'Quarterly Journal of the Geological Society of London,' vol. xxiv (1868), p. 318. 
Rat-kangaroos would hardly, in that state of division, be fit for swallowing; accordingly we find a provision of not less than sixteen square and broad-cromed, ridged, and tuberculate grinders, superadded to the trenchant teeth, in order to pound up the chopped roots and grass, and to well blend those dry vegetable cuttings with abundant salivary secretion, in order to prepare a bolus fit for deglutition and subsequent digestion.

\section{§ MIX. Objections to the Carnivority of Plagiaulax examined.}

The procumbent pair of lower incisors in Pocplaga oppose the upper surface, not the end of the tootl, to three pairs of upper ineisors, of which the foremost is longest. By the analogy of Thylacoleo the suberect pointed pair of lower incisors in Plagiaulax would be crossed by a correspondingly developed and deflected pair of laniariform incisors ; and, if these were followed by others in the premaxillary hones, they wonld probably be rudimental and limited, as in Thylacoleo, to a single pair.

The functional incisors in both jaws would act as in Tliylacoleo, the lower ones like a pair of bayonets, cemented side by sicle, with the muscular forces of

F1G. 16. hoth mandibular rami concentrated on the thrust. A like advantage

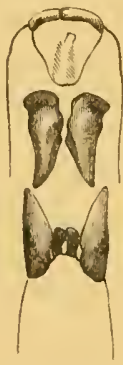

Front view of upper and lower incisive laniaries, Potamogale velo $x$; twice nat. size. ${ }^{3}$ in lethal stabling power is gained by the same "collateral arrangement in the axis "1 of the perforating stroke, in many of the Ferines ("Carnassiers") of the Cuvierian system. It is interesting to note, however, that these instances occur in the orders ('Inscctivores, Marsupiaux') which I have proposed to place, through cerebral characters, on lower steps in the Mammalian series; the lissencephalous and lyencephalous couditions of brain seeming to me of greater taxonomic value than the "possession of elaws and of three kinds of teeth." 2 With lower intelligence the power of the killing teeth is heightened; and a like relation is not unfrequently exemplified.

Observation of the luabits and actions of the lissencephalous Otter (Potamogale, Du Chaillu), with approximate or "collateral" laniaries (fig. 16), shows them to be as efficient, to say the least, in the capture and slanghter of its prey, as are the divaricate laniaries in the gyrencephalous Otter (Lutra). The Hedgelog

1 Falconer, "On the disputed Affinity of the Mammalian Genus Plagiaulax from the Purbeck Beds," in 'Quarterly Journal of the Geological Society,' vol, xriii (1862), p. 352 ; also, "Palæontological Memoirs," vol. ii, p. 435.

2 "Les Carnassiers forment une rúunion considérable et variée de quadrupèdes onguiculés, qui possèdent les trois sortes de dents." Cuvier, 'Regne Animal,' tom. i, ed. 1829, p. 110. But see, Owex, "On the Characters, Principles of Division, and Primary Groups of the Class MFammalia," in 'Proceedings of the Linnean Society,' Feb., 1857 ; also, "Anatomy of Vertebrates," 8vo, vol. ii, p. 296.

3 I am indebted for the drawing from which ent fig. 16 was Iaken to Prof. Allyan, F.R.S., of the University of Edinburgh, where the unique skeleton of that rare genus is preserved. 
(Erinaceus) adds yommg Rabbits to its miscellaneous and lower animal diet, and kills them as effectually by its approximate laniaries as does the Stont by its divaricate ones. Breeders of poultry will hardly be prepared to endorse the epithet " mild " applied by Prof. Flower to "the ferncity and destructive power" of the Rat as compared with the Ferret $;^{1}$ if the application of their respective lethal weapons upon clefenceless birds be the subject for consideration. No doubt, in combat, the Terrier or the Ferret gets the better of the carnivorous rodent. We may admit that Triconodon mordax, the contemporary of the Plagiaulax minor, might have overcome and devoured that little predatory Diprotodont; but this would afford no ground for denying the power of the latter to pierce and slay, by means of its approximate laniaries, the comparatively defenceless Saurilli, Macellodi, Nuthetes, ${ }^{2}$ and other diminutive lacertines.

In the Insectivora, as in the Marsupialia, there are two local conditions of the teeth which are adapted "to pierce, retain, and kill." In some, c.g. Gymmura, Dasyurus, the laniaries answer, in position, to the canines of gyrencephalous Carnivora, and 'are held well apart through the interposition of a line of incisors:' in others, e.g. Potamogale (fig. 16), Solenodon, Erinaccus, Scalops, Urotrichus (fig. 17), Plagiaulax, Thylacoleo (fig. 18), the laniaries are approximate, or are separated at their base by only a single pair of minute incisors (fig. 16).

FIG. 17.

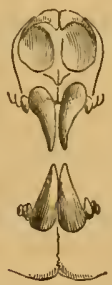

Front view of upper and lower laniaries, Urotrichus talpoïdcs, magn.
FIG. 18 .

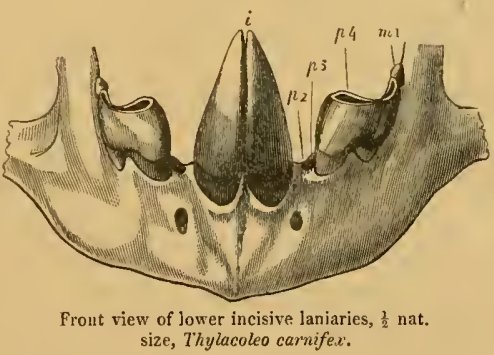

The transference of the laniary form and function from the canines to the incisors, the development of the latter locally characterised teeth into lethal weapons, is the rule in the lissencephalous member's of Cuvier's 'Carnassiers.' Whether, however, the laniaries, which "are kept well apart" in Moschus, as in Felis, or which are approximate in Plagiaulax as in the many predaceous species above cited, be really used to pierce, hold, and kill other animals for food, cannot be determined in an extinct species "by a facile observation of mere form," ${ }^{3}$ but by the laws of physiological correlation. Referning to the molars of

1 'Quarterly Journal of the Geological Society,' vol. xxiv (1868), p. 318.

2 Owen, 'Quarterly Journal of the Geological Society,' vol. x (1854), p. 420.

s Falconer, 'Quarterly Journal,' \&c., p. 358, 'Palæontological Memoirs,' p. 441. 
Moschus, we should be justified, if we knew that animal solely by its petrified jaws and dentition, in concluding that its canines, notwithstanding thcir formidable development and their position as "held well apart," with "the points of penetration doubled, the dilacerating and killing powers multiplied," "were, nevertheless, not used for predaceous ends, but merely as weapons of sexual combat and defencc. Similarly, a reference to the molars of Plagiaulax and Thylacoleo teaches that the approximate laniaries, "placed collaterally in the axis of the jaws, one on each side, above and below," were related to carnivorous habits.

As beautiful as they are true are the laws of correlation rightly discerned. With the carnivorons type of dentition of Plagianlax are associated the characters of the carnivorous type of mandible (fig. 12). With the herbivorous teeth of Hypsiprymmus go the high-placed condyle, the small sloping coronoid, and the extension of jaw below the condyle for adequate implantation of the pterygoid muscles chiefly concerned in the working of molars framed for grinding vegetable substances (figs. 13 and 14).

In my memoir on the Aye-aye I had to note that the mandibular condyle was "sessile,

FIG. 19.

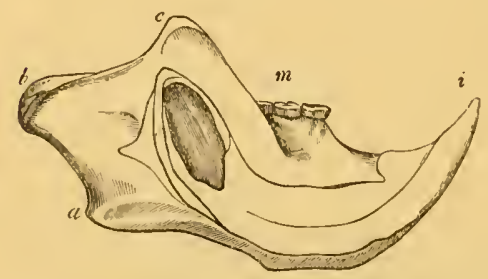

Cheiromys: mandible and teeth, the incisor exposed: nat. narrow, rather long, convex both across and lengthwise, and placed on the level of the grinding teeth," and I remarked that " the sessile condyle contrasts strongly with the pedunculate one, especially in the small extinct ferines (Plagiaulax and Triconodon) of the Purbeck beds, a concomitant difference being slown in the dentition; trenchant teeth, grooved as in the lower camassials of Thylacoleo, take the place of the flat-crowned molars of Cheiromys."

Prior to this discovery no such low position of the mandibular condyle was known, "in any herbivorous or mixed-feeding Mammal," supposing the Aye-aye to be such.

DE BLAinvilLe had stated that the condyle was " nearly at the posterior extremity of the entire jaw," "and he might have affirmed it to be quite there; but of its relative position to the alveolar series neither the text gave information, nor did the figure of the skull with the co-articulated mandible permit of a certain conclusion on that point. Dr. Falconer reproducing the same view of the detached mandibular ranus of Cheiromys which I had given in pl. 20, figs. 7, 8, of my memoir (see fig. 19), omits any notice of that figure. He cites only the work which I published the year before I received the unique

' Falconer, ‘Quarterly Journal,' \&c., p. 352, ‘Patrontological Memoirs,' p. 435.

2 Ib., ib., p. 352; jb., p. 435.

3 'Transactions of the Zoological Society of Loudon,' vol. v, pt, 2, 4to, 1863 (read January 14 and 28, 1862), pp. 50, 81 .

4 "Preãque à l'extremité postérieure de toute la mâchoire," 'Ostéographie, Mémoire sur l'Aye-aye,' p. 19. 
specimen of Aye-aye, and then turns upon me the weapon with which I had furnished him." "The author of "Palæontology' states that it is a "character unknown among any herbivorous or mixed-feeding animal." "I again refer my reader," pursues Dr. FaLconer, "to the figure (fig. 20) of the lower jaw of the Aye-aye. In it the articular surface of the condyle, although directed subvertically, or at the most diagonally, is wholly below the grinding plane of the molars. It looks still more depressed in Plagiaulax Becklesii; but this is, in part, owing to the inflected margin of the angle being broken off in the fossil, while it is entire and salient in the recent form, thus elevating the condyle above the lower plane of the ramns, and leading to an appearance of a greater amount of difference than exists in nature." 2

I will presently refer to the grounds assigned for concluding Cheiromys to be a herbivorous or mixed-feeding genus; and, referring to the description of the mandible in Plagianlax Becklesii (p. 77) for the evidence of non-extension of the angle beyond the lower end of the condyle in that species, I will now offer a few remarks bearing upon the relative value of the molar teeth, and the position of the condyle of the mandible in the interpretation of the habits and food of an extinct Nammal.

Position of condyle relates to the force with which the mandible is worked, shape and pedunculation of the condyle to the direction of the working force.

The flattened or less convex articular surface favonrs the rotatory movements; the more convex, especially transversely extended, and pedunculate or subpedunculate condyle indicates the ginglymoid articulation with greater extent of divarication or wider gape, and more habitual movements in one plane, or limited more or less thereto. The rotatory grinding movements of the mandible are commonly associated with a high position of the condyle and vegetable diet; the vertical biting movements are commonly associated with a low position of the condyle and animal diet. But the advantage of a long lever afforded by a lofty coronoid process and low-placed condyle may co-relate with powerful biting and gnawing actions, as in the working of the maximised scalpriform teeth of Cheiromys.

These instruments are wielded by the porverful and favorably formed jaw with a force which enables the Aye-aye to rapidly erode or gouge away the hardest timber. To infer it to be a vegetable-feeder from the scalpriform teeth, and the associated low condyle, and other mandibular modifications, is to assume the ligueous fibre to be gnawed by the animal for food. But, were the species extinct, the molar teeth would teach that this could not be; few, small, flat-crowned, or tuberculate, they plainly point to operations on nutritive substances from the animal kingdom.

A captive Aye-aye, it is true, endured a regimen of rice for two months before it died. And this fact is cited to prove it to be a herbivore ! ${ }^{3}$

1 'Nemoir on Aye-aye,' op. cit., pl. xx, figs. 7,9; 'Palæontological Hemoirs,' vol. ii, pl. 34, fig. 13.

2 'Quarterly Journal of the Geol. Soc.,' vol. xviii (1862), p. 361 ; also, 'Palreontological Memoirs and Noter,' 8 vo, 1860, vol. ii, pp. $445,446$.

3 "One of the live specimens procured by Sonnerat lived in captivity two months fed on boiled rice. 
But were the maximised chisel-teetl, with a low-placed mandibular condyle and hiting power of jaw, needed to divide the stems of rice or the stalks of dates or of bananas?

Sonnerat, besides specifying the compulsory food on which his captive Aye-aye perished, describes the long, slender, naked, middle digit, and states: "Il s'en sert pour tirer des trous des arbres les vers qui sont sa nomriture." 1 I muderstand this to mean that larre ('vers') are its natmral or staple food. 'T'he affirmation may have been made from Sonverat's observations on Cheiromys in a state of nature, or on the reports of natives of Madagascar, or on both anthorities.

Dr. Sandwiru adds to his account of the substances on which he fed his Aye-aye a detailed statement of observations of its power of detecting, exposing, and extracting the xylophagons larva, which it eagerly devoured, confirmatory in an important and instructive degree of Sonnerat's statement of its food in a state of nature : ${ }^{1} n$ or is other testimony to the same fact wanting..$^{2}$ And to the acquisition of sucl animal food the dental and mandibular nachinery of Cheiromys are as perfectly adapted as was the same machinery in Plagianlax to the different kinds of animal food which that extinct Marsupial captured and fed upon.

The large front teeth in Cheiromys are curved in segments of circles (fig. 19, $i$ ), the depth of the tooth exceeding the breadth; the working surface is elongated, in breadth equalling that of the base of the tooth, with a front convex enamelled horder, forming the apex of the gouging tool.

With what molars are these scalpriform teeth associated? Few, small, tubercular (fig. $19, m$ ): fitted for squeezing the soft animal nutriment ont of the tegmmentary covering of a caterpillar; not adapted for trituratory mastication of sucl vegetable food as calls for the more complex and unassive molars of the Kangaroos, Potoroos, and Koalas, or of the xylophagous Voles and Beavers.

In another part of the polemical paper advocating the macropodal affinities of Plagiaulax, the angular process of the jaw as a salient apophysis is stated to be wanting in that genus, and an argument for its herbivority is based upon the assertion that "this process is a very constant character of the carnivorous jaw," and that "it is well developed in the minute insectivorous Nyrmecobius."

To this I reply, that the angular process is not present in Stenorlynclus and somc The species of Iypsiprymnus are strictly vegetable-feeders." Falconen, 'Quarterly Journal of the Geological Society,' vol. xviii (1862), p. 364; 'Palæontological Memoirs,' 8vo, 1s68, vol. ii, p. 449 . “Dr. SANDwrт fed his captive Aye-aye upon bananas and dales." Ib., ib., p. 450. By parity of reasoning the Kite (Home, "Lectures on Comp. Anat.," 4to, vol. i, p. 271) and Sea-gull (Owen, "Physiol. Catalogue of Mus. Coll. Surgeons," 2nd ed., 8vo, p. 151) might be cited as herbivorous. This and the passage on the rice-feeding were read to the Zool. Soc., Jan. 1.4th, 1862.

1 "Voyage aux Indes Orientales," Sc., Paris, 4to, 1782, and Ed. 8vo, 1806, vol. iv, p. 122.

2 Owen, "On the Aye-aye," 4to, 1S63, p. 25.

3 Fa Lconer, 'Quart. Journ. Geol. Soc.,' vol, xviii, p. 363 ; 'Palicont. Memoirs,' p. 448. 
other Seals; nor is it peculiar to the mandible of Carnivora even "as a salient process ;" and, furthermore, as such, it is not wanting in Plagiaulax; only, it is directed inward immediately below the condyle in that Marsupial, not, as in MIyrmecobius from a part of the jaw continued downward below the condyle.

The differences which the Marsupialia present in the position, form, and degree of inflection of the angle of the jaw are noted in the works cited below. " "The condyle of the jaw is nearer the plane of the inferior margin of the ramus in the Thylacine, (fig. 5,

FIG. 20.

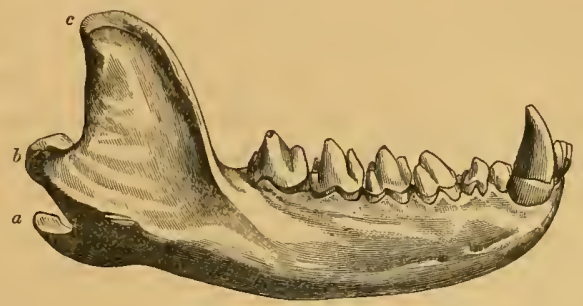

Mandible and teeth, Dasyurus ursinus.

p. 74) and Dasyure (fig. 20), than in the Opossums; and, consequently, when the inflected angle is broken off, the curve of the line continued from the condyle along the lower margin of the jaw is least; in this particular again the Phascolothere resembles the Thylacine." " The Plagiaulax repeats this characteristic of the most carnivorous members of its order, but with still less degree of curvature.

One other proposition seems of sufficient weight, in relation to the scientific standing of the Objectors to my conclusions as to the habits and affinities of Plagiaulax, to call for notice; although its very suggestion betrays a sense of the insecurity of the grounds on which the herbivorous and saltatory nature of Plagiaulax has been contended for.

'I'he species of this genus are affirmed to have been animals too small, too feeble, to have preyed upon others, especially when much larger than themselves.

Whoever has witnessed the well-kuown zoological phenomenon of the pertinaceous pursuit and fatal attack of a Hare by the diminutive Weasel would pause, however, before renturing on such ground.

Dr. FALCONER, ${ }^{3}$ selecting for his example the most diminutive of the species of Plagiaulax, remarks :- "The entire length of the specimen, including the six molars and premolars, together with the procumbent incisor (according to the metrical line $e$ ), does not exceed 4 of an inch, of which the six cheek-teeth united make only about two and

1 'Geological Transactions,' 2nd series, vol. vi, p. 50; 'Zoological Transactions,' vol. ii, p. 392 ; 'Cyclopædia of Anatomy,' Art. MIarsupialia, vol. iii, p. 275.

2 'Hist. of British Fossil Mammals,' Svo, 1940, p. 65.

3 Falconer, opera cit., pp. 363 and 448. 
a half lines $(-25 \mathrm{inch})$. I ask any zoologist or comparative anatomist to look at it, and say whether the dental apparatus of this extremely minute creature is competent to perform the duties required of a predaceons carnivore.

"Magnitnde in this case is an important ingredient, as it necessarily involves measure of force. Could P. minor have preyed on small Mammals and Lizards? Is it not more probable that this pigmy form was itself an object of prey in the Purbeck Fauna?"1

To this I reply that the original, now before me, of "fig. 15, Plagiaulax minor, of the 'Quarterly Journal of the Geological Society of London' for August, 1857 (vol. xiii, p. 281),", reproduced in the subsequent polemical paper of Dr. FALConer, in 'Quarterly Journal,' \&c., for June, 1862 (vol. xviii, p. 367), and copied in pl. 34, fig. 2, of the Posthumous Work 'Palæontological Memoirs' (p. 416), shows two molars and four premolars; the incisor is neither chisel-shaped nor procumbent; but rises with a slight curve to its FIG. 21. pointed apex at an angle of $120^{\circ}$ with the line of the molar alveoli (fig. 21). Nonery length of the dental series from the apex of the laniariform incisor to Mandible and teeth, the hind part of the second molar is seven sixtcenths of an inch, precisely the nat. size, Plagiau- length of the dental series in Urotriclus talpoïdes - a transitional Shrew five
lar minor. inches long, from the snout to the tip of the tail, with a skull one inch in length, and a pair of lower pointed incisors (fig. 17) npcurved at the same angle as in $P l$. minor, but relatively less and shorter (fig. 22, A).

I am not cognizant of any grounds afforded by Zoology which forbid the supposition that a Mammal of five inches in length, with the carnivorous type of dentition of Plagiaulax, may have been able to capture and kill the diminutive species of Lizard (Saurillus, ${ }^{2}$ \&c.) abundantly associated with Plagiaulax in the Purbeck shales. Comparative anatomy suggests that the modifications of the dentition of Plagiaulax minor, as compared with the similarly sized Shrew (Urotrichus), would give the Purbeck Marsupial both the disposition and power to attack and prey upon animals of a larger size and higher organization than worms and insects. But the question of the carnivority of the genus Plagianlax, if weighed by 'magnitude as a measure of force,' is not fully or fairly tested by the exclusive example of the most diminutive species.

In Plagiaulax Falconcri (Pl. IV, fig. 16) the extent of the dental series, lower jaw, is nine sixteenths of an inch : in Plagiaulax Becklesii (ib., figs. 10,11, 12, and fig. 8, p. 86), it is ten sixteenths of an incli.

The entire length of the mandible in this species, inclusive of the incisor, in a straight line, is one inch three sixteenths; the depth of the ramus at the back part of the large carnassial is five sixteenths of an inch.

In the Weasel (Mustela vulgaris, fig. 22, c) the extent of the dental series, lower jaw, is eight sixteenths of an inch; the entire length of the mandible, inclusive of the

' FALCONER, op. cit. lb., p. 363 ; ib., p. 448.

2 OWen, 'Quarterly Journal of the Geological Society,' No. 40, 1854, p. 420. 
incisors, in a straight line, is thirteen sixteenths of an inch; the deptl of the ramus at the back part of the large carnassial is two sixteenths of an inch.

In the Opossum, Didelplyys dorsigera (fig. 22, B), the extent of the mandibular dentition is ten sixteenths of an incl.

With the greater relative depth and consequent strength of the jaw of Plagiaulax (fig. 23), a greater size and strength of both laniary $(i)$ and carnassial teeth $(p)$ are concomitant. The condyle $(b)$, which is on the level of the dental series in the Weasel, and above it in the Opossum, is below that level in Plagiaulax. Every modification of the snall Marsupial by which it departs from the little bloodthirsty placental is in the direction of greater carnivority.

In Plascogale penicillata the extent of the dental series, lower jaw, is fourteen sixteenths of an inch. It has four true molar teeth, relatively smaller laniaries, and still smaller sectorial premolars; the mandibular condyle is raised a little above the dental line; the carnivorous adaptation of both jaw and teeth is less marked than in the Purbeck Marsupial. But what is the testimony in regard to the habits of the existing ponched carnivore no bigger than a rat?

GouLd, who would be the last to repeat testimony to which zoology and comparative anatomy ran counter, writes :-_-“ Plascogale penicillata, small as it is comparatively, is charged with killing fowls and other birds." I I can bear personal testimony, and that to my own loss, of the attack and slaugliter of nearly full-grown Shang-hai pullets by Nus decumanus. Comparative anatomy lends more aid to the credibility of the predatorial power of the carnivorous Marsupial than of the equally small Rodent; but that both of them do attack and destroy animals more than twice their own size and weight is a zoological fact.

Though magnitude may be, in one sense, a measure of

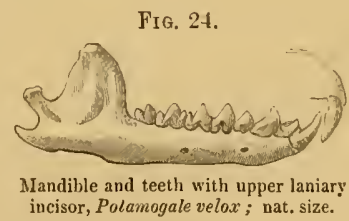
force, it by no means necessarily involves, or teaches, the application of such force, and consequently is anything but 'an important ingredient' in the question of the carnivority of Mus, Mustela, Phascogale, and Plagiaulax.

But whatever bears on the interpretation of the singular dentition of the suall 'paucidentate' Marsupial logically applies to the larger. one. There I admit the superiority of Mr. Kreffr, Prof. Flower and Mr. Boyd Dawkins, over Dr. Falconer, at least in consistency.

Mr. Krefrr gives clrawings of sections of the " lower incisor of Thylacoleo, Nototherium, I 'Mammals of Australia,' folio, Introduction, p. 18. 
Diprotodon, Thylacinus, and Sarcoplitus;" also of the "upper incisor and lower incisor of Felis tigris;" showing the relative size of the teeth in these animals, and, he asserts, "proving sufficiently that the Thylacoleo was far inferior in strength to a modern Tiger, and no match for ponderous Diprotodons and Nototheriums." 1

If the carnassial tooth were selected instead of an incisor, it would show, on the above basis, that Thylacoleo was "far superior in strength and carnivority to the modern tigers and lions." But I wonld submit that the relative size of a single tooth, if even the objector were able to recognise the homologous one in other Mammals, is not a decisive or sufficient test in the present question. It is evident that Mr. 'Kreff's figures 7 and 8 are sections of the canine, not the incisor, of the Tiger. But if the canine of the Hippopotamus were exemplified by a similar section, it would be no element, or a very deceptive one, in conchuding as to the strength or carnivority of Behemoth. The canines of Moschus and other like instances will at once suggest themselves to the competent comparative anatomist. ${ }^{2}$

To the vague and rhetorical assertion of the 'gigantic Nototheres, \&c., being "many times as large as the Thylacoleo;" I will oppose a few inatters of fact and mensuration. The length of the skull of the largest species of Nototherium (N. Mitchelli) is one foot six inches: ${ }^{3}$ the length of the skull of Thylacoleo carnifex is nine inches eight lines; were the occipital ridge and spine entire in the specimen measured, it might be set down at ten inches. It will be within the bounds of accuracy to say that the Notothere was twice as large as the Thylacoleo. The skull of the Diprotodon is three feet in length : it is, however, large in proportion to the trunk and limbs: bulk for bulk, it was probably not much, if at all, larger in comparison with the Thylacoleo, than is the Giraffe in proportion to its destroyer the Lion. 'T'he disproportion between the Wolverene (Gulo luscus) and its prey, the Reindeer, must be greater than that which the dimensions of the known fossils of Thylacoleo and Diprotodon suggest. The length of a Lion's skull before me is one foot; that of the skull of a South African Giraffe is two feet two inches.

If we next compare, not a single tonth, merely, but the whole lethal dental weapons of Thylacoleo and Felis tigris, we get the following results. The length from the fore part of the laniary to the lind part of the carnassial, upper jaw, is in Thylacoleo four inches two lines; in Felis tigris, three inches seven lines; in Fclis spelar, four inches; in the lower jaw the same measurement in Thylacoleo carnifex gives four inches threc lines.

1 "On the Dentition of Thylacoleo carnifex" $\left(\mathrm{OW}_{\mathrm{w}}\right)$ : in the "Annals and Magazine of Natural History,' 3rd series, vol, xviii, 1866, p. 148 .

2 Prof. Flower, F.R.S., however, lends his sanction to Mr. KrefFT's objection, and rejects the hypothesis "that Thylacoleo was the destroyer of the gigantic herbivorous Narsupials (many times as large as itself) with which its remains are found associated, the Diprotodons and the Nototheres." "Quarterly Journal of the Geological Sociely,' vol. xxiv (1868), p. 31 .

3 Owex, "On some Outhine Drawiugs and Photographs of the Skull of Nototherium," 'Quarterly Journal of the Geological Society of London,' vol. xv, p. 173, pl. vii (1S5S). 
The proportions are reversed in Felines; but the difference affords no reasonable ground for infering such inferiority of strength or destructive power as to support the inference that 7rylacoleo was incapable of playing the same part in relation to Nototheres and Diprotodons as the Lion now performs in relation to Buffaloes and Giraffes.

The remains of the large extinct Herbivora of the Pleistocene period in Britain, which have been found in the limestone caves of Weston-super-Mare, Torquay, Pickering, \&c., are held to have been, in most cases, parts of animals which have fallen a prey to the contemporary Carnivora now also extinct.

The caves of the limestone district of Wellington Valley, Australia, reveal phenomena of extinct animal life closely analogons. I infer that the fossils, always more fragmentary than those from the tranquil fresh-water deposits, of the Diprotodons, Nototheres, large Kangarons and Wombats, surpassing in size any cxisting species, were remains of animals which had fallen a prey to contemporary Carnivora. Now, no species bearing such proportion to the Diprotodon and Nototherium, as the'spelæan Lion, Bear and Hyæna, bore to the Mammoths, Rhinoceroses, primigenial Oxen, luge Deer; \&c., in Europe, has hitherto been detected in Australian bone-caves, save the Thylacoleo carnifex. To its associated carnivorous cave-fossils, the Thylacine, or the Dasyure (Sarcoplitus), the oljection of defective strength and bulk might be specious; but, as applied to the Thalaculeo, it is simply absurd.

A comparison of fig. 15 , p. 93 , with fig. 12, p. 90, will show, lyy the obvious similarity of their subjects, that a refutation of the asserted herbivority of Thylacoleo is associated with the grounds of the interpretation submitted, in the present Monograph, of the Plagiaulax as a marsupial Carnivore allied to the later, larger, and more specialised carnivorous I'ilylacoleo.

In the main the descriptions or definitions of the characters of the fossil remains of Plagiaulax by my antagonists and nyself are the same: the chief difference herein is, that I interpret the fractured surface of the angle of the jaw in a specimen of Plagiaulax Becklesii (Pl. IV, fig. 10, a) as indicative of that part having been bent inward immediately below the neck of the condyle as in Sarcoplitus (fig. 20, a) and Thylacinus (fig. 5, a); whilst Dr. Fatconer contends that the part broken away clescended below the condyle as in the mandible of the Aye-aye (fig. 19, a). To elucidate this discrepancy as to matter of fact, I have reproduced, in fig. 12, p. 90 , the magnified view of the mandible of Plagiculax given by FaLconer (loc. cit.), of' a specimen which I have not seen, and hold it to be confirmatory of my deductions from the specimens (Pl. IV, figs. 9 -15) which I lave carefully scrutinised.

So likewise with regard to Thylacoleo, I interpret the evidences of the fossil mandible (fig. 15) as inclicative of an agreement with Plagiaulax, and with existing Marsupial Carnivora, in the form and proportions of the coronoid process, and the indication of the low position of the condyle and its proximity to the inflected angle of the jaw. 
Messrs. Krefft (fig. 25) and Flower (fig. 26) restore the mandible of Thylacolco, in regard to thcse light-giving structures, according to the analogies of the carpophagous

Fia. 25.

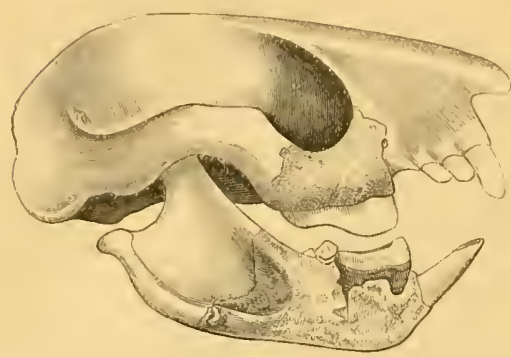

Restoration of the skull and teeth of Thylacoleo, by Mr. Krefft, on the herbivorous hypothesis ("Ann. and Mag. of Nat. Hist.,' 1866 , pl. xi).
FIG. 26.

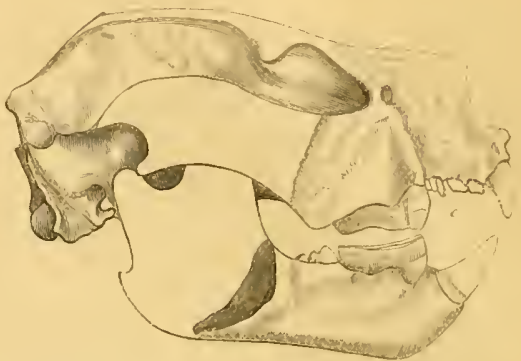

Restoration of the skull of Thylacoleo, by Professor Flower on the herbivorous hypothesis ("Quart. Journ. Geol. Soc.,' 1868, vol. xxiv, fig. 1, p. 312).

Phalangers and Koalas, and the poephagous Potoroos. But this restoration is shown by the specimen before me (fig. 15) to be erroneous. The dentition of the upper jaw restored on the same analogies is proved by the specimen figured in my last Memoir on Thylacoleo, communicated to the Royal Society, to be equally unfortunate.

The labours of Dr. Falconer are worthy of highest praise; but loyalty to our common science compels me to say that he fell into his mistake as to Plagiaulax by neglecting its fundamental principle. (See Notc, p. 96.)

Observing a general community of trenchant character, with grooves and ridges, between the premolar in certain Poephaga and one of the premolars of Plagianlax, Dr. Falconer jumped at the conclusion that the Plagianlax was an herbivorous or 'Rodent' Marsupial like the Kangaroo-rat (IIypsiprymnus).

The one-and-twenty pages of the 'Quarterly Journal of the Geological Society,' and the forty-three pages of the postliumous volume of his 'Palæontological Memoirs,' devoted to a defence of this conchusion, have nevertheless seemed 'masterly' to some, ' 'amply demonstrative' to others." Something, therefore, needs to be said, by way of warning to beginners in Palæontology and in vindication of the noble science itself.

A few words, first, as to the extent to which affinity or conformity of organization, involving proportions and structure of limbs, resultant specialities of locomotion, habits, and food, may be predicated or inferred from the occurrence of secondary characters, such as grooves and ridges, in homologous teeth, not being molars. Certain Quadrumana have

1 Prof. Flower, \&c., op. cit., p. 307.

2 Mr. Boyd Dawkins, as quoted at p. 95. 
long and large laniariform canines, longitudinally grooved, ${ }^{1}$ sharp-pointed, with 'a trenchant posterior margin.'

In the Carnivora these characters distinguish the canines of Felines from those of other families and genera of the order. The correspondence in the number and direction (verticality) of the grooves on the crown of the sharp-pointed posteriorly trenchant canines, as well as in the number of those teeth, in the genera of Quadrumana, cited below, and in the genus Felis, is much closer than in the grooved trenchant premolars of Plagiaulax and Hypsiprymus.

Now, suppose that our knowledge of the genus Felis was founded upon fossil remains of the mandible and mandibular dentition, from Mesozoic deposits. A Palæontologist detecting the correspondence of the fossil canine in the vertical grooves and trenchant hinder border, superadded to the common characters of a laniary tooth, with the canines of the existing Monkeys and Baboons, might infer that a Mammal had existed at the Mesozoic period with quadrumauous modification of limbs, scansorial habits and frugivorous diet.

Dr. FaLconer has drawn the parallel inference from the correspondence, such as it is, in the grooved and trenchant premolar teeth of Plagiaulax with those of Hypsiprymmus, namely, that there existed, at a Mesozoic period, a Marsupial with the saltatorial modification of limbs, leaping mode of progression, and herbivorous diet.

Mr. Boyd Dawkins, therefore, draws the same conclusion, though with a much lower degree of likeness, in the assumed ridged and trenchant premolars, in regard to his "Hypsiprymnopsis Rhaticus of the Watchet Shore." 2

The alleged "ample demonstration by Dr. FAtconer of the alliance of Plagiaulax to the Kangaroo-rats" is of the same kind and degree as that by which a Feline might be demonstrated to be a Baboon-ally.

The proof of the insufficiency of the ground afforded by the similarity of canine teeth is of the same kind as that by which I believe myself to have demonstrated the insufficiency of the ground afforded by the similarity of premolar teeth held to be 'amply demonstrative ' of Plagiaulax being a 'Kangaroo-rat ally.'

The alleged correspondence of premolars is more than connterbalanced by the concomitant difference in the series of true molars presented by Plagiaulax and Hypsiprymnus. To the inference from the fossil jaw of Felis with canines having not only the same

1 Owen's 'Odontography ;' canines of Hapale (p. 439): canines of Cebus, - "those above being marked by the deep anterior groove : there is also a second longitudinal groove on the inner side of the crown near its posterior margin" (p. 440): in Cynocephalus, besides the grooves, the "trenchant posterior margin" of the long, pointed canine, is specified (p. 442): in Papio maimon "the anterior longitudinal groove of the canine is very deep, the posterior margin very sharp" (p. 316). The same character of canines is pointed out in Papio porcarius in the 'Catalogue of the Osteology in the Museum of the Royal College of Surgeons,' vol. ii (1853), p. 734, No. 4723. See also 'Anatomy of Vertebrates,' vol. iii, p. 316.

2 Quarterly Journal of the Geological Society of London,' vol. xx (1864), p. 412. 
peculiarity of grooving, but the grooves in the same rlirection, with some slight difference of position, and associated with the same trenchant hind border of the canine, that, therefore, it must be the jaw of a frugivorous or mixed-feeding Quadrumanons animal, I must have objected, as a disciple of Cuvier, and a believer in his 'Law of Correlation,' that the grooved and trenehant eanines were associated in the Mesozoic fossil with large carnassial and small and few tubercular molars; wherens in the existing Qundrumana the grooved and trenchant canines are associated with several and large tubercular molars.

Similarly, the grooved and trenchant premolars of Plagiaulax are associated, in that Mesozoic fossil, with large laniaries and few and small tubercular molars; wherens in the existing "Macropoda (Van der H. = Poephlaya, Owen)" the grooved and trenchant premolars are associated with many and large tubercular molars, lesides being dissociated from large laniaries.

To me, therefore, the affinity of Plagiaulax to Hypsiprymmus, and the concomitant assumption of the saltatorial and herbivorous character of the small extinct Mesozoic Marsupial, are not demonstrated in any degree; the demonstration of the carnivority of Plagiaulax appears to be much more ample.

Referring to the page quoted by Mr. Bord Dawkins as proof of my opinion of the close alliance of Microlestes to Plagiaulax, I find the following:- "Amongst existing Mammals some of the small molirs of the marsupial and insectivorous Mryrmecobius of Anstralia offer the nearest resemblance to these fossil teeth, but a still closer one is presented by the small tubereular molars of the extinct Mammal ealled Plagianlax." ("Palrontology," 1st el., p. 302 ; 2nd ed, p. 339.)

Now, here is 110 affirmation of alliance, close or loose, between Microlestes and Plagiaulux, but simply a statement of a resemblance between certain of their teeth. To be able to affirm of a 'close alliance' between Plagiaulax and Microlestes, the Paleontologist must know, not only the degree of resemblance between certain of their teeth, but also that between the rest of their dental system.

One must first learn in what numbers the small tubercular teeth of Microlestes were present in its jaws, and next with what other kind of teeth they may have been associated.

If my inferences be just and the conclusions they support be honoured by acceptance in Palieontology, it will not imply that my opponents had "fallen into errors of observation and description " 1 so much as it will "expose the fallacions train of reasoning which had led them astray;" " for which they "lave no excuse to plead on the score of haste or want of due consideration." 3 Should Plagiaulax be permitted to rest, after the facts and reasonings on the fossil evidences at my command, in the pancidentate section of diprotodont Marsupials, with Thylacoleo, amongst the predaceous feeders on flesh, and

\footnotetext{
' Falconer, opp. citt., pp. 350, 433.

2 Ib., ib. $\quad 3$ Ib., ib.
} 
not with IIypsiprymnus amongst the harmless saltatorial Herbivora, it will only be further proof of the worth and trinth of the principle which Cuvien laid down as our guide in such dark routes in Palæontology.

\section{$\S$ XX. CONCLUSION.}

The number of Mammalian species discovered in deposits of Mesozoic antiquity supports the inference of progressive advance. These early, if not initial, forms of the class are referable, on more or less demonstrative evidence, to the lyencephalous subclass; to that in which the brain has received least addition to its avian and reptilian status. Where the marsupial character is least clear in these little fragmentary fossils, the alternative from the plainer evidence is to the lissencephalous subclass. And it may well be, since, amongst the Lissencephala, the modern Insectivores show the first steps in the development or extension of the hippocampal commissure, entitling it to be called 'corpus callosum,' or 'supra-ventricular cross-band,' that intermediate steps in this cerebral progress may have been made by some of these Mesozoic Mammals, in which the marsupial characteristics are least differentiated from the modern Insectivorous types.

To the objection of the 'Uniformitarian,' that the fossil record of Mesozoic Mammalogy is too imperfect for inference, we may ask,-when he would be pleased to admit the evidence to be sufficient to affect belief or judgment? Is any class of fossils from any geological formation so extensively known as to justify the assumption that nothing exceptional or contradictory to conclusions therefrom may not ultimately turn up? Can the Zoologist demonstrate that he knows all the existing species of any one genus, order, or class? Does any misgiving of the imperfection of the records of living species warrant the suppression of the instinctive tendency to generalise from the facts at hand? Or, on the other hand, give liberty to guess or theorise withont or against such facts?

In the present Monograph I submit evidence from three distinct and probably, as to time, very remote stages of that grand geological group of deposits, called 'Mesozoic.' There is a highly suggestive concurrence in the evidence, as at present derived, from Rhætic, Lower Oolitic and Upper Oolitic periods. To my mind it has a significance; and I believe its meaning and teaching to be against the uniformitarian assmmption, and in favour of " orderly succession and progression due to Natıral Law or Secondary Cause." 1

Mesozoic Mammalian life is, without exception, on this evidence, low, insignificant in size and power, adapted for insect-food, for preying upon small lizards, or on the smaller and weaker members of their own low mammalian grade.

1 Owen, 'On the Nature of Limbs,' 8vo, 1849, p. 86. 
An easy show of a superior philosophy may be made by a profession of cantious expectancy, an assumption of dne power of restraint, of reticence of reasoning, of selfdenying abstinence from inference. Bnlky Mammals, we may be reminded, are less numerous thin dwarf kinds, so the chances of discovery of their remains are fewer; gyrencephalons Ungulates and Carnivores may still be found at Stonesfield, or Durdlestone, or elsewhere. And, if not, "In what circumstances is the Phascolotherium more embryonic, or of a more generalised type, than the modern Opossum?" asks Prof. Huxuey, in his character of Advocate for the Uniformitarian view. ${ }^{1}$

There is not, to be sure, much of the old Marsmpial left to cnable the competent and equal observer to answer this question; but, if a clear reply be given by but half its jaw, we may infer that the whole animal would have been consistent in its ampler testimony.

Phace the mandibular ramus and teeth of a Didelpllys by the side of that of Phascolotherium (as in the specimen in the British Mnseum), and the more generalised type is conspicnous in the absence of the differentiation of the seven molars in the Oolitic fossil, which differentiation characterises the homologous teeth in the modern Opossum. The canine of the Phascolothere shows but a slight superiority of size over the antecedent teetl, which are of like shape to it, and are divided from each other by similar intervals. In the modern Opossum the canine is marked by greater relative size and difference of shape from the close-set group of small incisors anterior thereto. The seven molars of Phascolotherium show gradational differences of size, while that of shape is limited to slight simplification of the two smallest, which are the first and last of the seven teeth. In Didelplyys the last four molars are abruptly and markedly differentiated both by size and complexity of structure, from the three preceding ones ; so that zoologists distinguish the four as "true molars" from the three which are their "false molars." Plascolotherinm shows no such grounds of distinction.

Only a physical defect, of vision could fail to discern these "circumstances" by which the Oolitic Marsupial exemplifies the "more generalised type."

When hazarded assumptions and vague suppositions become facts, right reason will draw the proper deductions. In the meanwhile, on the basis gained by the results of the present research, the mind ponders on the prospect commanded over the Mesozoic eartl.

We see, at every level and distance within such range, nothing moving of Mammalian life, save the low and the small; rat-like, shrew-like, forms of the most stupid and unintelligent order of sucklers. The results of Neozoic palæontology sometimes move one to exclaim, in regard to Mammals, "there were giants in those days !" but, descending to earlier periods, we find only dwarfs.

Amongst these initial forms of Marsupialia we may see in Amplitherium the prototype

'Speaking for Mr. Leonhard ILorner, P.G.S., 'Quarterly Journal of the Geological Society of London,' vol. xviii (1s62), pl. li. 
of Myrmecolius; Stylodon has its analogne in Chrysocloris; Peralestes has culminated in Sarcoplitus ; Triconodon in Thylacimus; Plagiaulax is to Thylacolco what the Weasel is to the Lion. But derivative change has not advanced to the long-limbed saltatory herbivorons type of Marsupial; nor has any evidence yet been had of a Mesozoic predecessor of the clinıbing Koala, the volant Petaurist, or the burrowing Wombat.

The American Mesozoic Marsupial (fig. 3, p. 20) exemplified the vegetative repetition of many molars, significant of the same low comparatively unspecialised grade of Mammal, evidence of which has been less sparingly, not to say more abundantly, got from Europenu deposits of corresponding geological age.

The Marsupial type, through the operation, as I still believe, of some foreordained natural law or secondary cause, has, in America, "progressed to, and been succeeded by " the more specialised form of Didelphys; in which, with reduction of molars to the present type number, there lias been a specialisation of some as "premolars," of others as " true molars," strongly marked and carried to a degree far beyond anything which either figures or descriptions allow us to infer in the dimimutive many-molared Dromatherium sylvestre.

The derivative descendants of the ancient American primeval forms of Marsupialia are reduced to that one genus or family çalled properly "Opossums" (Didelphys or Didelphida), now split up into such insignificant groups as Plitander, Hemiurus, Microdelplys, Thylamys, Chironectes, \&c., all having essentially the same modification and specialisation of Marsupial dentition as in Didelphys proper.

It is remarkable and perplexing in the endeavour to conjecture out the operation of the derivative law, to note, that the Mesozoic Marsupials of Europe, whose low, comparatively non-differentiated condition has been sufficiently exemplified and dwelt upon, have been also sncceeded and finally represented in Europe by differentiated carnivorous Climbers (Didelphida); but on this continent they did not survive to enter the latter half of the Neozoic period. Our latest European fossil Marsupial is a Miocene Opossum.

Does the present rich and varied condition of Marsupial life in Australasia exemplify the changes which lyencephalous mammalian organization in Mesozoic America and Europe may have undergone or ramified into during the vast periods of time and changes of terrestrial surface which have intervened between the formation of the coal-fields of Virginia and its now growing gum-trees; or between the Rhætic breccias of Wirtemberg and the lacustrine marls of Auvergne?

If Australia possessed Marsupials as far back in time as did America and Europe, aualogy wonld lead us to suppose that the primitive diminutive multimolar insectivorous type prevailed. It las not there yet become extinct; but it seems to have been reduced to the solitary exceptional form of the Myrmecobius.

Let us suppose all the now existing Marsupials of Australia to have lived there, 1 'Nature of Limbs,' p. 86. 
contemporaneously with Dromatherium and Amphitherium in other and far distant parts of the earth, and with them to have become extinct; let us also suppose that our knowledge of such Australian Mesozoic Mammals depended, as in America and Europe, on the acquisition of their fossilized remnants in Triassic or Oolitic rocks. What, it may be asked, would be the chances of the geologist hitting upon the exceptional Myrmecobian?

At the dates of the publications of the works of WATLRHouse and Gould on Australiam Marsupials, the Pocplaga (kangaroos, potoroos, \&c.) numbered forty-three species; the Rhizoplaga (wombats) three species; the Carpopliaga (phalangers, petaurists, koalas) twenty-two species; the typodentate Entomophaga (bandicoots, \&c.) ten species; the Sarcoplaga (thylacines, dasynres, phascogales) twenty-one specics.

The probability is that the specially modified diprotodont dentition of the saltatorial herbivorous Kangaroos and Potoroos, since thoir numerons species are represented by more mmerous individuals than are the species of the flesh-feeders, would be exemplified in the fossil series in a like mumerical proportion with the multidentate polyprotodont genera in British Mesozoic beds.

Evidence, however, of Mammalian life from the corresponding epoch in Australia has yet to be obtained.

If the correlative Rhæetic and Oolitic rocks there exist, entombing relics of the Mammals of the period, analogy would lead ns to expect results like those now obtained from the study of the Mesozoic fossils of Europe and America.

Our knowledge of the extinct Australian Mammals has been hitherto supplied by fresh-water deposits and cares; and these, like the correspondingly recent graves of European Quaternary Mammals, yield evidence of progress to great diversity and specialisation of structures; manifested, moreover, in many species, with magnitudes indicating the favorable conditions under which Diprotodons, Nototherians, Thylacoleons, gigantic Kangaroos, Wallabees, and Wombats ranged and flourished before the advent in Australia of the destructive and all-conquering archencephalous biped.

By that which it has becn my present aim to make known-the number and nature of British Mesozoic Mammals-and through considerations to which their contemplation has given rise, my belief has been strengthened in the Law of the Progress from the General to the Special, from the low to the high. It is illustrated in the succession of Mammals from the 'Trias upwards, as it is by that of other classes from the dawn of life (Eozoon) to the present period. 
Table of Genera of Mesozorc Mammals.

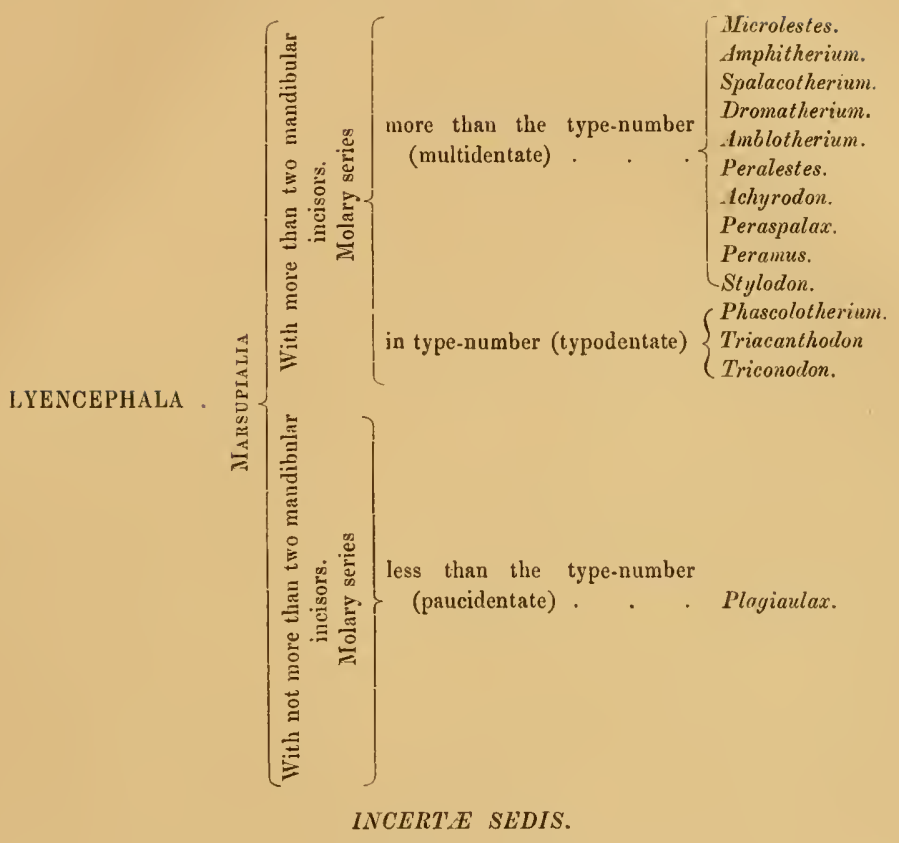

Stereognathus. Bolodon. 


PLATE I.

\section{Microlestes Moorei.}

Fig.

l. Upper molar, working surface.

2. 1 b., inner side.

3. Ib., front side.

4. Ih., base view.

5. Upper molar, onter side.

6. Lower nolar, working surface.

7. Lower molar, working surface.

7A. Ib., outer side.

From near Frome, Somersetshire. In the passession of the discoverer, CHarLes Moore, Esq., F.G.S.

14. Lower molar, ontside view ?

15. Ib., inside view

\section{Microlestes antiquns.}

15A. Ih., working surface $\}$ (after PLIENinger).

From a Rhætic (Keuper) bone-bed at Diegerloch, Würtemberg. In the possession of the discoverer, Prof. Dr.

Plieninger, of Stuttgart.

16. Lower molar.

\section{Microlestes rhaticus (IIypsiprymnopsis, Dawkins).}

16.. Side view of abraded surface.

$16 a$. Part of working surface, with probable outline restored.

From Lower Rhætic marlstone, Watchet, Somersetshire. In the Geological Musenm, Oxford.

All the foregoing specimens of Microlestes are magnified 4 diam.; the natural size of the fossil is given in outline.

17. Lower premolar $\left(p_{4}\right)$ of Hypsiprymnus murinus; nat. size.

15. Ib. ( $p .4)$ of Bettongia penicillata; twice nat. size.

19. Upper molar, working surface, Myrmecobius fasciatus; magn. 4 diam.

20. Lower molar, griuding surface, ", " magn. 4 diam.

21. Amphitheriun Prevostii, left mandibular ramns," mutilated; nat. size.

2lA. " " $\quad$ ib., dentigerons portion; magu. 4 diam.

22. $\quad " \quad$ left niandibular ramus, more entire; nat. size.

22. " " " ib., horizontal portion; magn. 2 diam.

23. " " right mandibular ramus, with teetlı; nat. size.

23A. " " ib., magn. 2 diam.

24. Myrnecobius fasciatus, left mandibular ramus and teeth; nat. size.

25. Amphitherium Broderipii, left mandibular ramus and molar teeth; nat. sizc.

25 A. " " ib.; magn. 2 diam. B. lb., side-view of a molar tooth; magn. I diam.

26. Phascutotherium Bucklandi, mandibular ramns and teeth; nat. size.

26 A. " " $\quad$ ib.; magn. 2 diam.

27. Slereognalhus ooliticus, portion of mandible, with three molar teeth, $a, b, c$, npper view ; nat. size.

27 A. " " ib., side view; nat. size.

28. " " " $\quad$ inner side view of erown of molar, $b ;$ magn. 6 diam.

29. " " $\quad$ outer side view of ditto; magn. 6 diam.

30. " " " $\quad$ upper view, or grinding snrface, of ditto; magn. 6 diam.

31. " $"$ ib. of lower molar of Pliolophus vulpieeps; magn. 2 diam.

32. Spalacotherium tricuspidens, part of left mandibular ramus, with teeth; nat. size.

32 A. " " $\quad$ ib.; magn. 2 diam. B. Ib., oblique view of a molar tooth; magn. 4 dian. c Ib.,

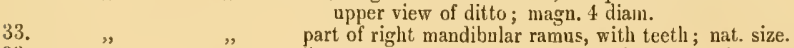

33 A. " " $\quad$ " $\quad$ ib.; magn. 2 diam. B. Ib., back view of a molar tooth; magn. 4 diam. $\quad$ (. Ib., upper view of ditto; magn. 4 diam.

34. " " part of left mandihular ranus; nat. size.

34 A. " " $\quad$ ib. ; magn. 2 diam. B. inner view of the two molars, 4,5 ; magn. 1 dian.

35. " " $\quad$ part of left mandibular ramus; nat. size.

35 A. " " " ib. ; nagn. 3 diam.

36 " " $"$ part and impression of part of the right mandibular ranus; nat. size.

36 s. $\quad " \quad$ ib.; magn. 3 dian. B. Ib., npper view of two fractured molars; nagn. 3 diam.

$37 . \quad$ " 3 part, and impression of part, of the same mandibular ramus in the counterpart slab uf matrix.

37 A. " " $\quad$ ib.; magn, 3 diam.

35. " " " " left mandibular ramus.

35 A. " " " " ib. ; magn. 2 diam.

39. Spalacotherium minus, left mandibular ramus; nat. size.

39 A. , " ib.; magn. 3 dian.

40. Phaseolestes dubius, part of right mandibnlar ramus; nat. size.

40 A. " " $\quad$ ib.; magn. 2 diam.

41. " " fragment of right mandibular ramns; nat. size.

4I A. "3 " ib.; magn, 2 diam.

FIgs. $2 \dot{1}, 22,2 \ddot{3}$ are in the Iusenn of Geology, University of Oxford, and are from the Lower Oolite, Oxfordshire. The subject of fig. 25 is in the Museum of the Philosophical Society, York, that of fig. 26 in the British Museum, that of figs. $27-30$ in the Collection of the Rev. J. P. B. Densis, M.A.; these are also from the Lower Oolite, Oxforishire. The subjects of figs. 35- 1.1 are from the fresh-water marl (mammaliferons) of the Middle Purbeck, Durdlestone Bay, Dorsetshire; and are in the Collection of Samuel Husbands Beckles, Esq, F.R.S., St. Leonard's-on-Sea. 
8.

$20 \times 30$

(2), जिए की

2,22 की

1 I)
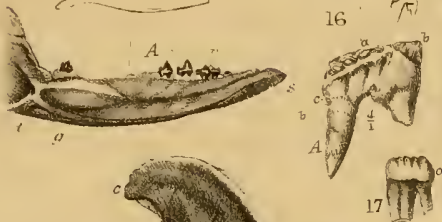

(I)

(2)
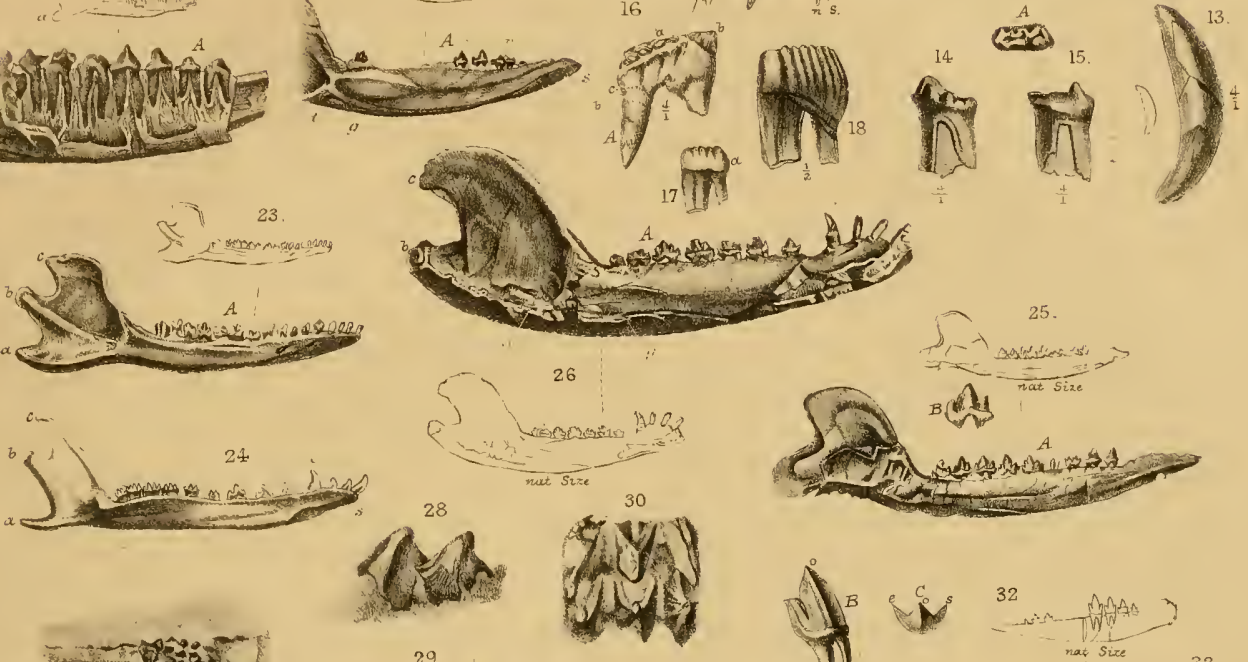

- $-5,-23 \frac{1}{2}$

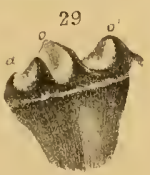

27
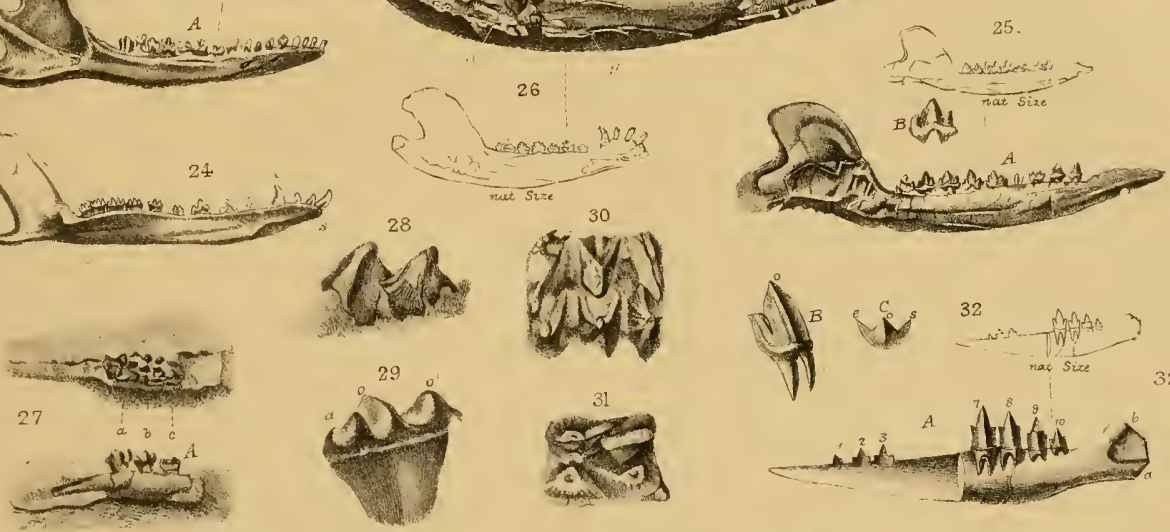

i) $V_{0}^{33}-\frac{1}{2}$

exdandus

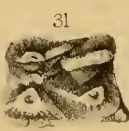

if 42 and

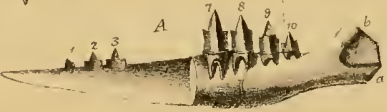

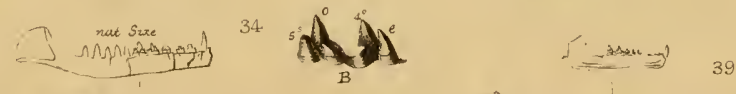

\section{max size}

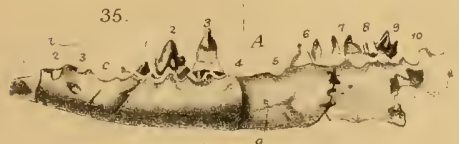

Save.

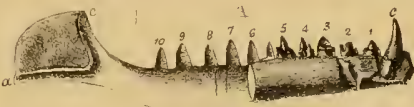

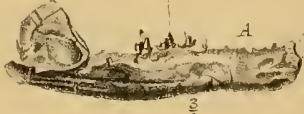

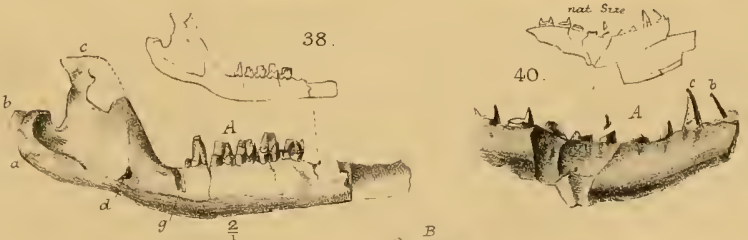

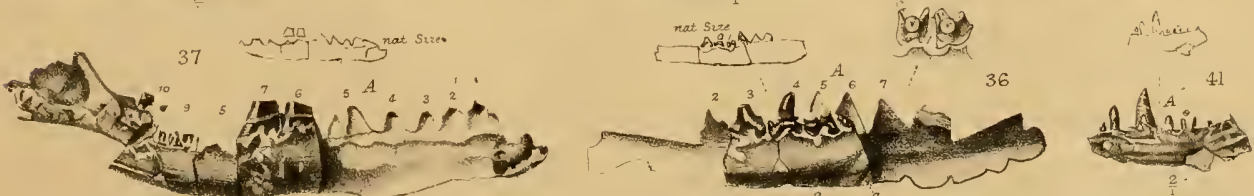






\section{PLATE II.}

FIG.

1. Amblotherium soricinum.

Right mandibular ramus; nat, size.

1 .

,"

"

Ib. ; magn. 3 diam. : B, third molar, magn. 6 diam.

2. ", mustelulu.

2 A.

Right maudibular ramus; nat. size.

3. Peralestes longirostris.

Ib. ; magn. 3 diam.

$3 \mathrm{~A} . \quad, \quad$,

Right maxilla ; nat size.

Ib. ; magn. 3 diam.

3в. " " $\quad$ Ib. ; working surface of molars; magn. 3 diam.

3c. Outer side view of third upper molar of Sarcophilus ursinus; nat. size.

4. Peralestes longirostris. Left mandibular ramus; nat. size.

4 A. " " Ib. ; magn. 3 diam. : B, third molar magn. 6 diam.

4c. Inver side view of third lower molar of Sarcophilus ursinus; nat. size.

5. Achyrodon nanus. Part of right mandibular ramus; nat. size.

5.1. " " $\quad$ Ib. ; magn. 3 diam.

6. " " $\quad$ Left mandibular ramus; nat. size : $\Lambda$, ib. ; magn. 3 dian.

7. $" \quad$ Ib. ; nat. size : A, ib., magn. 3 diam. : B, sixth molar; magn. 6 diam.

8. $\quad$ pusillus. Ib. ; $A$, ib., magn. 3 diam.

9. Peraspalax talpoüles. Left mandibular ramus; nat. size.

9s. " "

9c. Didelphys opossum.

10. Peramus tenuirostris.

Ib.; magn. 3 diam. : B, sixth and seventh molars; magn. 4 diam.

Inner side view of molar; nat. size.

Left mandibular ramus; nat. size.

10 A. , ,

10c. , , ,

11. Peramus tenuirostris.

Ib. ; magn. 3 diam. : B, under border of ascending ramus; magn. 3 diam.

$11 \mathrm{A.}, \quad$,

Outer side view of molar; magu. 5 diam.

$\begin{array}{lll}\text { 11. } & \Rightarrow & \\ 12 . & \end{array}$

13.

14. Stylodon pusillus.

Fore part of left mandibular ramus ; nat. size.

Ib. ; magu. 3 diam.

Fore part of left mandibular ramus ; nat. size: $A$, ib. ; magn. 3 diam.

14. " ",

Left mandibular ramus; nat. size: $\Lambda$, ib., magn. 3 diam.

Left maxilla; nat. size.

$11 \mathrm{~B} . \quad, "$

Ib. ; magn. 3 diam.

Ib.; working surface of sixth and seventh molars; magn. 3 diam.

$15 . \quad, \quad$,

16. ",

$16 \mathrm{~A} . \quad, \quad, 2$

$17 . \quad, \quad$,

17.,$\quad$,

18. " " "

18. " " ,

19.

Ib. ; bind part of left mandibular ramus; nat. size : $A$, ib., magn. 3 diam.

Ib. ; right mandibular ramus, with parts of maxillary molars; nat. size.

Ib. ; magn. 3 diam.

Fore part of left mandibular ramus ; nat. size.

Ib. ; magn. 3 diam.

Mandibular rami; nat. size.

Ib. ; left ramus; magn. 3 diam.

Portion of the left mandibular ramus; nat. size: $\triangle$, ib., magn. 3 diam.

From the fresli-water mammaliferous marl-beds of the Middle Purbeck, Durdlestone Bay, Dorsetshire. The subject of figure 15 is in the Collection of the Rev. Peter Belienger Brodie, M.A., F.G.S., Rowington Vicarage, near Warwick; the subjects of the other figures are in the Collection of SAMUEL. Husbands Beckles, Esq., F.R.S., St. Leonard's-on-Sea. 

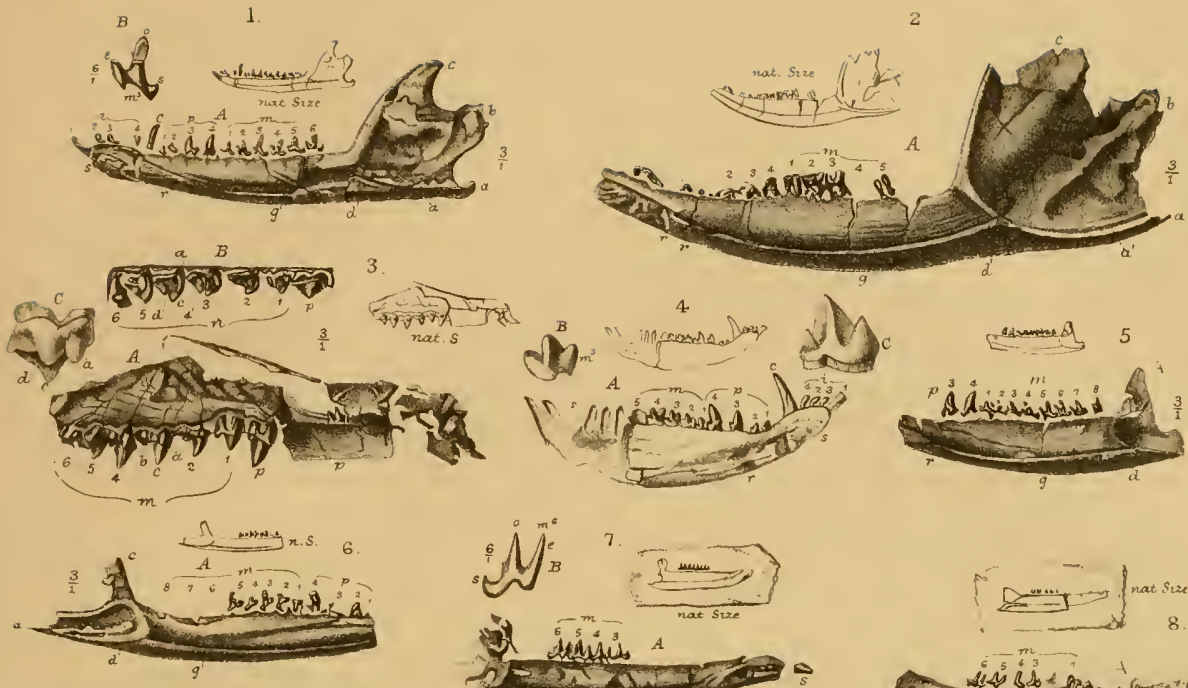

A dis
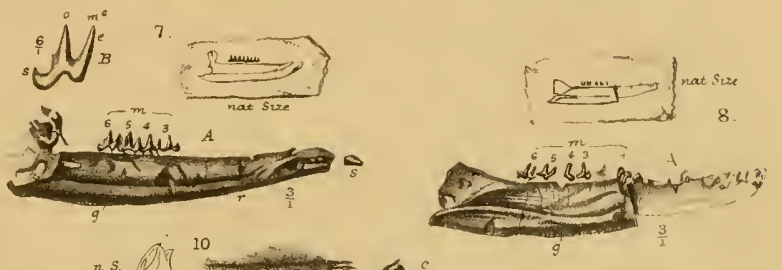

resoning a

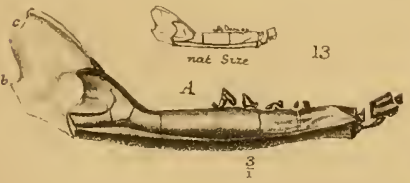

$$
+20 \text { attespossing }
$$

17

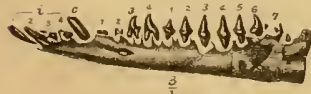
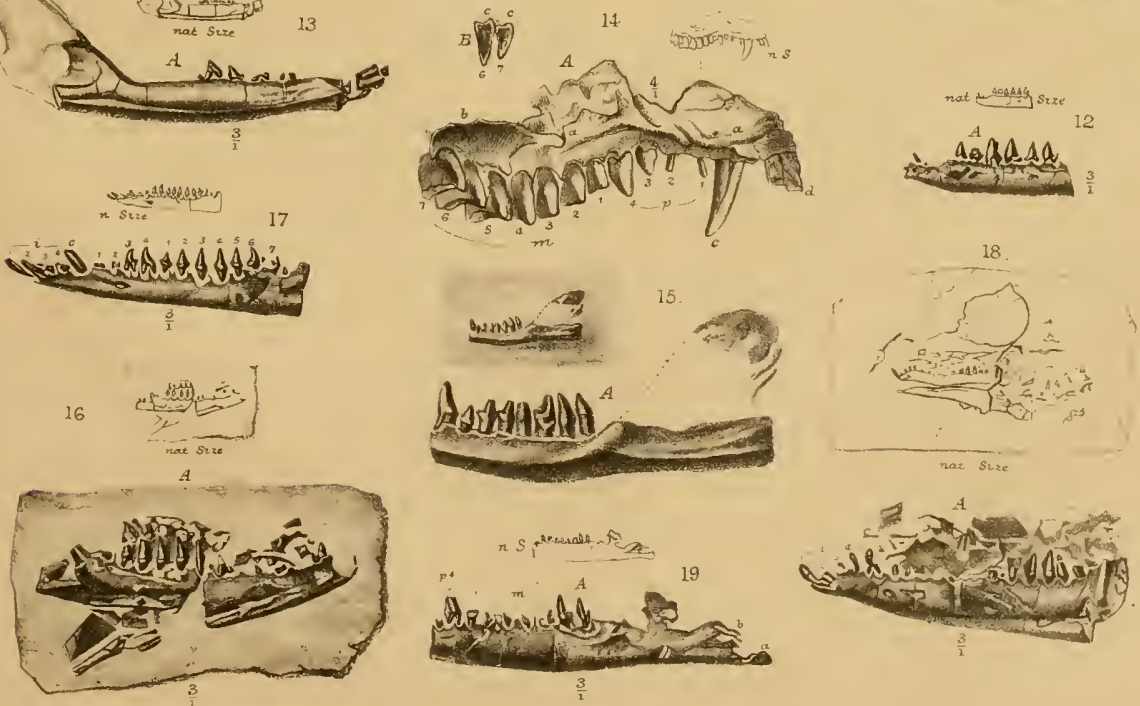




\section{PLA'TE III.}

FIG.

1. Stylodon robustus. Left mandibular ramus; nat. size.

1 A. " " $\quad$ 1b. ; magn. 3 diam.

2. " pusillus. Portion of left mandibular ramus, and teeth; nat. size.

2 A. " $\quad$ Ib.; magn. 3 diam.

3. " " $\quad$ Left mandibular ramus; nat. size.

3 A. " " Ib. ; magn. 3 diam.

4. Leptocladus dubius. Left mandibular ramus; nat. size.

5. Bolodon crassidens. Right maxilla; nat. size.

5 A. " " $\quad$ Ib. ; magn. 3 diam.

5 B. " " $\quad$ Working surface of upper molars; magn. 3 diam.

6. " " Portion of upper jaw and palate; nat. size: A, two left upper molars: B, three right upper molars; magn. 3 diau.

†. Triconodon mordax. Left mandibular ramus; nat. size.

7 A. " $\quad$ Ib. ; magn. 2 diam.

S. " " $\quad$ Portion of left mandibular ramus; nat. size : $A$, molar tooth; magn. 3 diam.

$9 . \quad, \quad$,

Portion of right mandibular ramus; nat. size: A, molar tootlı; magn. 3 diam.

10. Triconodon ferox.

Left mandibular ramus; nat. size: A, teeth, magn. 3 diam.

Ib., A, third molar; magn. 3 diam.: $B$, broken angle of the jaw; magu. 3 diam.

12. $" \quad$ Left mandibular ramus; nat. size.

13. " " Hind part of left mandibular ramus; nat. size.

14. "sp. ind. Portion of right mandibular ramus; nat. size.

14. A. " ", Worm molar; magn. 3 diam.: B, premolar; magn. 3 dian.

15. "sp. ind. Portion of right mandibular ramus; nat. size.

15 A. " " $\quad$ Ib. ; magn. 3 diam.

16. "sp. ind. Left mandibular ramus; nat. size.

$16 \mathrm{~A}$. " " $\quad$ Ib. ; magn. 3 diam.

17. Triconodon ferox. Portion of right maxilla; nat. size.

17 A. $\quad$ " $\quad$ lb. ; magn. 3 diam.

18. " " $\quad$ Portion of left maxilla ; nat. size.

IS A. " " $\quad$ 1b.; magn. 3 diam.

is в. " " $\quad$ 1b. ; working smrface of premolar and molar teeth; mingu. 3 dian.

19. " " Fragment of right mandibular ramus; nat. size.

19 A. " " $\quad$ Ib. ; magn. 3 dian.

$\approx 0$. $\quad$ sp. ind. Impression of left mandibulall ramus: $\mathbf{A}$, camine ; magn. 3 clian.

21. $\Rightarrow$ sp. ind. Portion of right mandibular ramus; nat. size.

From the fresh-water mammaliferous marl-beds of the Middle Purbeck, 1)nrllestone Bay, Dorsetshire. In the Collection of Samuel Husbands Beckles, Esq., F.R.S., St. Leonard's-on-Sea. 


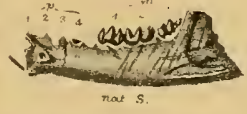

(i)

7

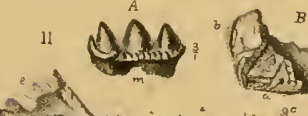

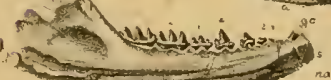
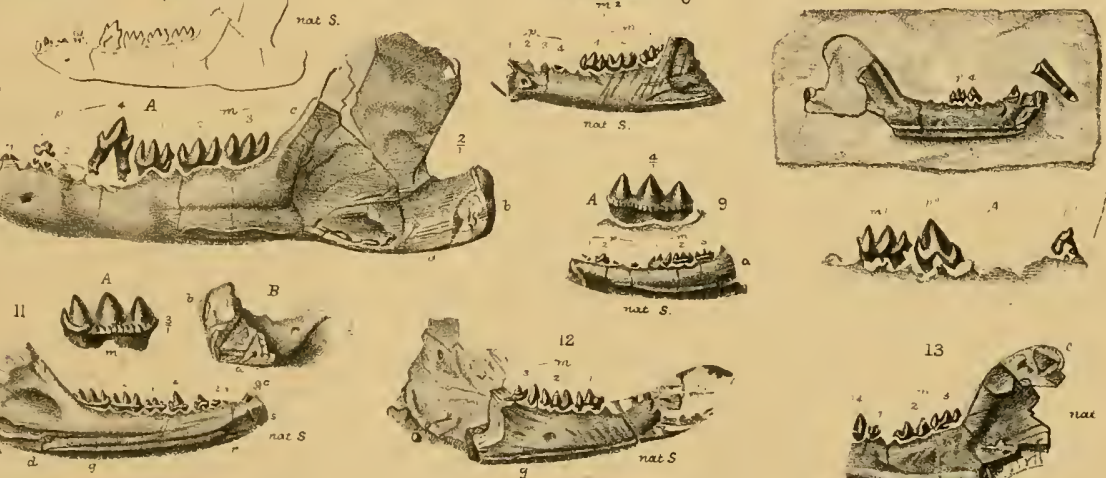

if

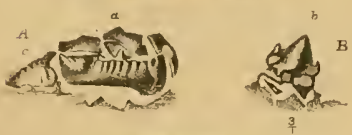

a dis

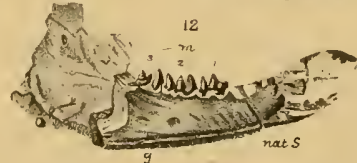

Mand
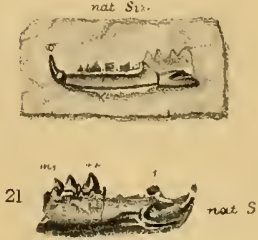




\section{PLATE IV.}

It

1. Triconodon ferox. Portions of upper and lower jaws; nat. size: A, upper molar ; magn. 4 diam.: B, right, c, left, mandibular ramus; hoth magu. 2 diam.

$\therefore$ " occisor. Right and left mandibular rami; nat. size.

2. A. " " " I'eeth of left ramus; B, teeth of right ramus; both magn. 2 diam.

3. " major. Right mandibular ramus; nat. size: $a$, section of fractured fore part.

4. $"$ sp. ind. Right mandibular ramus; nat. size.

5. $\quad " \quad$ Portion of right maxilla; $a$, under view; $b$, end view ; nat. size.

.) $\mathrm{A}$, " " Side view; magn. 3 diam.

(i. "minor (?). Right mandibular ramus; nat. size : A, ib., three molars ; magn. 3 dianı.

7. Trirecanthodon serrula. Portion aud impression of left mandibular ramus : A, ib. ; magn. 2 diam.

5. " " Counterpart impression and portion of the same ramus ; nat. size: A, ib. ; magn. two diam.

9. Plagiaulax minor. Dentigerons part of right mandibular ramus and teeth; nat. size.

9 A. " " "1). ; magn. 3 dian.: B, the two molars; magn. 6 diam.

10. „Becklesii. Portion and impression of right mandibular ramus; nat. size.

in A. $\quad$ " $\quad$ Ib. ; magn. 3 diam. : B, condyle, magn. 3 diam. : c, condyle of Hypsiprymus minor, nat. size: D, condyle of Thylacinus; $\frac{1}{3}$ rd nat. size.

11. " " Counterpart impression and portion of the same ramus; nat. size.

$11 \AA . \quad$, " $\quad$ Ib. ; magn. 3 diam.

1:. " " $\quad$ Fragment of right mandibular ramus ; nat. size.

12 A. " " ,

Ib.; magn. 3 diam. : B, working surface of the two molar teeth; magn. 3 diam.

13. " " Fore part of right mandibular ramus, inner side; nat. size.

13 A. " " Ib.; magn. 3 diam. : $b$, section of jaw and premolar, $p 4$.

1 4. " " $\quad$ Ib. ; ib. ; outer side, nat. size.

14. A. " " $\quad$ Ib.; ib. ; magn. 3 diam.

1.). " " Ib. ; teeth and impression of the fore part of a mandibular ramus; nat. size.

15 A. " " Ib. ; magu. 3 diam.: 136 , section of laniary incisor, magn. 3 diam.

16. "Falconeri. Right mandibular ramus, nat. size.

If A. " " " $\quad$ lb. ; magn. 3 diam. : B, section of laniary, magn. 3 diam.

from the fresh-water mammaliferons mart-beds of the Middle Purbeck, Durdlestone Bay, Dorsetshire. In the Collection of Samuel Husbands Beckles, Esq., F.R.S., St. leonard's-on-Sea. 

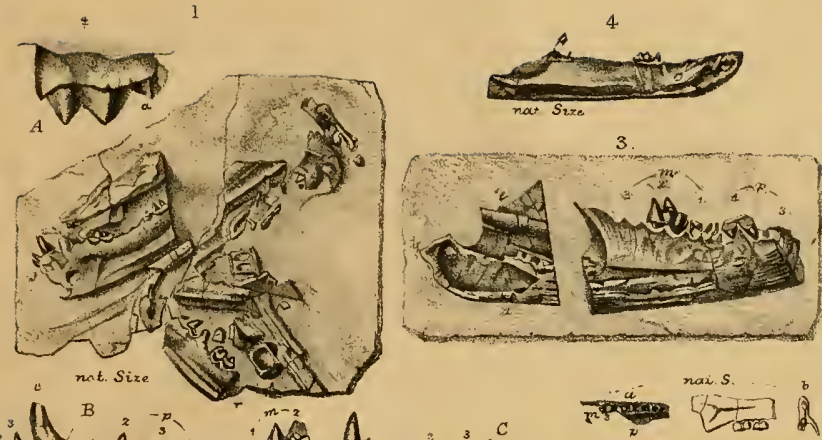

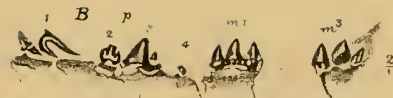

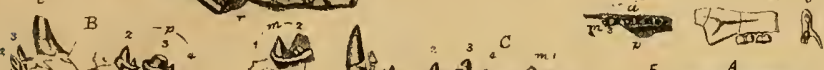

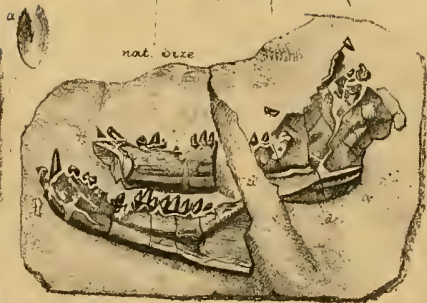

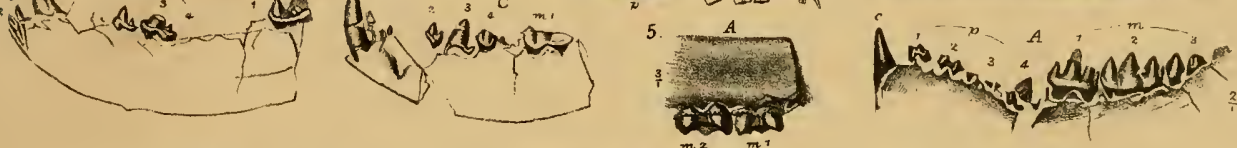

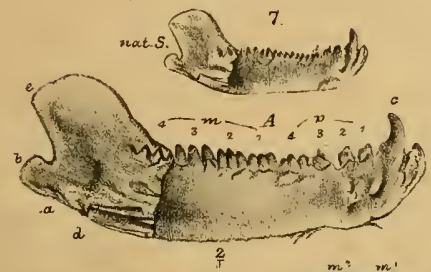

Non

$6 \mathrm{~m}, A$

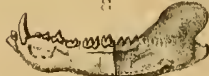

$\sin ^{m} \cos ^{2} \cos ^{2}$

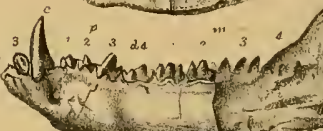

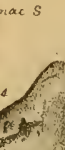

C

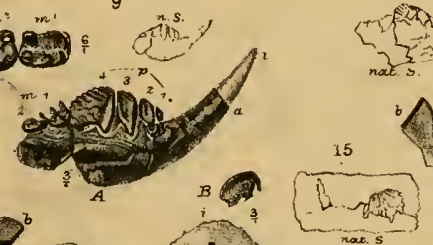

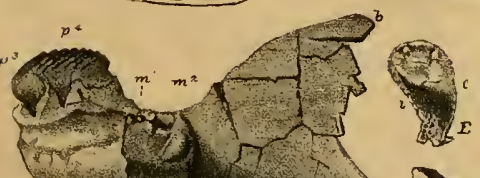

$\frac{3}{1}$
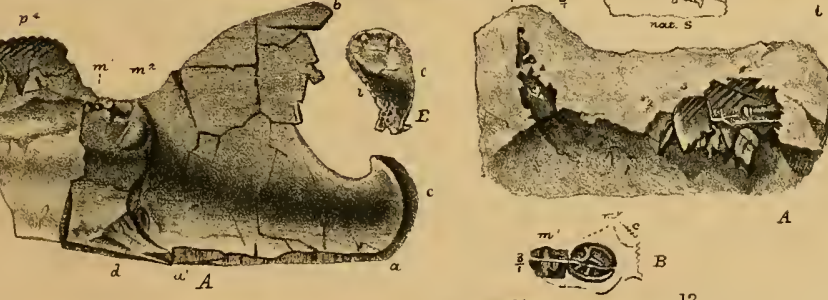

$\frac{m}{12}$
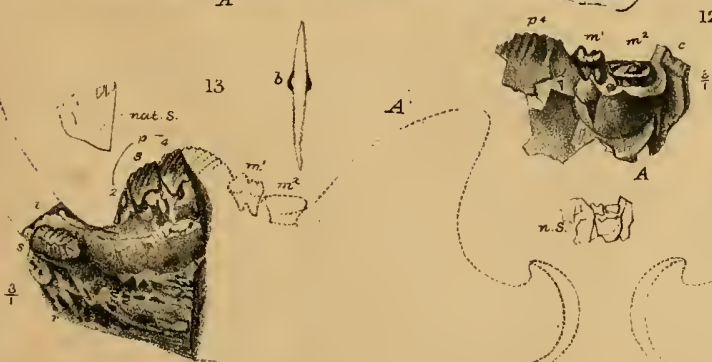

n. . लिखी
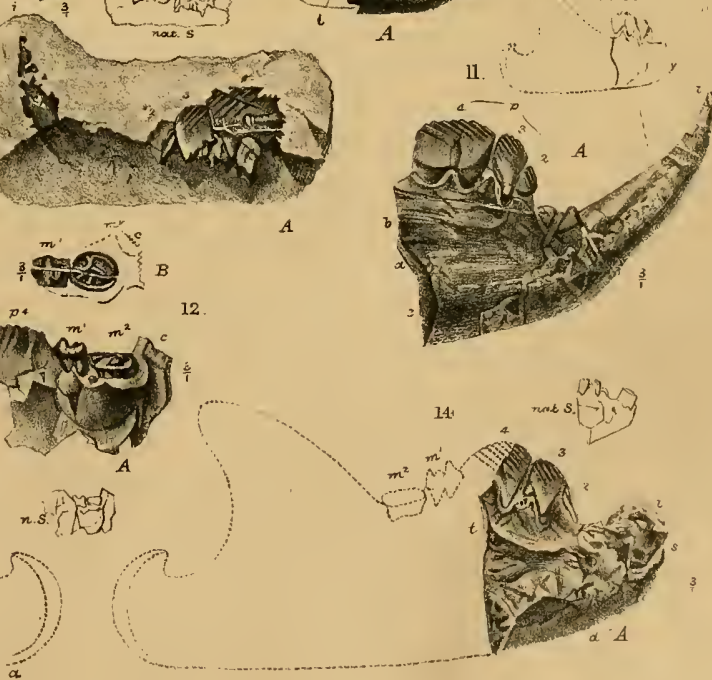








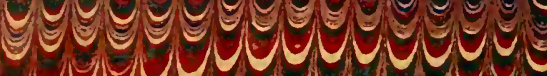

sy

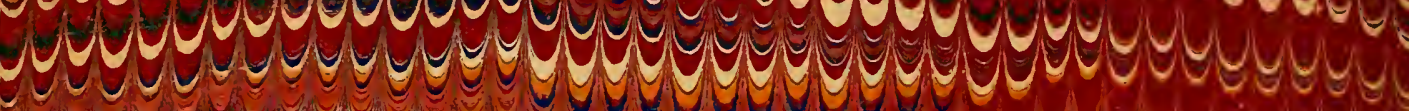

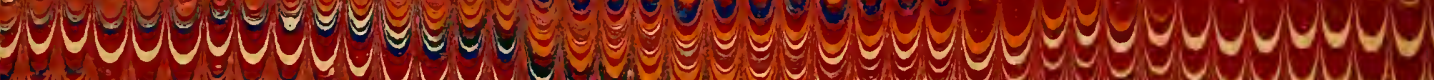

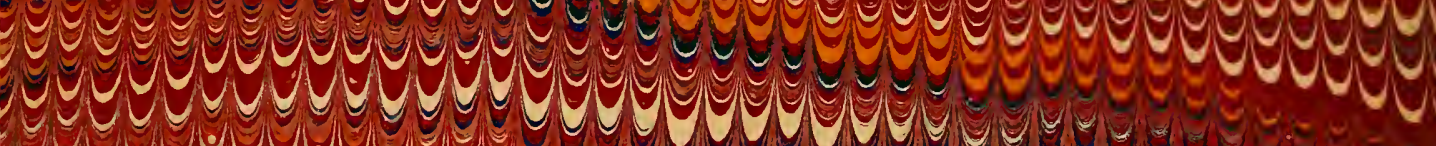
cragers

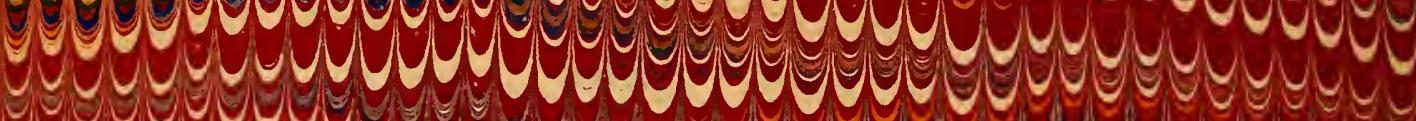

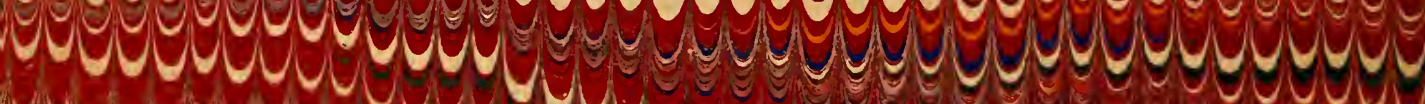

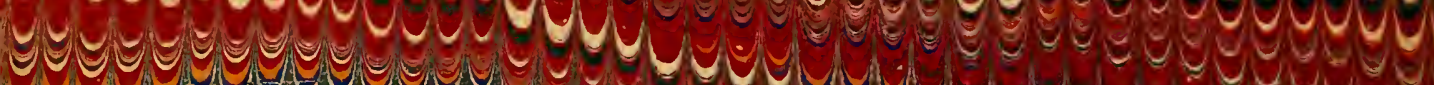

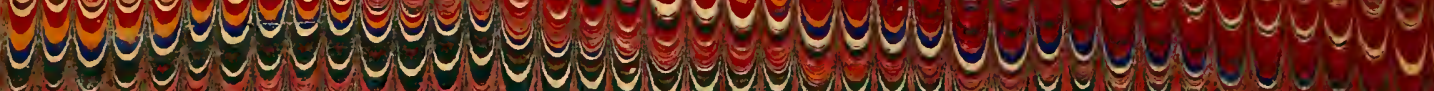

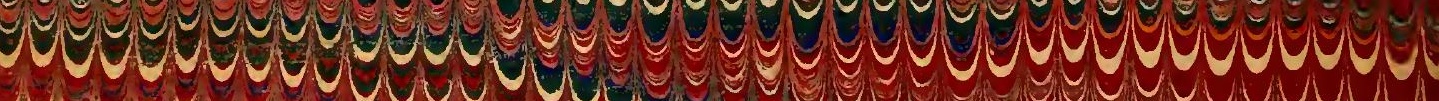
50 S

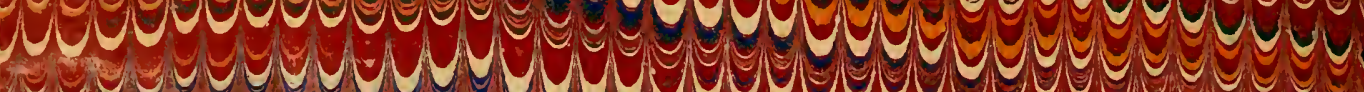

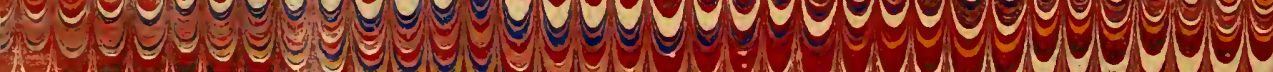
Nu co

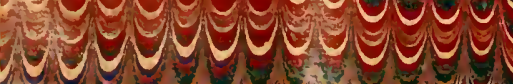

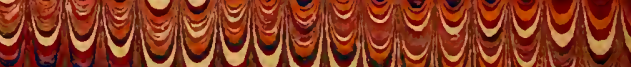

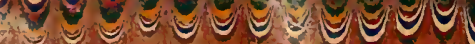
- a y y y

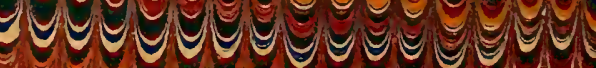
Y 


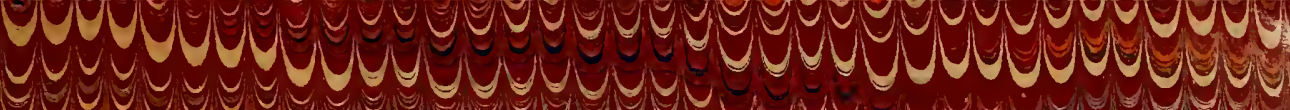

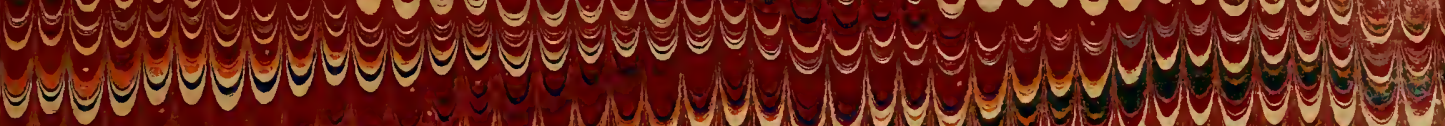

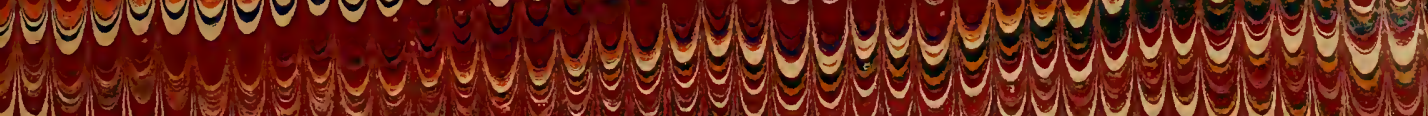
Y.

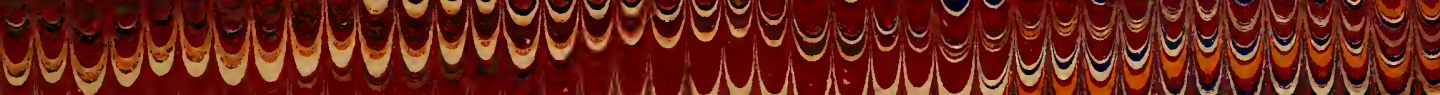

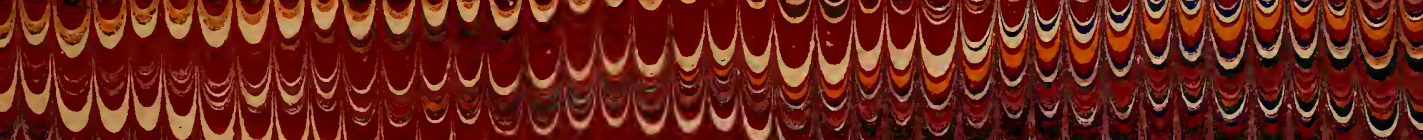
U.

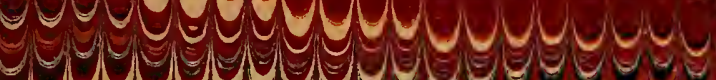

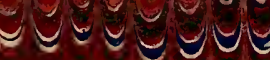
SY

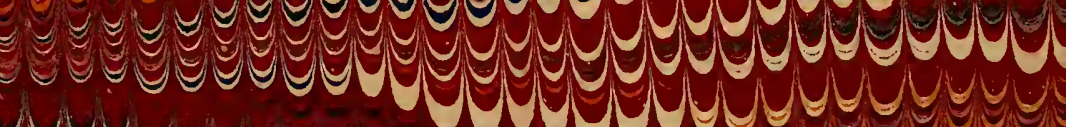

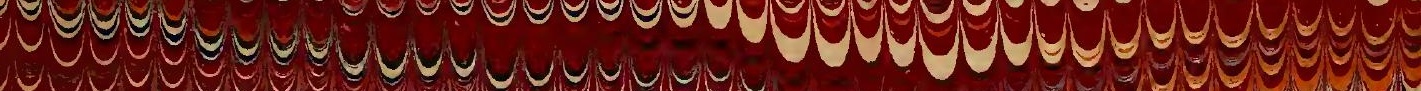

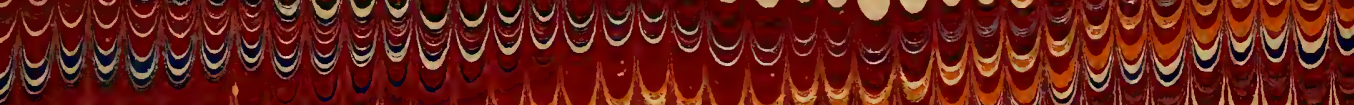

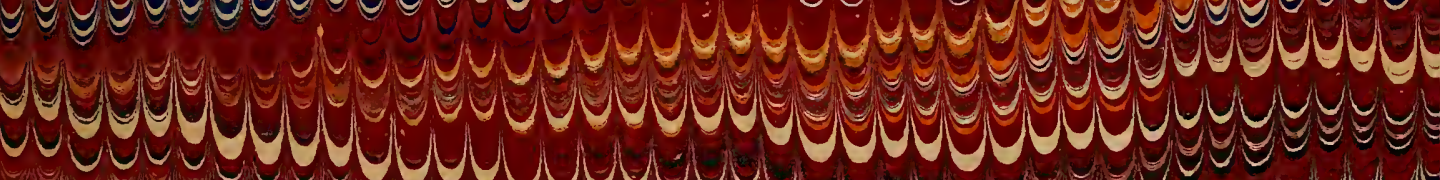

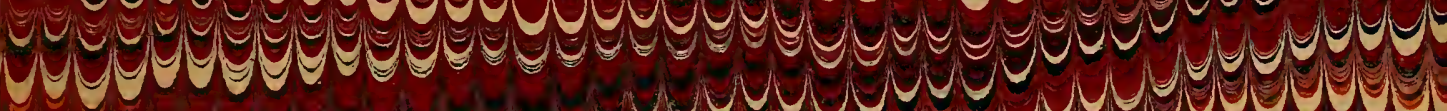

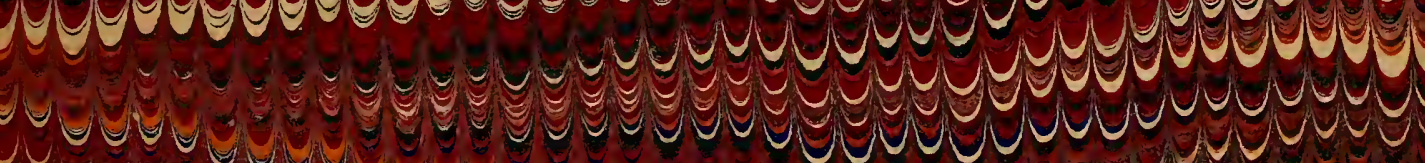
He

:

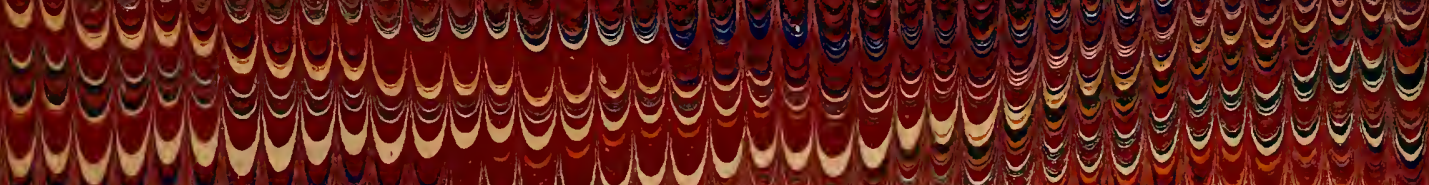

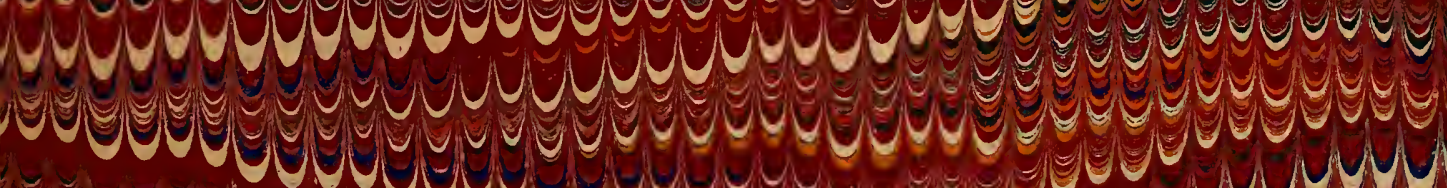
alover 
